\title{
Intertidal Community Differences Between the Cook Strait and Wellington Harbour
}

\author{
Jamie C. Tam \\ 2012
}

This thesis is submitted in total fulfilment of the requirements of the degree of Doctor of Philosophy in Marine Biology

Victoria University of Wellington

New Zealand 


\section{Acknowledgements}

I would like to thank my supervisor Dr. Jonathan Gardner for his giving me the freedom and independence to perform this work from start to finish. His continual questions and criticisms have allowed me to develop a body of work that I am proud to have completed. Thank you to Victoria University of Wellington for the Victoria $\mathrm{PhD}$ award and the VUW Submission Scholarship. There are several people to whom I am indebted to for helping me logistically and in the field. They are in no particular order, but each deserves a multitude of thanks: Aya Hozumi, Tim Jones, Sandra Doherty, Rachel Clausing, Sayani Ghosh, Katie Clemens-Seely and Nicky Fitzgibbon. I would like to thank Dr. Karyne Rogers and Andy Phillips for providing guidance and use of the machinery in the Stable Isotope Laboratory at Geological and Nuclear Science. Thank you to Dr. Shane Geange, Dr. Nicole Phillips, Dr. Ken Ryan and Dr. James Bell for helpful input into my thesis. Thank you to Daniel McNaughton and John van der Sman for technical help and to Neville Higgison for help building my dynamometers. Thanks to Mary Murray and Sandra Taylor for all of their administrative help. Special thanks to Hawea Tomoana, Helen Kettles and Peter Simpson at the Department of Conservation for help with permits for the Taputeranga Marine Reserve and field help. Lastly, I would like to give the biggest thanks to Matthew Hauser who has seen me through this entire thesis. 


\section{Abstract}

Wellington Harbour which lies near the southern tip of the North Island, New Zealand, exhibits a typical rocky intertidal shoreline with groups of species similar to those found on many temperate rocky coasts around the world. A short distance away, the Cook Strait displays a very different shoreline in community composition compared with Wellington Harbour, most notably a distinct lack of filter feeders. This thesis aims to examine how exactly the community composition is different between the two coasts at a species level and if there are any environmental factors that can explain the differing distributions. Here, a series of field and laboratory experiments aim to examine why certain filter feeders (mussels) are absent from the Cook Strait shore, yet so abundant in Wellington Harbour.

In Chapter 2, a baseline survey of the mid-intertidal zone over a two year period found distinct differences between sites from the Cook Strait and Wellington Harbour. Coralline algae, the surf barnacle (Chamaesipho brunnea) and limpets (Cellana ornata and Cellana denticulata) were dominant species along the Cook Strait, while the acorn barnacle (Chamaesipho columna) and the blue mussel (Mytilus galloprovincialis) were dominant in Wellington Harbour. Sea surface temperature, chl a, nitrate, percent organic matter and particulate organic matter concentrations were found to explain $41 \%$ of the differences between the two coasts across the 4 sampling seasons (winter, spring, summer and autumn). Low winter values of particulate organic matter and $c h l a$ were found to have an influence on filter feeder abundances in the Cook Strait.

A transplant study (Chapter 3) was performed to determine if mussels were limited by wave exposure to Wellington Harbour, as Cook Strait shores are thought to have higher wave velocities. Mussels were found to have a decreased condition index during the winter months in the Cook Strait when particulate organic matter was lowest. In the same season in 
Wellington Harbour, mussels had a higher condition index. Adult mussels transplanted to the Cook Strait survived over the 14 month experiment, indicating that the factors limiting mussels to Wellington Harbour may have a larger impact at the pre-settlement stage.

Stable $\mathrm{C}$ and $\mathrm{N}$ isotope analysis (Chapter 4 ) revealed that there are dietary differences between filter feeding species living in the Cook Strait and those in Wellington Harbour. The diet composition of filter feeders according to the IsoSource model showed that there was a seasonal shift in the diets of filter feeders on the Cook Strait, indicating that food sources or availability may change between the summer and winter seasons. This indicates that the ability to shift between food sources may play a key role in the survival of filter feeders on Cook Strait shores. If particulate organic matter in the water column is low during the winter months in the Cook Strait, then filter feeders are required to consume other sources of food to survive. Thus, seasonal shifts in food availability are likely limiting mussels from the Cook Strait.

Through feeding experiments (Chapter 5), it was found that there were fewer food particles for mussels to feed on in the winter along the Cook Strait compared with Wellington Harbour. It was also found that mussels primarily consumed smaller particles (2-14 $\mu \mathrm{m}$ spherical diameter). Filter feeding crabs (Petrolisthes elongatus) were found to consume smaller amounts of food throughout the year along both coasts, but also ate significantly more large food particles than mussels. This indicates that filter feeding crabs are able to survive in the Cook Strait as they consume less and have a more flexible and varied diet than mussels. In times of low food availability, mussels are unable to cope, due to higher metabolic demands than filter feeding crabs and are unable to consume enough larger sized particles to survive.

This work indicates that the Cook Strait coastline has lower filter feeder abundances and an overall different community composition than Wellington Harbour. The cause of these 
differences appears to be bottom up regulation through the lack of food availability (phytoplankton) during winter months in the Cook Strait. The high commercial value of coastal environments in both fisheries and tourism heightens the need to understand these habitats. Unravelling the complex relationships between the seasonal changes in the water column and onshore biota is important for conserving and protecting these essential ecosystems in New Zealand and temperate shores worldwide. 


\section{Table of Contents}

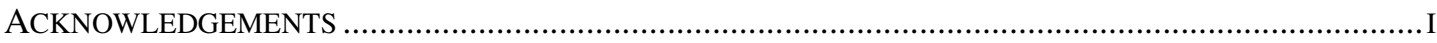

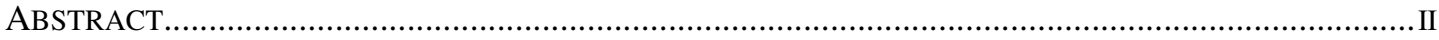

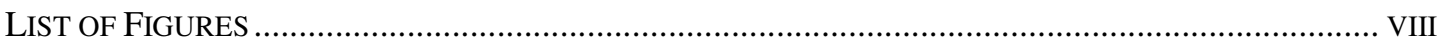

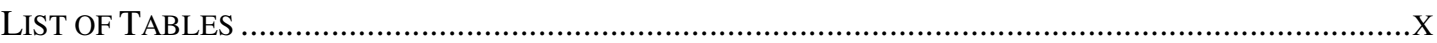

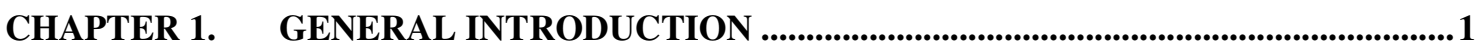

1.1. INTERTIDAL COMMUNITY ORGANISATION AND ECOLOGY ……........................................... 1

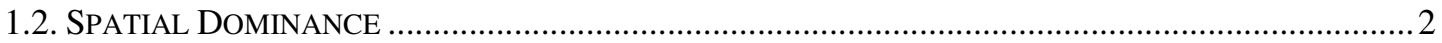

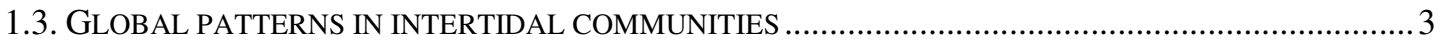

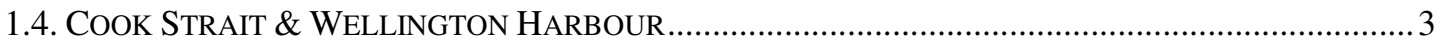

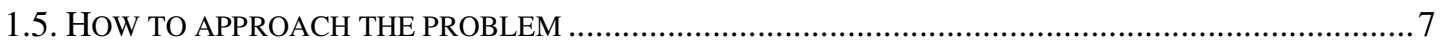

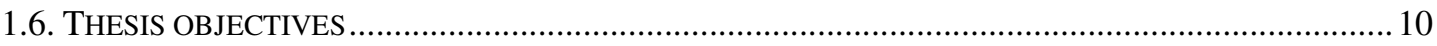

CHAPTER 2. DO SEASONAL CHANGES IN THE WATER COLUMN DETERMINE THE DIFFERENCES IN INTERTIDAL COMMUNITY COMPOSITION BETWEEN THE

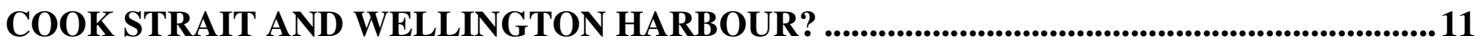

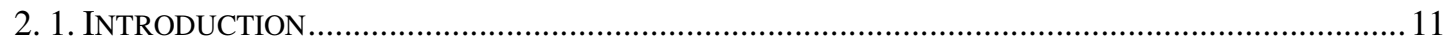

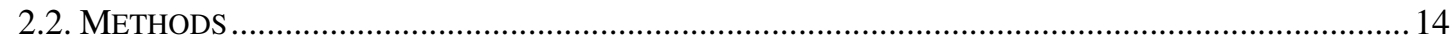

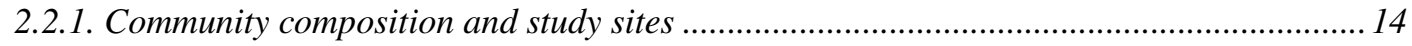

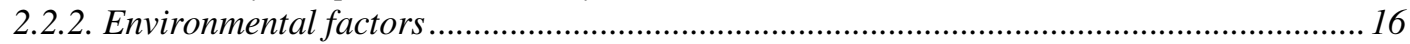

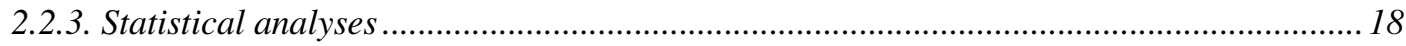

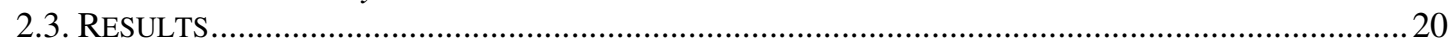

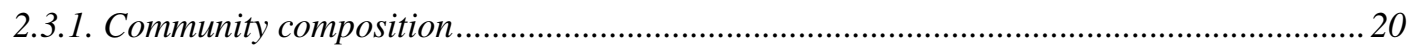

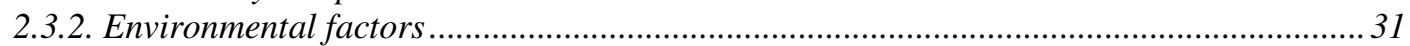

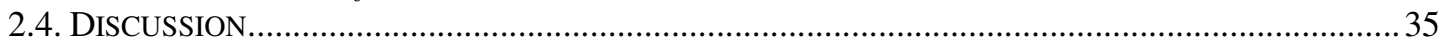

2.4.1. Community composition in the Cook Strait vs. Wellington Harbour ................................. 35

2.4.2. Mussel abundances in the Cook Strait vs Wellington Harbour ........................................... 37

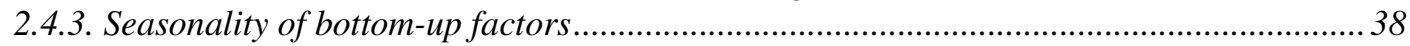

2.4.4. Phytoplankton community differences between Cook Strait and Wellington Harbour....... 39

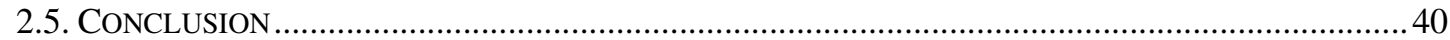

\section{CHAPTER 3. DOES WAVE EXPOSURE LIMIT THE DISTRIBUTION OF MUSSELS}

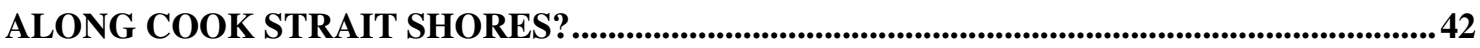

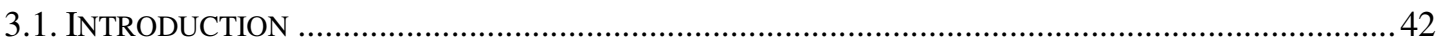

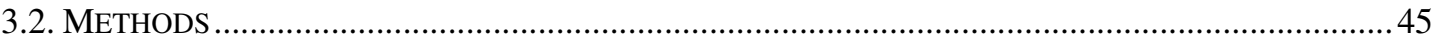

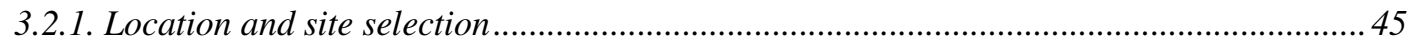

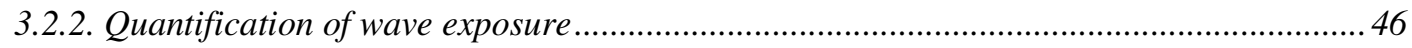

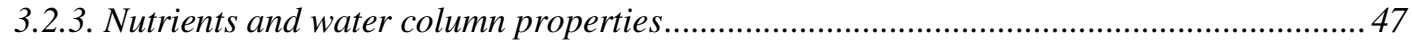

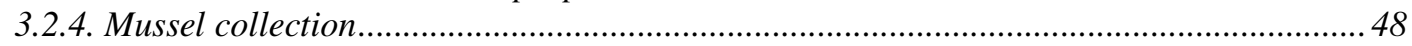

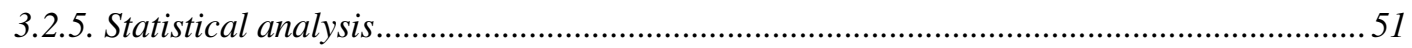

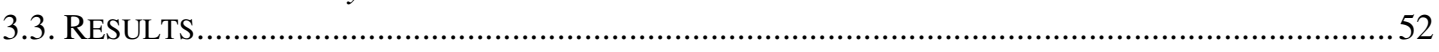

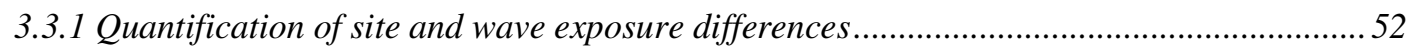

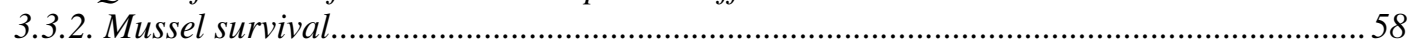

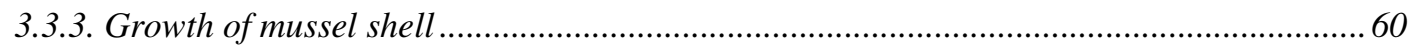

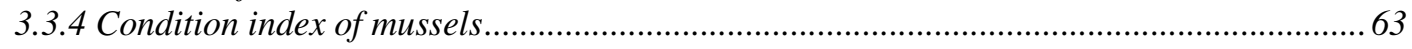

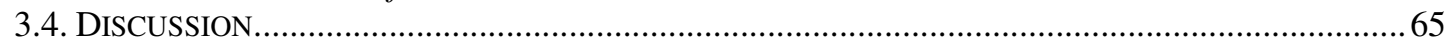

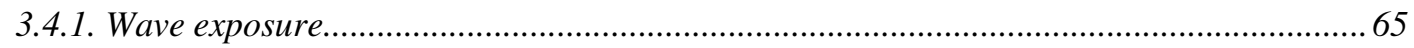

3.4.2. Coastal differences in mussel survival, growth and condition ..........................................6 67

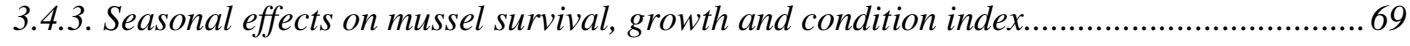

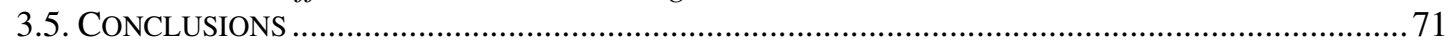




\section{CHAPTER 4. YOU ARE WHERE YOU EAT: SEASONAL DIFFERENCES IN FILTER FEEDER DIETS ON TWO DISPARATE SHORES}

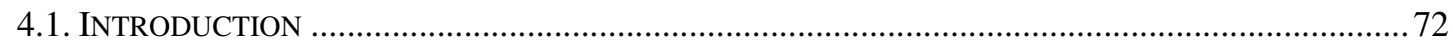

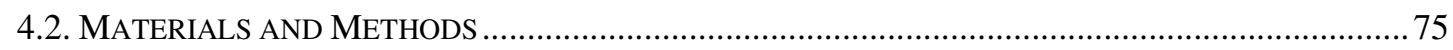

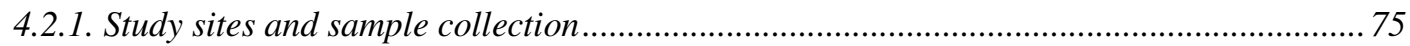

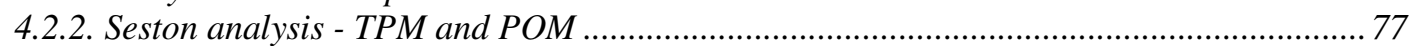

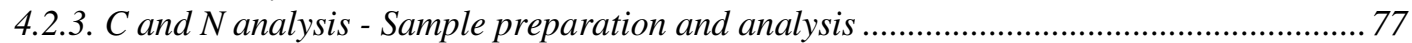

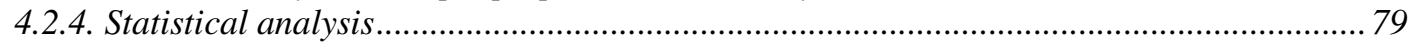

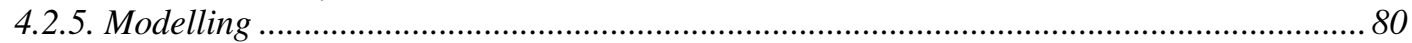

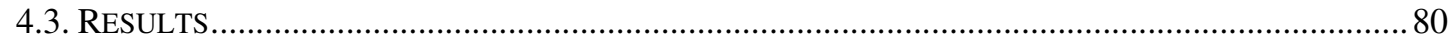

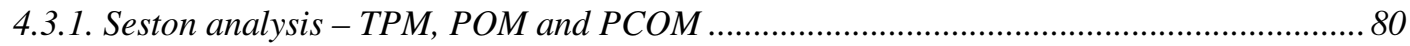

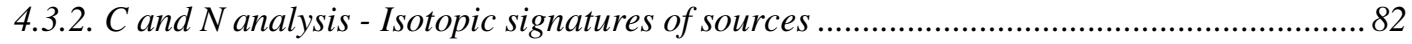

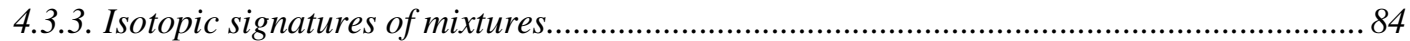

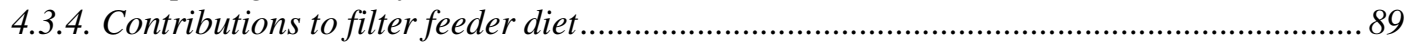

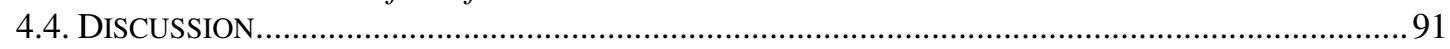

4.4.1. Seasonality in $C$ and $N$ isotopes of filter feeders and their food sources............................ 91

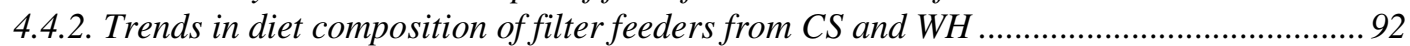

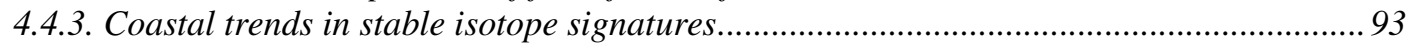

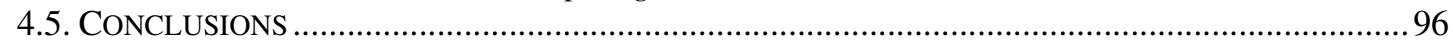

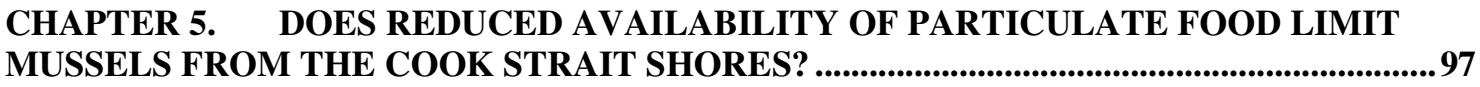

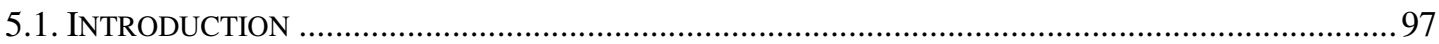

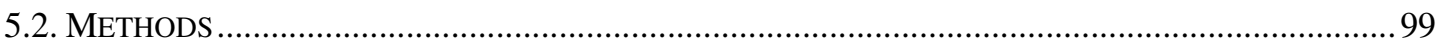

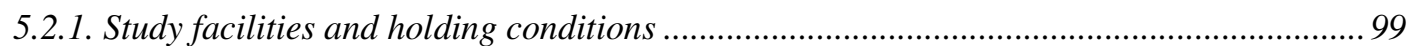

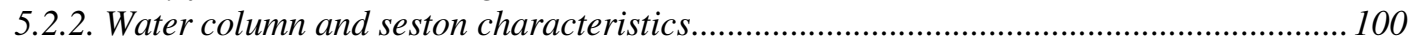

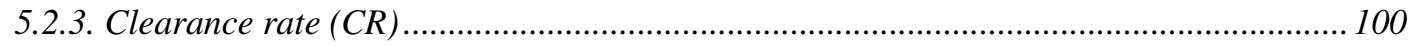

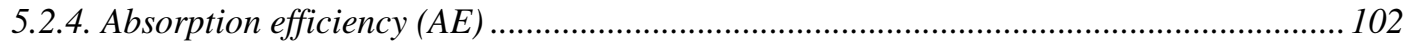

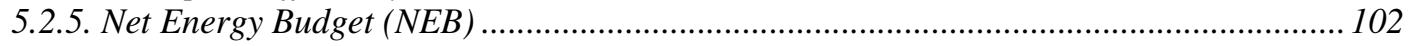

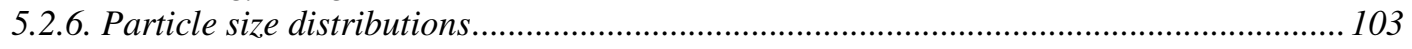

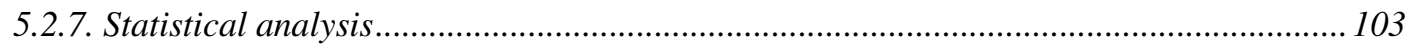

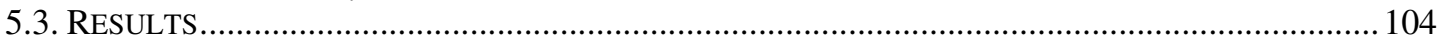

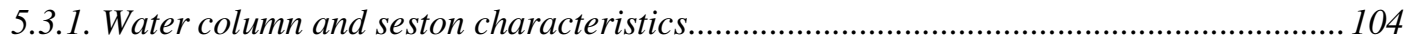

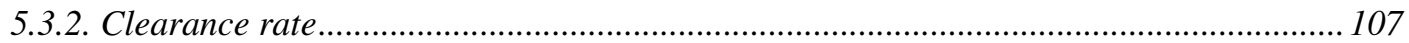

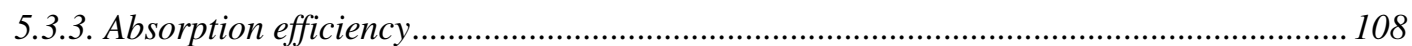

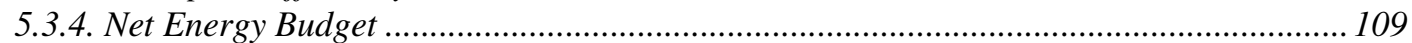

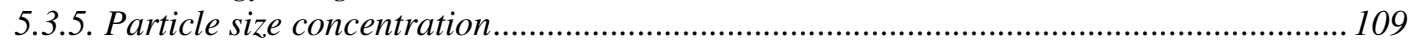

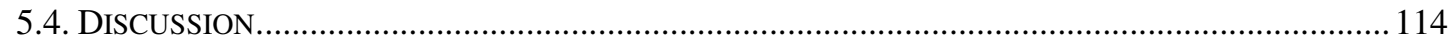

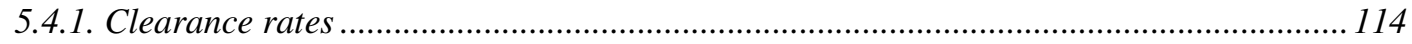

5.4.2. Absorption efficiency and net energy budget .............................................................. 114

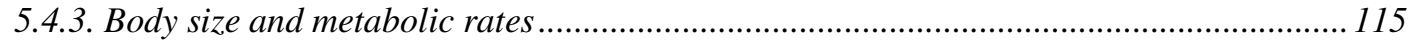

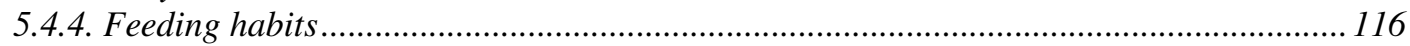

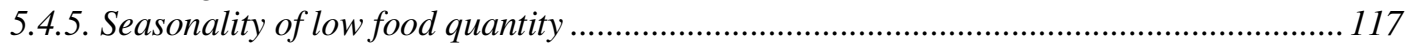

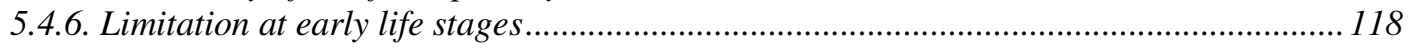

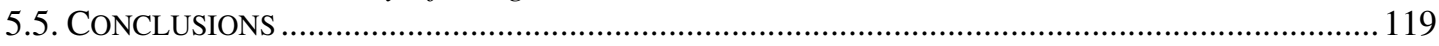

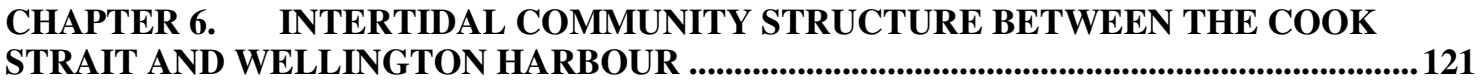

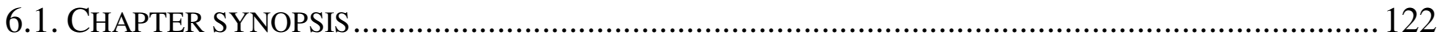

6.2. CHANGES IN THE INTERTIDAL ZONE OF THE TAPUTERANGA MARINE RESERVE......................124

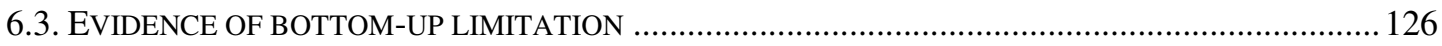

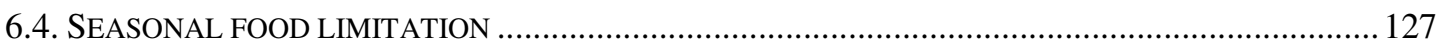

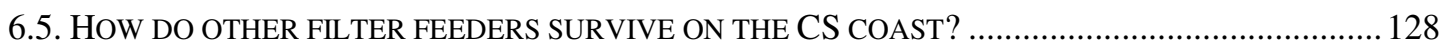




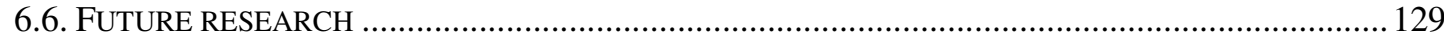

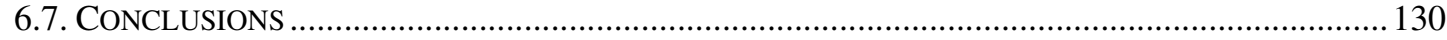

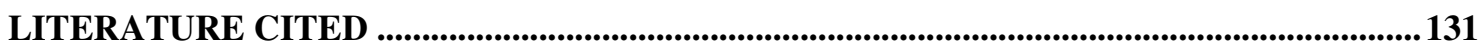




\section{List of Figures}

Figure 1.1. Differing stages of mussels with issues associated with their presence on the temperate rocky shores of the Wellington Cook Strait. Helson and Gardner (2004) found that larvae were present, while other studies indicate they should be able to settle on shore. This study will focus on factors that may be affecting mussel recruitment (shown in bold), using multiple techniques to approach a common problem. 7

Figure 2.1. Map of the study sites in the Cook Strait: Sinclair head (SH), Red Rocks (RR), Owhiro Bay (OB), Sirens (SI), Houghton Bay (HB), Moa Point (MP), Palmer Head (PH), Breaker Bay (BB), and in Wellington Harbour: Seatoun (ST), Evans Bay (EB), Lambton Harbour (LH), Inconsistent Point (IP). Sites within the Taputeranga Marine Reserve (TMR) are surrounded by a red line.

Figure 2.2. Two-dimensional non-metric multidimensional scaling plot (MDS, stress $=0.13$ ) of multivariate community data from the mid-intertidal zone of 8 sites in the Cook Strait which are represented by the data points grouped on the right (SH: Sinclair head, RR: Red Rocks, OB: Owhiro Bay, SI: Sirens, HB: Houghton Bay, MP: Moa Point, PH: Palmer Head, BB: Breaker Bay) and 4 sites in Wellington Harbour which are represented by the data points grouped on the left (ST: Seatoun, EB: Evans Bay, LH: Lambton Harbour, IP: Inconsistent Point). The sites in the Taputeranga Marine Reserve are OB, SI and HB. ........21

Figure 2.3. Two-dimensional MDS ordination plot (stress $=0.13$ ) of multivariate community data from the midintertidal zone of 8 sites in the Cook Strait which are represented by the data points grouped on the right and 4 sites in Wellington Harbour which are represented by the data points grouped on the left. Clustering at $50 \%$ similarity is denoted by a broken black line. Seasonal data at each of the sites is represented by a differing symbol.

Figure 2.4. CAP plot for sites along a geographical gradient where SH: Sinclair Head, RR: Red Rocks, OB: Owhiro Bay, SI: Sirens, HB: Houghton Bay, MP: Moa Point, PH: Palmer Head, BB: Breaker Bay, ST: Seatoun, EB: Evans Bay, LH: Lambton Harbour, IP: Inconsistent Point. The numbers in the legend coincide with the geographical position of each site from west to east......

Figure 2.5 Shannon diversity index (H'), richness (S) and evenness (J') at each of the study sites. A line denotes sites in Wellington Harbour, all other sites are within the Cook Strait.

Figure 2.6 Species accumulation curve as a function of season for Cook Strait (CS) and Wellington Harbour (WH) sites

Figure 2.7 Bubble plots on MDS ordinations describing the percent cover of key intertidal species determined through BVSTEP analysis from 12 sites, 8 sites in the Cook Strait (SH: Sinclair head, RR: Red Rocks, OB: Owhiro Bay, SI: Sirens, HB: Houghton Bay, MP: Moa Point, PH: Palmer Head, BB: Breaker Bay) and 4 sites in Wellington Harbour (ST: Seatoun, EB: Evans Bay, LH: Lambton Harbour, IP: Inconsistent Point).

Figure 2.8 Measurements of $\mathrm{NO}_{3}$, percent organic matter (PCOM) and particulate organic matter (POM) from 8 sites (Mean \pm SE). Sites within Wellington Harbour are indicated by a line to differentiate from those in Cook Strait.

Figure 2.9 Seasonal Chlorophyll a (chl a) and Sea Surface Temperature (SST) in the Cook Strait and Wellington Harbour (mean $\pm \mathrm{SE})$.

Figure 3.1. Map of locations in Wellington Harbour (WH) and on Cook Strait (CS)..............................45

Figure 3.2. Devices used to measure levels of wave exposure a) dynamometer and b) clod card.....................46

Figure 3.3. Example of etched markings on mussels for individual identification purposes. Arrow is showing an example of a borehole made by a whelk.

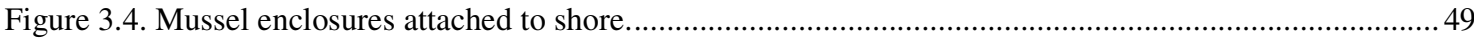

Figure 3.5. Wave exposure measurements from a) dynamometers and b) clod cards. Differing letters indicate significant differences.

Figure 3.6. Sea surface temperature (SST) for both the Cook Strait and Wellington Harbour. Data was collected from 4 seasons over 2010-2011.

Figure 3.7. Nutrient concentrations (mean \pm SE) along the Cook Strait and Wellington Harbour for a) nitrate, b) phosphate and c) silicate. Measurements were taken during 4 seasons during 2010-2011.....................55

Figure 3.8. Seston measurements (mean \pm SE) from the Cook Strait and Wellington Harbour across 4 seasons during 2010-2011 for a) total particulate matter, b) particulate organic matter, c) percent organic matter. Differing letters denote significant differences.

Figure 3.9. Slopes of the survivorship regressions for a) A. maoriana and b) M. galloprovincialis from the Cook Strait (CS) and Wellington Harbour (WH) for both wave sheltered and exposed sites. Higher values on the $\mathrm{X}$-axis indicate a higher mean rate of survivorship over time..... 
Figure 3.11 Mussel growth (addition of new shell length since etching) for a) A. maoriana and b) $M$. galloprovincialis along the Cook Strait (CS) and Wellington Harbour (WH) at wave sheltered and exposed sites across each month (September 2010 - October 2011).

Figure 3.12 Slopes of the growth regressions for a) A. maoriana and b) M. galloprovincialis from Cook Strait (CS) and Wellington Harbour (WH) for both wave-sheltered and exposed habitats....

Figure 3.13 Mussel condition index for a) A. maoriana and b) M. galloprovincialis on Cook Strait (CS) and in Wellington Harbour (WH) at wave sheltered and exposed sites as a function of time (September 2010October 2011).

Figure 4.1. Location of study sites along Cook Strait (RR: Red Rocks, SI: Sirens) and Wellington Harbour (EB: Evans Bay and IP: Inconsistent Point).

Figure 4.2. TPM: total particulate matter and POM: particulate organic matter (mean \pm SD) from the Cook Strait and Wellington Harbour for Summer 2010 and Winter 2010. Differing letters indicate significant

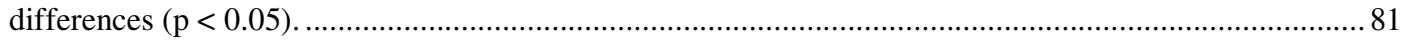

Figure 4.3 Stable carbon and nitrogen isotope signatures (means \pm SD \%o) for micro- and macroalgal sources in the CS and WH for the Summer 2010 and Winter 2010 seasons.

Figure 4.4 Stable carbon and nitrogen isotope signatures (means \pm SD \%o) for filter feeder (mixture signals) that were found in the CS and WH for the Summer 2010 and Winter 2010 seasons...................................8 86

Figure 4.5 Stable carbon and nitrogen isotope signatures (means \pm SD \%o) for filter feeder (mixture signals) that were found in either the CS or WH for the Summer 2010 and Winter 2010 seasons.

Figure 4.6 Proportional contribution of differing micro- and macroalgal sources to the diets of filter feeders for the Summer and Winter of 2010. Source species are LV: Lessonia variegata, DA: Durvillea antarctica, ZA: Zonaria aureomarginata, UN: Undaria spp., MP: Macrosystis....

Figure 5.1. Concentration of particles consumed (mean $\pm \mathrm{SE}$ ) in the size range of $2 \mu \mathrm{m}$ to $7 \mu \mathrm{m}$ spherical diameter for Mytilus galloprovincialis (MG), Aulacomya maoriana (AM) andPetrolisthes elongatus (PE) compared to the control.

Figure 5.2 Concentration of particles consumed (mean $\pm \mathrm{SE}$ ) in the size range of $8 \mu \mathrm{m}$ to $14 \mu \mathrm{m}$ spherical diameter for Mytilus galloprovincialis (MG), Aulacomya maoriana (AM) and Petrolisthes elongatus (PE) compared to the control.

Figure 5.3 Concentration of particles consumed (mean $\pm \mathrm{SE}$ ) in the size range of $15 \mu \mathrm{m}$ to $59 \mu \mathrm{m}$ spherical diameter for Mytilus galloprovincialis (MG), Aulacomya maoriana (AM) and Petrolisthes elongatus (PE) compared to the control.

Figure 6.1. Generalised pattern of zonation on a rocky temperate shore. EHWS - extreme high water springs (highest level of high tide); ELWS - extreme low water springs (lowest level of low tide). Modified from Stephenson and Stephenson (1949) 


\section{List of Tables}

Table 2.1. PERMANOVA analysis of diversity, richness and evenness across coast, site and season. Values in bold denote significant differences.

Table 2.2. List of all species found at study sites in the Cook Strait and Wellington Harbour ..........................26

Table 2.3. PERMANOVA analysis of the percent covers of intertidal species across coast, site and season. Bold

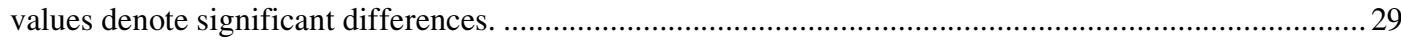

Table 2.4. PERMANOVA analysis of key environmental variables by coast, site and season determined through DistlM analysis. Bold values denote significant differences......

Table 2.5. PERMANOVA analysis of key environmental variables by coast and season determined through DistlM analysis. Bold values denote significant differences......................................................... 35

Table 3.1. Generlized Linear Model equations for A. maoriana and M. galloprovincialis at each location and site......

Table 3.2 PERMANOVA of mussel condition index between location, exposure level and month. An asterisk denotes a significant difference.

Table 4.1 MANOVA analysis of sources and post hoc MANOVA analyses for individual species. Individual species are CM: Carpophyllum maschalocarpum, DA: Durvillea antarctica, LV: Lessonia variegata, MP: Macrosystis pyrifera, UL: laminate Ulva spp., UN: Undaria spp., ZA: Zonaria aureomarginata, NW: nearshore water, OW: offshore water. An asterisk $(*)$ denotes statistical significance $(\mathrm{p}<0.05)$.

Table 4.2 MANOVA analysis for filter feeders (mixture samples) that were found on both coasts. Mixtures are LP: Limnoperna pulex and PE: Petrolisthes elongatus. Post hoc MANOVA analyses were performed for individual species. An asterisk (*) denotes significant differences.

Table 4.3 MANOVA analysis for filter feeders (mixture signals) that were found on either the CS or WH coasts. Mixtures are CB: Chamaesipho brunnea (CS coast), CC: Chamaesipho.....

Table 5.1 ANOVA results of temperature, salinity and dissolved oxygen. An asterisk denotes significant differences.

Table 5.2 Mean $( \pm \mathrm{SE})$ temperature $\left({ }^{\circ} \mathrm{C}\right)$, salinity (PSU) and dissolved oxygen $(\%)$ from the laboratory experiment in Wellington Harbour (WH) and Cook Strait (CS). Differing letters denote a significant difference within factor (Tukey's HSD).

Table 5.3 ANOVA of total particulate matter (TPM), particulate organic matter (POM) and percent organic matter (PCOM) by season (summer and winter), coast (Wellington Harbour and Cook Strait). An asterisk (*) denotes significance.

Table 5.4 Mean $( \pm$ SE) total particulate matter $(\mathrm{TPM})$, particulate organic matter $(\mathrm{POM})$ and percent organic matter (PCOM). Differing letters indicate significant differences within factor (Tukey's HSD).

Table 5.5 ANOVA table of size standardised clearance rates (CRs), absorption efficiency (AE) and net energy budget (NEB) by season (summer and winter), coast (Wellington Harbour and Cook Strait), and species (A. maoriana, M. galloprovincialis and P. elongatus). An asterisk (*) denotes significance.

Table 5.6 Size standardised clearance rates (CRs), absorption efficiencies (AE) and net energy budget (NEB) (Mean \pm SE). Differing letters indicate significant differences within factor (Tukey's HSD).......

Table 5.7 Percentage (\%) of individuals who had a negative absorption efficiency (-AE) and negative net energy budget (-NEB). 


\section{Chapter 1. General Introduction}

\subsection{Intertidal Community Organisation and Ecology}

Temperate intertidal shores have been widely used as a model habitat to study ecological theory. From a physiological perspective, species that live on these shores must contend with extremely harsh terrestrial forces that occur at each low tide. As such, the studies performed on temperate shores provide insight into the ecology of both terrestrial and aquatic environments. Temperate rocky intertidal communities are typically segregated into groups, based on aerial exposure tolerance, with similar upper and lower limits or vertical zonation. One or many physical or physiological stressors, such as temperature and desiccation, generally determine the upper limit of a species' distribution, while the lower limit is usually determined by biological factors, particularly predation (Connell 1972). The result is very distinct vertical bands of species across the shoreline. Ecologically similar species tend to live at the same vertical zone on most temperate rocky shores. For example, in the high intertidal, barnacles and grazing littorinid snails tend to be dominant, in the midintertidal, seaweeds and mussels cover the shore, while the low intertidal is typically dominated by kelp (Stephenson and Stephenson 1949, Morton and Miller 1968, Menge et al. 1999, Gardner 2008). This general pattern of dominant shoreline organisms is so common on temperate rocky shores that it has practically become a global paradigm.

The predictability and ease of access to rocky intertidal shores makes them useful for studying ecological theory. Many intertidal organisms are sessile or slow moving with a general biology that is well understood. In particular, seaweeds and sessile invertebrates have been used in a multitude of ecological studies because they are quick growing and have short generation times, which make them especially good for studying succession and effects of 
physical or physiological stressors (Connell 1972, Sousa 1984, Bergeron and Bourget 1986, Harley and Helmuth 2003, Harley et al. 2006, Helmuth et al. 2006a).

\subsection{Spatial Dominance}

Mussels generally occupy a significant amount of space in rocky intertidal habitats. They have life history qualities that make them not only successful invasive species, but also dominant species on rocky substrates. While invasive and dominant species are often considered nuisances, they can have positive impacts on species diversity. For example, in areas of Patagonia (Argentina) where wind forces create an arid intertidal environment, mussels that aggregate in large beds provide suitable habitat for organisms that would otherwise not be able to survive the desiccation stress (Crain and Bertness 2006). Mussels also possess high fecundity and long-lived larvae that may connect populations over large spatial scales. Their strong byssus threads enable them to attach to various substrates requiring immense forces to remove them (Gardner and Skibinski 1991, Lachowicz 2005, Zardi et al. 2006, 2007). Intertidal mussels are also extremely tolerant of stress. They can tolerate a wide range of temperatures (Hutchins 1947, Denny and Paine 1998, Helmuth and Hofmann 2001, Gilman et al. 2006, Helmuth et al. 2006a, 2006b), high wave forces (Hunt and Scheibling 2001a, Carrington 2002), and as fluctuations in salinity (Gardner and Thompson 2001a, Qiu et al. 2002, Westerbom et al. 2002).

The relationship between mussels and spatially dominant seaweeds has been a topic of a great interest, particularly in the New England area of the USA. Studies on temperate rocky shores have concluded that the variance in wave exposure determines the species composition on a particular shore (mussel vs. seaweed dominance). In wave exposed habitats there are higher maximum wave velocities, drag forces and pounding, where common predators (sea stars, crabs and whelks which tend to be larger and more susceptible to being washed off shore) have reduced abundance (Bertness 2007). Thus, sessile invertebrates 
(barnacles and mussels) are likely to dominate wave exposed shorelines because they are seldom preyed upon in these habitats. In wave-sheltered habitats, mussel populations are controlled by predators (top-down control), which allow seaweeds to dominate (Paine 1969, Hunt and Scheibling 1996, 1998, Bertness et al. 2004).

\subsection{Global patterns in intertidal communities}

It is undeniable that there is a deep history of research in intertidal community composition on temperate rocky intertidal shores worldwide and that the patterns observed can be generalised into a global rule of thumb. Patterns of intertidal flora and fauna share many similarities in temperate regions around the world (Stephenson and Stephenson 1949), with intertidal mussels often occupying the mid-intertidal zone. In many regions the study of intertidal community composition has revealed that top-down control yields fewer and larger mussels, as the mussels that escaped predation can reach a size that makes them difficult for predators to consume (Menge 1976, Bertness et al. 2002, Rilov and Schiel 2006a, 2006b). Bottom-up control results in one of two general types of communities. In the event of high primary productivity (or high chl $a$ concentrations) a higher abundance of mussels and lower abundance of macrophytes is observed in the mid-intertidal zone; whereas on less productive shores (lower chl $a$ concentrations), the opposite pattern occurs (Menge et al. 1997, 1999, McQuaid and Lindsay 2000, McQuaid and Phillips 2006, Blanchette et al. 2006b). Thus, while differing local conditions can often control the numbers of certain organisms or macrophytes, the vertical distribution of intertidal communities remains generally the same throughout the world and it is unusual to find shores that, in some form or another, do not fit the known pattern.

\subsection{Cook Strait \& Wellington Harbour}

With mussels playing such a large ecological role on many temperate rocky intertidal shores, it is unknown as to why they are nearly absent on many Cook Strait shores, in particular, the 
Cook Strait of Wellington (hereafter called the Cook Strait). One only needs to take a short walk along the Cook Strait to notice the incredible disparity between mussel abundance compared with any adjacent stretch of shore. What is even more striking is that while mussels are absent along the Cook Strait, nothing has occupied the space where mussels should be (in the mid to low intertidal), with the exception of the occasional patch of encrusting algae. Similar coastlines with equivalent wave exposures (e.g. west coast of Ireland, east coast of Canada) have high abundances of mussels (King et al. 1990, Heaven and Scrosati 2008, Tam and Scrosati 2011, 2013). Many of these areas also experience additional physical stressors such as freezing temperatures and higher predation rates than along Cook Strait shores (McCook and Chapman 1997, Scrosati and Heaven 2006, Scrosati and Eckersley 2007). The difficulty is that intertidal shores along the Cook Strait have not been extensively researched: there are several factors that affect mussel survival that have not yet been studied including nutrients, water seston quality, and phytoplankton abundances. Many questions still remain about not only mussels on the Cook Strait, but the entire intertidal community. Differences in community organisation between Cook Strait shores and other more typical rocky intertidal shores have not been documented and there is limited knowledge of the Cook Strait shores due to the difficulties associated with studying in this area (low tidal amplitude, high wind speeds and swell).

Much of the work compiled from the Cook Strait has focused on mussels. Helson and Gardner (2004) examined the presence of mussel larvae along Cook Strait shores and also compared the general water quality (organic matter and number of particles in nearshore water) between the Cook Strait and Wellington Harbour. The study found that larvae were present along the Cook Strait, but had lower abundance. Other life stages of mussels were not investigated (Figure 1.1). This study (and other work in the Gardner lab) suggests that the Cook Strait has lower seston quality than within Wellington Harbour, contributing to, but not 
totally explaining the low numbers of mussels (Gardner 2000, 2008, Gardner and Thompson 2001b).

There is evidence to suggest that nutrients play a role in the discrepancy in mussel abundances between the Cook Strait and Wellington Harbour. Wightman (2003) reported the presence of several mussel taxa in the immediate vicinity $(\sim 100 \mathrm{~m})$ of a storm drain at Lyall Bay, but their absence at a distance $>200 \mathrm{~m}$ from the drain along the Cook Strait. Her study indicated that freshwater outputs (most likely nutrients, but possibly particulates as well) are the cause for this small multi-species population that is not typically seen under any other conditions along Cook Strait shores.

There has been a recent suite of research on important subtidal species along the Cook Strait in light of the recent opening of the Taputeranga Marine Reserve (TMR) on $28^{\text {th }}$ August, 2008. However, monitoring or baseline studies of the intertidal zone have yet to be conducted for this area. Intertidal monitoring programmes are an important facet of Marine Reserves because changes in intertidal communities can sometimes reflect biological changes (e.g. community composition) throughout the entire reserve (Brown and Taylor 1999). In many cases intertidal organisms can be sensitive to changes in surface water chemistry, often reacting to eutrophication and pollution (Lopez Grappa et al. 1990). In the case of the TMR, the appearance of small multispecies mussel communities may indicate an important localised change in both the environment and the biological community health (Wightman 2003). Thus, it is important for conservation and management bodies to gain an understanding of how and why many of the intertidal species along the Cook Strait and Wellington Harbour exist where they exist, and how this might be influenced by protection from a marine reserve. 
Although there has been extensive research performed on temperate rocky intertidal shores, the uses of these habitats and the species that live within them are only beginning to be researched for their importance as indicators of biodiversity and community health, both intertidally and subtidally (Lubchenco et al. 2003). This study in particular is of great use, because sites are being monitored for the long-term from the establishment stage of the TMR and can be easily monitored by volunteers in the future. The idea of an intertidal baseline study for the TMR is already in the early stages of implementation by the Department of Conservation in Wellington, in conjunction with ongoing research at VUW. With this information it will be possible to determine which key species are most representative of changes within the marine reserve. 


\subsection{How to approach the problem}

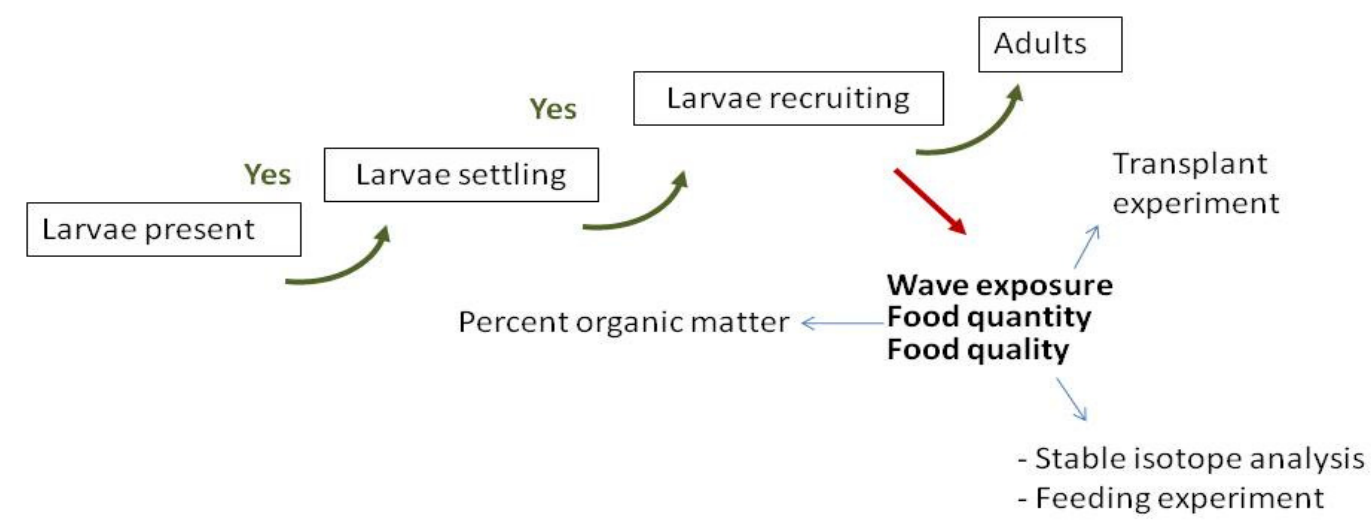

Figure 1.1. Differing stages of mussels with issues associated with their presence on the temperate rocky shores of the Wellington Cook Strait. Helson and Gardner (2004) found that larvae were present, while other studies indicate they should be able to settle on shore. This study will focus on factors that may be affecting mussel recruitment (shown in bold), using multiple techniques to approach a common problem.

While it is understood that there are differences in the presence/absence of mussels between Wellington Harbour and the Cook Strait (Helson and Gardner 2004, 2007, Helson et al. 2007) other intertidal community differences have not been quantified. Thus the initial objectives of this thesis were to examine the intertidal community differences between several sites along the Cook Strait and within Wellington Harbour. The sites chosen for this experiment were meant to coordinate with sites previously chosen for subtidal surveys (Pande and Gardner 2009). Thus, it will be possible to examine the linkage between the intertidal and subtidal zones of both Wellington Harbour and the Cook Strait, as well as within a newly formed marine reserve.

Subsequent chapters in this thesis are focused on what might be causing differences in the intertidal community along these two adjacent but differing shores. To obtain a more comprehensive idea of how nutrients are affecting intertidal communities, a suite of differing 
approaches was employed. The general understanding of nutrients in the waters surrounding New Zealand, particularly along the Cook Strait, is that nutrient concentrations are relatively low compared to other shores (Menge et al. 1999, Guerry et al. 2009). In many bays and harbours surrounding large cities however, coastal waters can have higher nutrients due to natural and artificial eutrophication. Runoff from the surrounding area draining into Wellington Harbour from the Hutt River, in combination with the high retention time, makes Wellington Harbour a likely sink for high nutrient concentrations. High nutrient concentrations are often associated with high chlorophyll levels, thus translating to high phytoplankton densities. The major nutrients that are linked with microalgal growth are nitrite $\left(\mathrm{NO}_{2}\right)$, nitrate $\left(\mathrm{NO}_{3}\right)$, phosphate $\left(\mathrm{PO}_{4}\right)$, ammonium $\left(\mathrm{NH}_{3}\right)$ and silicate $\left(\mathrm{SiO}_{2}\right)$. Thus, an analysis of the nutrients from nearshore surface water will be employed to test the hypothesis that Wellington Harbour sites will have higher nutrient levels than the Cook Strait sites.

The role of wave exposure in determining the presence of mussels along the Cook Strait is questionable at best. Moderate levels of wave exposure are thought to promote mussel survival and growth as higher flow rates promote optimal feeding conditions for mussels (McQuaid and Lindsay 2000, 2007, Bertness et al. 2004). However, high levels of wave exposure can be detrimental to mussels if the strength of the waves is greater than the strength of attachment (Gardner and Skibinski 1991, Hunt and Scheibling 1998, Zardi et al. 2006, 2007). While the waves along stretches of Cook Strait shores can be large (swells of over $3 \mathrm{~m}$ ) and wind speeds in excess of 50 knots, it is unknown why mussels are not present in at least small populations. If mussels cannot settle because of high wave exposures, they should be present in protected crevices or in sheltered sides of rock outcroppings. By transplanting mussels into wave exposed and wave sheltered areas and measuring their growth, condition and survival, it will be possible to determine if mussels are being negatively affected by high levels of wave exposure. 
The quality of food supply is also important for sessile filter feeder growth and survival. The particle size of food available to filter feeders in the water column may give insight into what types of food they are predominantly eating (i.e. smaller phytoplankton or larger pieces of macroalgae). Studies on the effects of food availability on bivalve larvae and juveniles have shown that the timing of food availability as well as good food quality increases the survival of mussels into the post-settlement stage (Phillips 2002, 2004). Whether or not food quality has an equal impact on newly settled or adult mussels in the field under natural conditions has yet to be investigated.

While mussels are absent from Cook Strait shores, the presence of other suspension feeders (e.g., several different barnacle species and porcelain crabs) may offer insight into what might be limiting mussels. Suspension feeders on the Cook Strait may not be eating the same diet as suspension feeders in Wellington Harbour. Feeding experiments were conducted on common suspension feeding taxa found in Wellington Harbour and on Cook Strait shores to examine the types of food (size of food particles) that they are ingesting to quantify the possible impact of localised (spatially restricted) diet on filter feeding communities. 


\subsection{Thesis objectives}

Objective 1: Quantify the differences in species richness, species diversity and evenness of high, mid and low intertidal communities between the Cook Strait and Wellington Harbour by measuring the densities of individual species and percentage cover at 12 permanent sites along the two shores. Furthermore, this chapter aimed to identify the environmental factors contributing to the differences in the intertidal community organisation between the Cook Strait and Wellington Harbour through the collection and analysis of water samples.

Objective 2: Determine the relative importance of wave forces compared with correlative environmental factors on mussel communities by performing a mussel transplant experiment along the Cook Strait and Wellington Harbour. This experiment will determine if adult mussels can survive in the Cook Strait at differing wave exposure levels.

Objective 3: To measure the quantity and quality of food in the diet of basal species. Species-specific isotopic signatures will be used to predict the proportion of microalgae and macroalgal detritus in the diets of suspension feeders and to determine if mussels have a different food source than other filter feeders that live on in the Cook Strait and the differences in food preference is limiting mussels to Wellington Harbour.

Objective 4: Examine the role of food quality (phytoplankton and macroalgae) on the survival of differing intertidal filter feeders, through feeding experiments. This experiment will determine if mussels are feed on differently sized particles than another filter feeder that lives in the Cook Strait. 


\section{Chapter 2. Do seasonal changes in the water column determine the differences in intertidal community composition between the Cook Strait and Wellington Harbour?}

\section{1. Introduction}

Universal patterns of zonation on temperate rocky intertidal shores have been well known for over half a century with similar bands of the same types of organisms structuring the shoreline from region to region (Stephenson and Stephenson 1949). Temperate rocky intertidal zones typically comprise (from top to bottom) lichens, small grazing littorinid snails, barnacles, mussels and large macroalgae that create horizontal bands and vertical zonation. While the sizes and patchiness of each of these biological zones can change depending on bottom-up factors such as upwelling (Menge et al. 1997, 1999, Nielsen and Navarrete 2003, Broitman and Kinlan 2006, Blanchette et al. 2009, Bode et al. 2009, Neira et al. 2009) or top-down control by predator mediation (Hunt and Scheibling 1998, Menge et al. 1999, Seitz and Lipcius 2001, Bertness et al. 2004, Enderlein and Wahl 2004, Morelissen and Harley 2006, Navarrete et al. 2006), it is obvious that shores that do not fit this pattern are the odd ones out.

In the mid intertidal zone, mussels are often dominant space holders that can increase invertebrate species richness and diversity by acting as ecosystem engineers (Bertness and Leonard 1997, Bertness et al. 1999, Gutierez et al. 2003, Crain and Bertness 2006). For example, on the Patagonian shores where arid winds can prevent many invertebrates from living on shore, dense beds of Perumytilus purpuratus provide shelter and space for other species to live amongst (Bertness et al. 2006). Mussels and barnacles are widespread along 
temperate hard shorelines worldwide (Lubchenco 1980, Kautsky 1982, McQuaid et al. 2000, Helmuth et al. 2006a, Blanchette et al. 2009, Tam and Scrosati 2011). They are considered to be an important link between the water column and predatory species because they filter particles from the water and provide food for whelks, seastars, crabs, fish and seabirds (Paine 1969, Hunt and Scheibling 1998, Bertness et al. 2004, Griffen and Delaney 2007, Pincebourde et al. 2008). Thus, because of this tight benthic-pelagic coupling between mussels and other filter feeders and the organisms that eat them, it is important to consider that changes in the water column can cause differences in the assemblages of species on shore.

Several environmental factors and water column properties affect filter feeders. Nutrient limitation affects the amount of phytoplankton in the water column, drastically altering the amount of food available to filter feeding organisms (Menge et al. 1999). Thermal stress (Gilman et al. 2006, Helmuth et al. 2006a, 2007, Scrosati and Eckersley 2007), wave forces (Hunt and Scheibling 2001a, Carrington 2002) and salinity stress (Qiu et al. 2002, Westerbom et al. 2002) can cause patchiness in mussel populations. Low levels of particulate matter can cause mortality in mussels (Bayne et al. 1987, 1993, Gardner 2000, Helson et al. 2007) while high particulate matter concentrations have negative effects on filter feeding crabs (Trager and Genin 1993, Steger and Gardner 2007).

Seasonal variation is another important factor in shaping intertidal communities. In regions where temperatures fall below freezing, ice scour and cold temperatures can severely limit the abundances of intertidal organisms (McCook and Chapman 1997, Minchinton and Scheibling 1997, Scrosati and Eckersley 2007, Heaven and Scrosati 2008). Recruitment patterns of many intertidal species with pelagic stages are seasonally driven (Runge 1985, Porri et al. 2006a, 2006b) while variations in intertidal algae and phytoplankton abundances can change on a seasonal basis (Underwood 1981, Furnas and Mitchell 1986). These cyclical 
patterns are important to understanding intertidal assemblages as they can confound results in experimental work that focus solely on physical and physiological effects on intertidal communities.

Along the Cook Strait (CS) of New Zealand (the stretch of water that separates the North and South islands) much of the shoreline does not fit the universal pattern of zonation, with an almost complete absence of mussels (Gardner 2000, Gardner and Thompson 2001b, Helson and Gardner 2004, Helson et al. 2007, Demello and Phillips 2011). Taputeranga Marine Reserve (TMR - established in August 2008) also lies within the CS; this is a stretch of shore that can no longer be exploited for commercial or recreational use (no take). The TMR represents an unusual stretch of coastline unlike any other in NZ and its preservation will be of great importance for present and future work (Gardner and Bell 2008, Pande and Gardner 2009). What is also of great interest is that Wellington Harbour (hereafter WH, which is $8 \mathrm{~km}$ from TMR) does show the typical patterns of zonation in the intertidal community. A general description of the differences between these two shores was first made by Morton and Miller (1968), and further description of the high and mid intertidal zones was provided at the guild level by Demello and Phillips (2011). However, the differences in community composition between the CS and $\mathrm{WH}$ at the species level across a seasonal time scale have yet to be described in relation to the possible environmental factors controlling the differences.

Previous studies along the CS have suggested that water column differences between the $\mathrm{CS}$ and $\mathrm{WH}$ are the driving forces behind the disparate community compositions on both shores. Helson and Gardner (2004) and Demello and Phillips (2011) observed mussel larvae in CS waters and subsequent recruitment throughout the year and concluded that recruitment limitation is unlikely to be causing the absence of mussels in the CS. Thus, post settlement mortality due to the differences in water column properties is likely to be causing the 
differences in community composition between CS and WH shores. Several studies have examined the role of food limitation and the survival of mussels in the CS and on other temperate rocky intertidal shorelines (Menge et al. 1997, Gardner and Thompson 2001b, Gardner 2002, Helson and Gardner 2007, McQuaid and Lindsay 2007, Helson et al. 2007, Blanchette et al. 2009). Helson and Gardner (2007) have also suggested that seasonal food limitation may be causing the low abundances of mussels from the CS, but it is still unclear as to how the environmental factors affecting food availability change in both the CS and WH throughout the year.

The purpose of this study was first, to quantify the differences in species richness, species diversity and evenness of mid-intertidal communities between the CS and WH by measurements of percent cover at several sites along the CS and WH including three sites within the TMR. Secondly, this study aimed to link intertidal community compositional differences between the CS and WH to changes in the water column, specifically seasonal changes in dissolved nutrient levels, chl $a$ and particulate matter concentrations.

\subsection{Methods}

\subsubsection{Community composition and study sites}

To quantify the intertidal community composition along the two adjacent shores, study sites were selected on bedrock or permanent rocky outcrops facing the open ocean at 8 sites in the CS and 4 in WH. The sites were selected to match up with sites selected for subtidal monitoring both inside and outside the Taputeranga Marine Reserve (Pande and Gardner 2009, Eddy et al. 2012). The sites were at: Sinclair Head (SH: S $41^{\circ} 21.508^{\prime}$ E $\left.174^{\circ} 42.813^{\prime}\right)$, Red Rocks (RR: S 412 21.342’ E 17443.582’), Owhiro Bay (OB: S 41²0.952’ E 174²4.945'), Sirens (SI: S 41⒛939’ E 174 45.837’ ), Houghton Bay (HB: S $41^{\circ}$

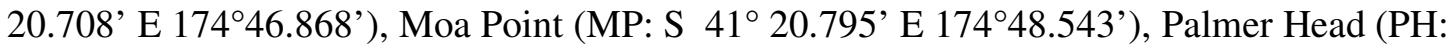




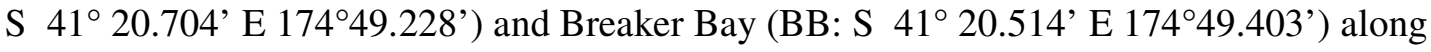
the Cook Strait with OB, SI and HB being inside the TMR; Seatoun (ST: S 41 $19.612^{\prime}$ E

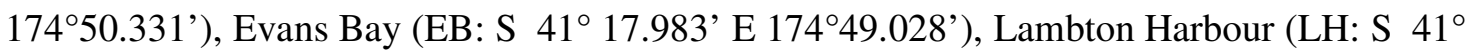
17.194' E $174^{\circ} 48.165^{\prime}$ ) and Inconsistent Point (IP: S 41 $19.111^{\prime}$ E $174^{\circ} 52.322^{\prime}$ ) in Wellington Harbour (Figure 2.1). At each site, 5 permanent 500 x $500 \mathrm{~mm}$ quadrats were set up at the mid-intertidal level (at approximately the mid-point between the highest barnacle and chart datum). Each quadrat was placed on exposed bedrock or large boulders, but was haphazardly placed within these constraints. Each quadrat was marked by 2 bolts into the rock at the top corners of the quadrat. Photographs were taken of each quadrat once per season (every 12 weeks) for 2 years from August 2009 to August 2011. Percent cover of sessile species was recorded using Coral Point Count with Excel extensions (CPCe) and the percent cover of mobile species was recorded visually using a removable quadrat with galvanized steel fencing with a $50 \times 50 \mathrm{~mm}$ mesh size creating squares equivalent to 1 percent of the total quadrat area. To improve the accuracy of each digital image, 4 photographs were taken of each quadrat, each photo capturing one quarter of the area sampled. This method of sampling the intertidal community allowed for optimal use of time in the field to collect a large amount of long-term data. Seasonal species accumulation curves were created using the total number of species observed along each coast. The mean number of species observed at either coast was calculated from all of the sites within each of the coasts. 

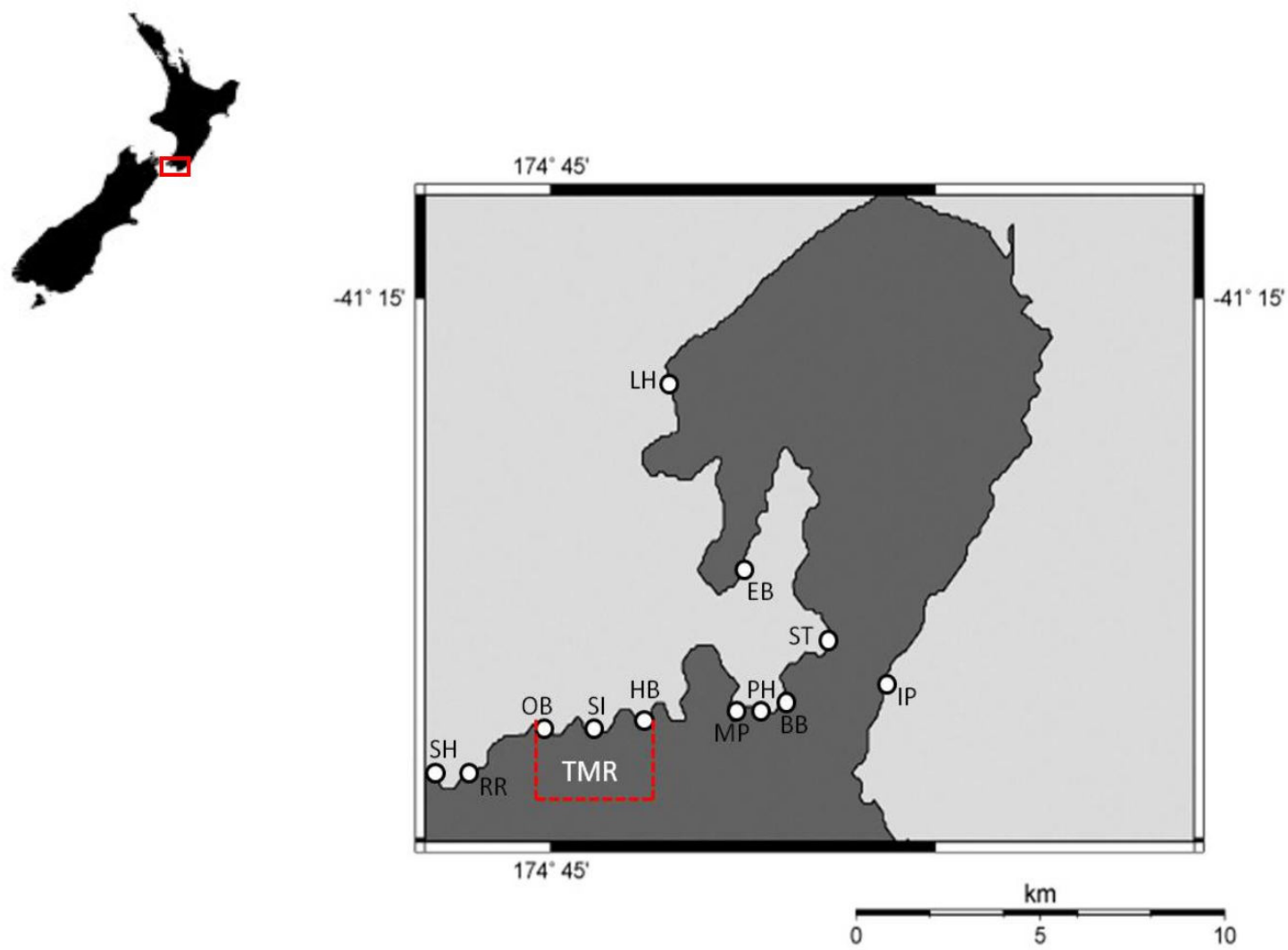

Figure 2.1. Map of the study sites in the Cook Strait: Sinclair head (SH), Red Rocks (RR), Owhiro Bay (OB), Sirens (SI), Houghton Bay (HB), Moa Point (MP), Palmer Head (PH), Breaker Bay (BB), and in Wellington Harbour: Seatoun (ST), Evans Bay (EB), Lambton Harbour (LH), Inconsistent Point (IP). Sites within the Taputeranga Marine Reserve (TMR) are surrounded by a red line.

\subsubsection{Environmental factors}

A major aim of this study is to determine if there is a link between intertidal community structure and the water column. To achieve this, nearshore water samples were taken every 12 weeks over 2 years (August 2009 to August 2011) at 8 of the 12 sites sampled (RR, SI, HB, MP on Cook Strait, and ST, EB, LH and IP in Wellington Harbour). The amount of water sampled from each site was $6 \mathrm{~L}$ (3 replicate samples of $2 \mathrm{~L}$ of surface seawater to measure total particulate matter (TPM), particulate organic matter (POM), percentage organic 
matter (PCOM)), $100 \mathrm{~mL}$ for nutrient analysis and $150 \mathrm{~mL}$ to measure particulate size and concentration. TPM, POM and PCOM were measured by filtering $2 \mathrm{~L}$ samples onto a preashed, pre-weighted Macherey-Nagel GF/C filter (Düren, Germany) and dried at $60^{\circ} \mathrm{C}$ for 24 h. Filters were weighed after drying to determine their dry weight or TPM and ashed at $450^{\circ} \mathrm{C}$ for $\approx 24 \mathrm{~h}$. The final ashed weight of the filters was determined and POM was calculated as TPM - ash weight. PCOM was calculated as (POM/TPM)*100 and is the percentage of TPM that is organic.

Measurements of nitrite, nitrate, phosphate, ammonia and silicate $\left(\mathrm{NO}_{2}, \mathrm{NO}_{3}, \mathrm{PO}_{4}\right.$ and $\mathrm{NH}_{3}$ ) were made using the Skalar $\mathrm{San}^{++}$System (Breda, The Netherlands), while silicate $\left(\mathrm{SiO}_{2}\right)$ was measured using the Orbeco Analyst 975MP (Florida, USA) portable water analyser. Particulate sizes and concentration were measured using a Beckman-Coulter MultisizerTM 3 Coulter Counter (Auckland, NZ). Other water quality measurements (temperature, salinity, chlorophyll $a$ and turbidity) were taken every minute using a Richard Brancker CTD sonde (XR 420) with integrated SeaPoint fluorometer and turbidimeter (units deployed for 4 week per 3 monthly intervals) at one site inside and outside WH. Due to logistical difficulties deploying the CTDs and their availability, two CTDs were deployed in total: one CTD unit was deployed in WH (at Matiu-Somes Island) and one unit for the CS (in the water holding tank at Victoria University Coastal Ecology Laboratory). Weekly averages of the data collected from the CTD were used for analysis. Supplementary temperature, salinity and dissolved oxygen measurements from all 8 sites were taken 3 times every 12 weeks at each site using a YSI Model 30 salinity and YSI Model 55 dissolved oxygen meter (Ohio, USA). 


\subsubsection{Statistical analyses}

Community species diversity, richness and evenness were calculated using Shannon index $\left(\mathrm{H}^{\prime}\right)$, total number of species (S) and Pielou's evenness index (J'), respectively. To identify any differences between coast, site and season with site nested within coast, permutational MANOVA (PERMANOVA) based on 10000 permutations was used in the Plymouth Routines in Multivariate Ecological Research statistical package (PRIMER v.6). Pairwise differences were also examined using PERMANOVA analysis based on 10000 permutations. To analyse differences in the community composition, MDS ordination was used to determine the best representation of the multivariate dataset from each site as points in twodimensional space with the distances between points representing the relative distance using Bray-Curtis similarity with 100 restarts to achieve the optimal solution. Species percent cover data were dispersion weighted and square root transformed to down-weight the effects of dominant and over-represented species from Poisson counts (Clarke and Gorley 2006). Cluster analysis with a permutational similarity profile test (SIMPROF) test was used to determine any genuine clustering between points in the MDS ordination plot. This cluster analysis with SIMPROF test does not test pre-defined group structures, but compares ranked resemblance curves to the expected ranked shape (based on 10000 permutations) with a significance level of 0.001 .

Analyses on subtidal data have revealed a geographical gradient that exists along the CS sites (Pande and Gardner 2009). Canonical analysis of principal coordinates (CAP) in PRIMER was used to examine if a geographical gradient exists in the multivariate community dataset at the mid intertidal level. The CAP analysis determines an axis through the multivariate cloud of points that has the strongest correlation along an a priori group (geographical gradient from west to east). For this particular analysis the geographic distances were not used, rather the general order of sites from west to east was used (Sinclair 
Head $=1$, Red Rocks $=2$, Sirens $=3$, etc. $)$. Canonical correlation $\left(\delta^{2}\right)$ is similar to the correlation coefficient $\left(\mathrm{R}^{2}\right)$ in linear correlation analysis and measures how well the points fit the model.

BEST analysis in PRIMER was employed to determine which species were contributing most to the overall patterns in community composition. Subsets of species that account for the whole continuous pattern of the multivariate matrix were determined using the stepwise search through backward elimination (BVSTEP within the BEST analysis). This test was chosen over ANOSIM and SIMPER analysis because it gives a more parsimonious combination of variables to describe the full set of species (Clarke and Gorley 2006) rather than looking at the differences at a particular treatment level (i.e. across site or season). The BVSTEP analysis was restricted to 10 variables (species) which best describe the multivariate dataset determined in the MDS analysis and uses Spearman's correlations and Bray-Curtis similarity on all species. The search terminates when the last added species to the current set gives a rank correlation $(\rho) \geq 0.95$, and dropping any of the species then reduces $\rho<0.95$, or if the increase in $\rho$ when adding the best new species is not more than 0.001 . Bubble plots of each species were used to represent the contribution of each species to the overall pattern of the multivariate community diversity data. The percent cover of each species was overlaid onto each site at each season as a representation of the contribution of relevant species to patterns found in the MDS analysis. PERMANOVA analysis was used to determine any significant differences between coast, site and season.

Distance-based linear models (DistlM) in PRIMER were used to determine the relationship between the multivariate community composition and the environmental factors (predictor variables). Environmental variables were first normalised as they are not in comparable measurement scales. DistlM analysis is a permutation method that provides quantitative measures of the variation in the community composition explained by one or 
more predictor variables using the Akaike Information Criterion (AICc) as the selection parameter for the goodness of fit of the model within the DistlM analysis which discourages over-fitting of the model (Anderson et al. 2008). AICc (which is AIC corrected for finite sample sizes) was chosen over AIC because it imposes an additional penalty when the sample size is low or the number of selection variables is high (18 environmental variables were examined for this study). A lower AICc value indicates a better fit of the model to the data.

Environmental variables contributing to the community composition were analysed for differences between coast, site and season (with site nested within coast) using PERMANOVA analysis.

\subsection{Results}

\subsubsection{Community composition}

The community composition at the mid intertidal zone across both the CS and WH was different according to the two-dimensional MDS plots with a low stress level of 0.13 (Figure 2.2 - stress values of $<0.2$ provide a good to reasonable 2-D representation of the data cloud). PERMANOVA analysis indicated that the community composition of sites within the TMR was not significantly different from the rest of the CS sites (Figure 2.2), but both the TMR and CS sites were significantly different from the WH sites (Pseudo-F $2,3=17.421, \mathrm{p}$ (perm) $=0.001)$. 


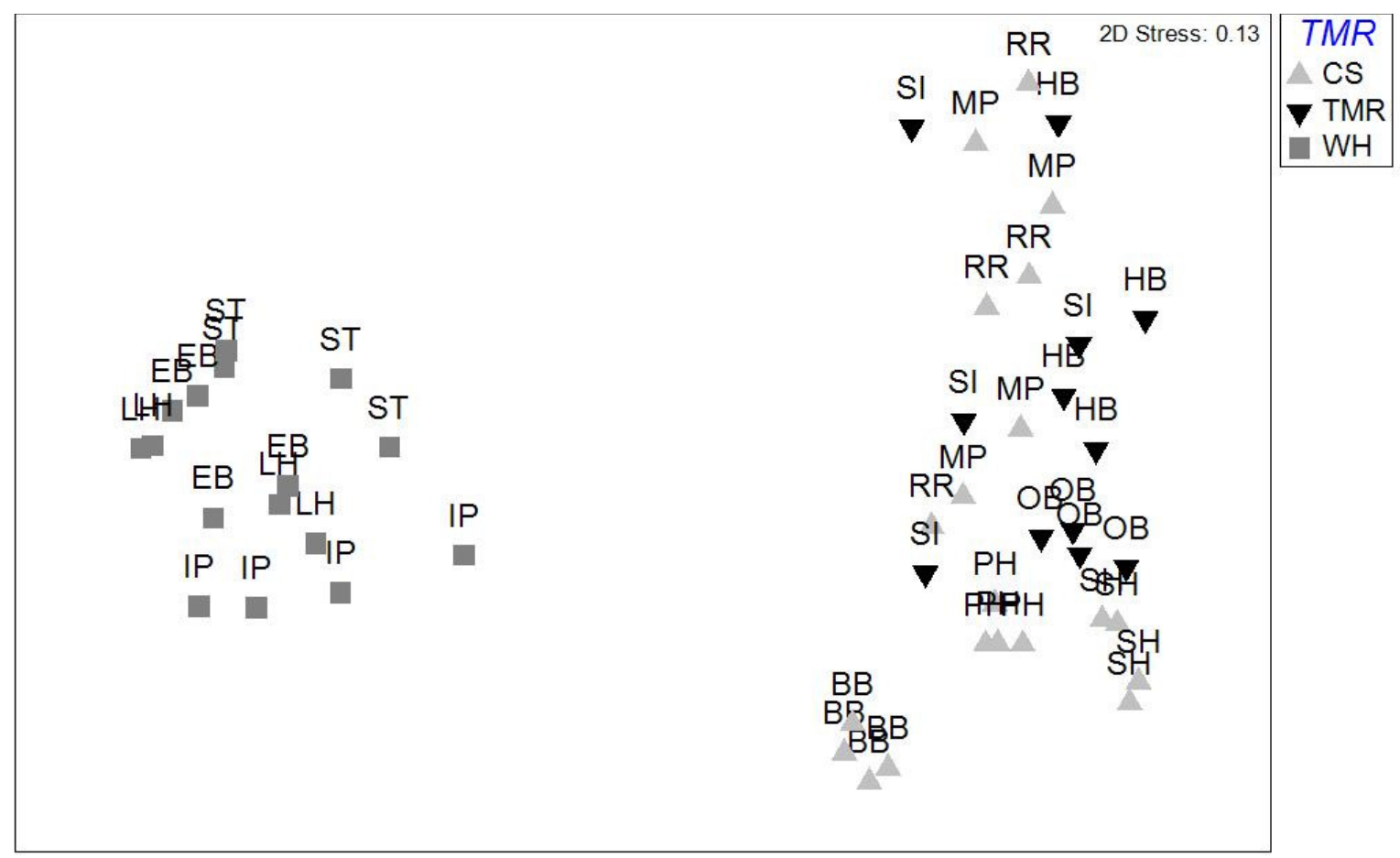

Figure 2.2. Two-dimensional non-metric multidimensional scaling plot (MDS, stress $=0.13)$ of multivariate community data from the mid-intertidal zone of 8 sites in the Cook Strait which are represented by the data points grouped on the right (SH: Sinclair head, RR: Red Rocks, OB: Owhiro Bay, SI: Sirens, HB: Houghton Bay, MP: Moa Point, PH: Palmer Head, BB: Breaker Bay) and 4 sites in Wellington Harbour which are represented by the data points grouped on the left (ST: Seatoun, EB: Evans Bay, LH: Lambton Harbour, IP: Inconsistent Point). The sites in the Taputeranga Marine Reserve are OB, SI and HB.

MDS analysis of all the sites and seasons indicated that community composition was more similar among seasons, than between coasts (Figure 2.3). The sites in the CS were more spread out and had a higher number of cluster groupings than those in WH. SIMPROF tests confirmed that there were more clusters among CS sites and season than between those of WH at a similarity of $50 \%(\pi=5.88, \mathrm{p}=0.01)$. There were distinct clusters in the CS at the BB site and between $\mathrm{PH}, \mathrm{OB}$ and $\mathrm{SH}$, however the other 4 sites (RR, IB, HB and MP) appeared to have more similarity in community composition between seasons with the summer and winter seasons separated by the spring and autumn seasons (Figure 2.3). 


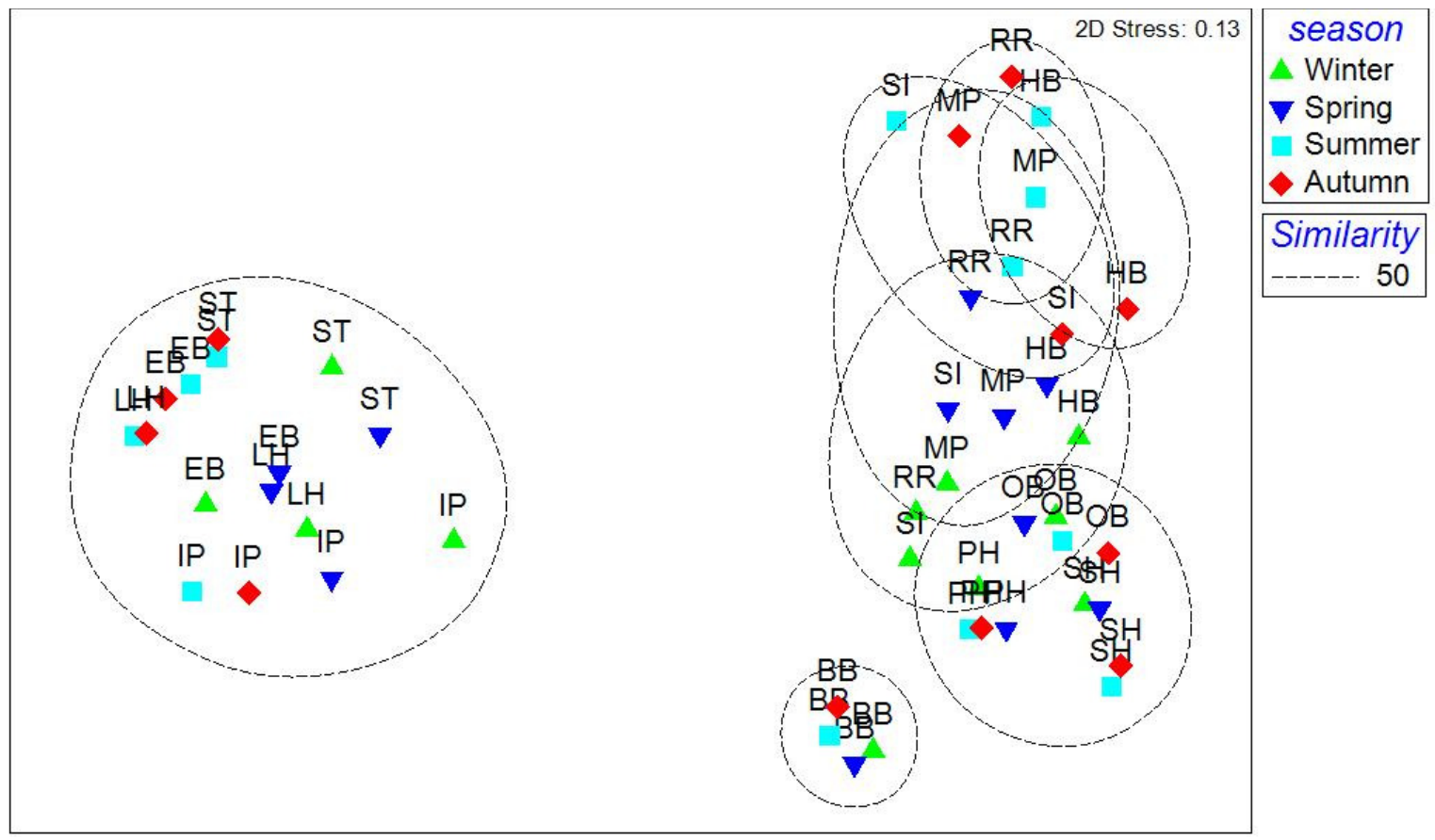

Figure 2.3. Two-dimensional MDS ordination plot (stress $=0.13$ ) of multivariate community data from the mid-intertidal zone of 8 sites in the Cook Strait which are represented by the data points grouped on the right (SH: Sinclair head, RR: Red Rocks, OB: Owhiro Bay, SI: Sirens, HB: Houghton Bay, MP: Moa Point, PH: Palmer Head, BB: Breaker Bay) and 4 sites in Wellington Harbour which are represented by the data points grouped on the left (ST: Seatoun, EB: Evans Bay, LH: Lambton Harbour, IP: Inconsistent Point). The sites in the Taputeranga Marine Reserve are OB, SI and HB. Clustering at 50\% similarity is denoted by a broken black line. Seasonal data at each of the sites is represented by a differing symbol.

Within the WH sites, there was distinctive overlapping of community composition at sites between the summer and autumn at SH, EB and LH, with winter and spring separate (Figure 2.3). At IP, the pattern of community composition was different between seasons, but not similar to the other 3 sites within WH. CAP analysis revealed that a geographical gradient exists in the mid intertidal community composition $\left(\delta^{2}=0.93, \mathrm{p}=0.001\right.$, Figure 2.4$)$. 


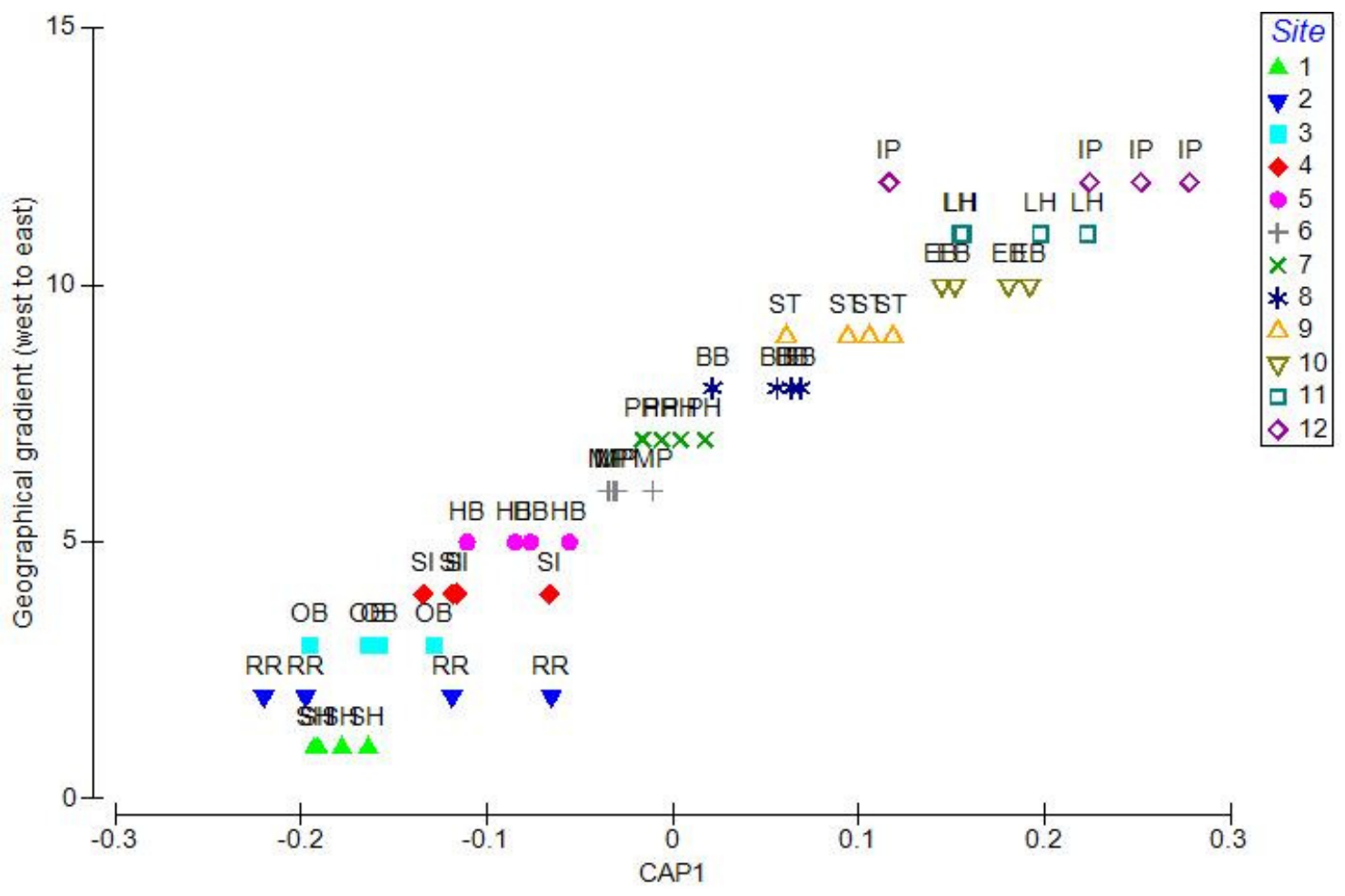

Figure 2.4. CAP plot for sites along a geographical gradient where SH: Sinclair Head, RR: Red Rocks, OB: Owhiro Bay, SI: Sirens, HB: Houghton Bay, MP: Moa Point, PH: Palmer Head, BB: Breaker Bay, ST: Seatoun, EB: Evans Bay, LH: Lambton Harbour, IP:

Inconsistent Point. The numbers in the legend coincide with the geographical position of each site from west to east.

Average species diversity and richness were higher at sites in the CS than in WH and showed strong seasonal trends with winter and spring having a higher diversity and richness than in the summer and autumn (Figure 2.5, Table 2.1). Sites in the CS had higher evenness than those in WH with winters in the CS differing from the summer and autumn. All other seasons differed significantly except for the autumn and summer and the autumn and spring in WH (Table 2.1). 

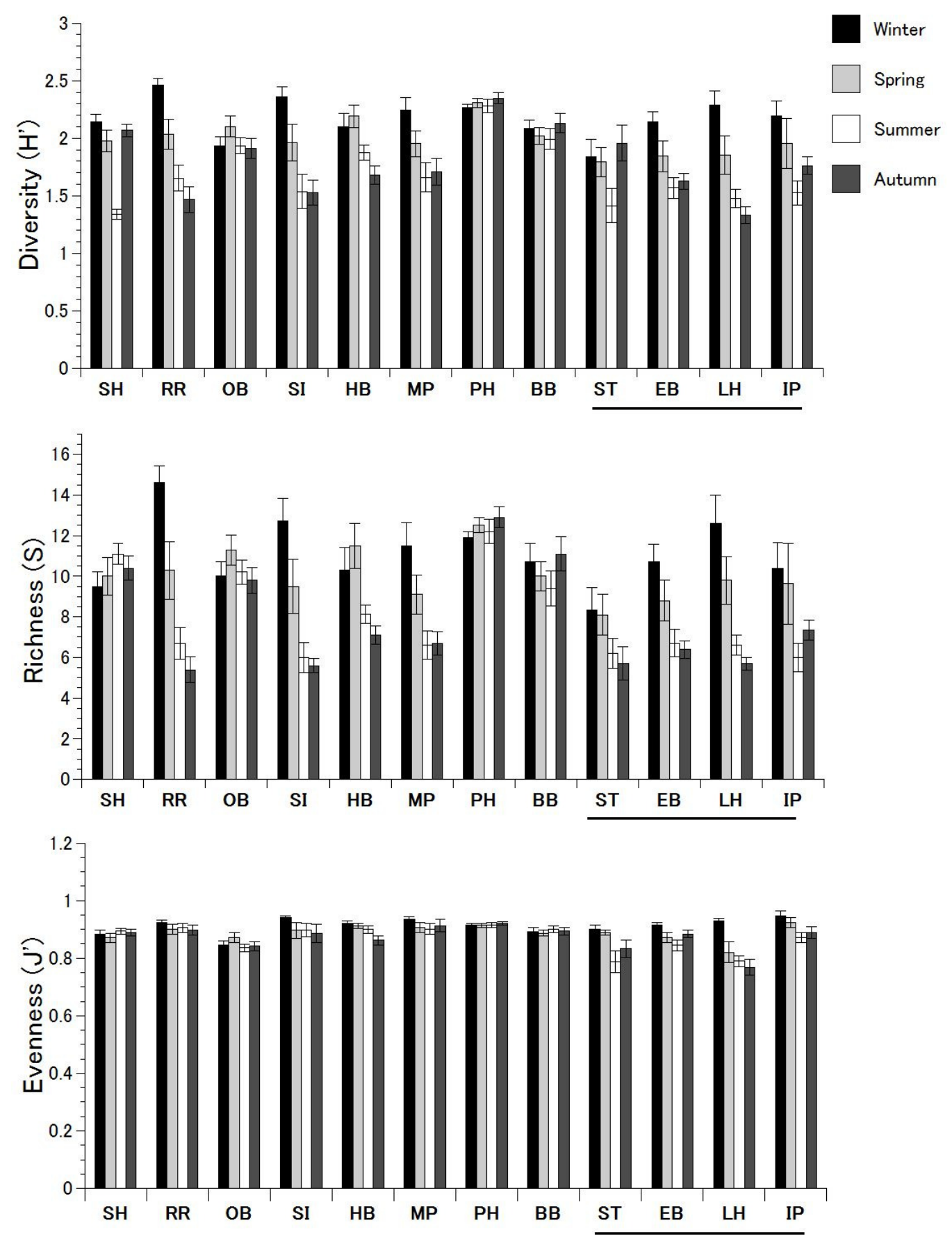

Sites

Figure 2.5 Shannon diversity index (H'), richness (S) and evenness (J') at each of the study sites. A line denotes sites in Wellington Harbour, all other sites are within the Cook Strait. 
Table 2.1. PERMANOVA analysis of diversity, richness and evenness across coast, site and season. Values in bold denote significant differences.

\begin{tabular}{lcrrrrrrr} 
& & \multicolumn{3}{c}{ Diversity } & \multicolumn{3}{c}{ Richness } & \multicolumn{3}{c}{ Evenness } \\
\cline { 3 - 9 } & df & Pseudo F & P(perm) & Pseudo F & P(perm) & Pseudo F & P(perm) \\
\hline Coast & 1 & 53.35 & $<\mathbf{0 . 0 0 1}$ & 45.79 & $<\mathbf{0 . 0 0 1}$ & 28.65 & $<\mathbf{0 . 0 0 1}$ \\
Season & 3 & 36.33 & $<\mathbf{0 . 0 0 1}$ & 33.49 & $<\mathbf{0 . 0 0 1}$ & 18.59 & $<\mathbf{0 . 0 0 1}$ \\
Site (Coast) & 10 & 6.27 & $<\mathbf{0 . 0 0 1}$ & 8.50 & $<\mathbf{0 . 0 0 1}$ & 7.55 & $<\mathbf{0 . 0 0 1}$ \\
Coast x Season & 3 & 4.53 & $\mathbf{0 . 0 3}$ & 2.06 & 0.08 & 10.34 & $<\mathbf{0 . 0 0 1}$ \\
Site (Coast) x Season & 30 & 2.67 & $<\mathbf{0 . 0 0 1}$ & 3.17 & $<\mathbf{0 . 0 0 1}$ & 1.26 & 0.17 \\
\hline
\end{tabular}

Species accumulation curves across seasons indicate that there were fewer increases in the number of species in the CS, but WH had a larger variation of the species recorded across season (Figure 2.6). More macroalgal species (red, green and brown) were recorded in the CS (34) than in WH (30). Conversely, there was a higher number of invertebrate species (filter feeders, grazers and predators) in WH (38) than in the CS (30) (Table 2.2).

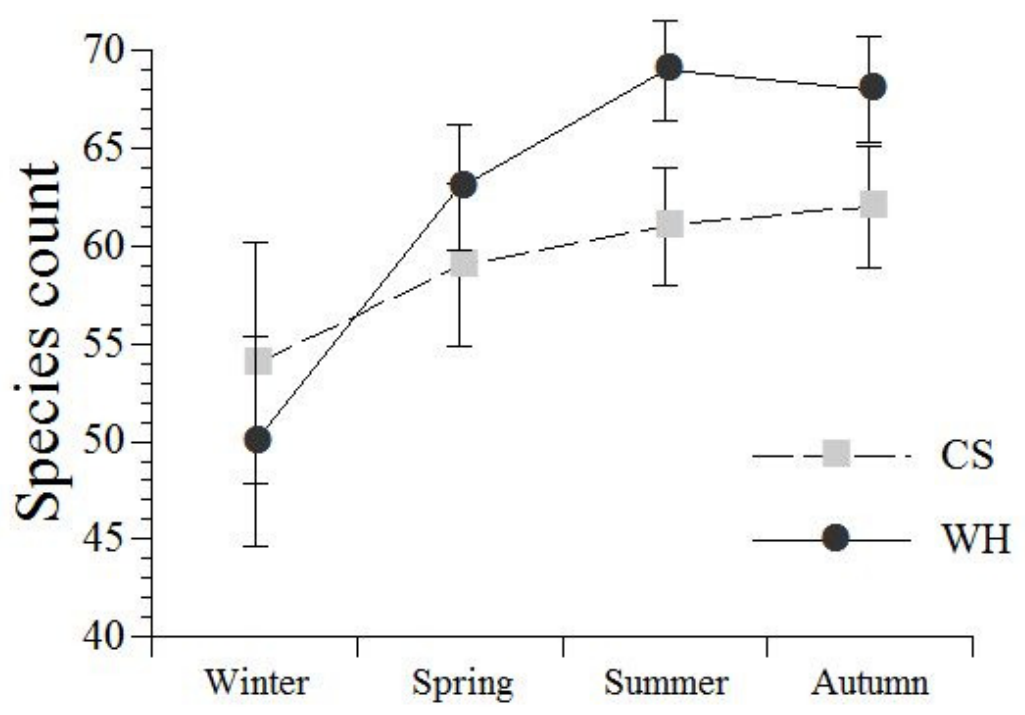

Figure 2.6 Species accumulation curve as a function of season for Cook Strait (CS) and Wellington Harbour (WH) sites. 
Table 2.2. List of all species found at study sites in the Cook Strait and Wellington Harbour

\begin{tabular}{|c|c|c|}
\hline & Cook Strait & Wellington Harbour \\
\hline \multirow[t]{18}{*}{ Rhodophyta } & Corallina spp. (encrusting) & Apophlaea sinclairii (Hooker \& Harvey, 1845) \\
\hline & Corallina spp. (geniculate) & Arthrocardia wardii (Chapman \& Parkinson, 1974) \\
\hline & Botryocladia spp. & Corallina spp. (encrusting) \\
\hline & Champia novae-zealandiae (Hooker \& Harvey, 1845) & Corallina spp. (geniculate) \\
\hline & Chondria macrocarpia (Harvey, 1855) & Ceramium rubrum (Agardh, 1811) \\
\hline & Echinothamnion spp. & Champia novae-zealandiae (Hooker \& Harvey, 1845) \\
\hline & Gelidium pusillum (Stackhouse, 1863 ) & Chondria macrocarpia (Harvey, 1855) \\
\hline & Gigartina circumcincta (Agardh, 1876) & Gelidium pusillum (Stackhouse, 1863) \\
\hline & Gigartina dicipiens (Hooker \& Harvey, 1855) & Gigartina ciramcincta (Agardh, 1876) \\
\hline & Gigartina livida (Turner, 1842) & Gigartina livida (Turner, 1842) \\
\hline & Haliptilon roseum (Lamarck, 1815) & Grateloupia urvilleana (Montagne, 1845) \\
\hline & Helminthocladia spp. & Helminthocladia spp. \\
\hline & Hildenbrandia spp & Hildenbrandia spp. \\
\hline & Hymenena spp. & Hymenena spp. \\
\hline & Lophothamnion hirtum (Hooker \& Harvey, 1840) & Lomentaria umbellata (Hooker \& Harvey, 1855) \\
\hline & Polysiphonia spp. & Lophothamnion hirtum (Hooker \& Harvey, 1840) \\
\hline & Porphyra spp. & Porphyra spp. \\
\hline & Stictosiphonia spp. & \\
\hline \multirow[t]{3}{*}{ Chlorophyta } & Codium convolutum (Dellow, 1952) & Codium convolutum (Dellow, 1952) \\
\hline & Codium fragile (van Goor, 1955) & Ulva spp. \\
\hline & Ulva spp. & \\
\hline \multirow[t]{13}{*}{ Phaeophyta } & Adenocystis utricularis (Bory de Saint-Vincent, 1825) & Adenocystis utricularis (ADU) \\
\hline & Carpophyllum maschalocarpum (Turner, 1819) & Carpophyllum maschalocarpum (Turner, 1819) \\
\hline & Colpomenia sinuosa (Mertens ex Roth, 1851) & Colpomenia sinuosa (Mertens ex Roth, 1851) \\
\hline & Desmarestia lingulata (Stackhouse, 1813) & Cystophora torulosa (Brown ex Turner, 1819) \\
\hline & Durvillaea antarctica (Chamisso, 1822) & Glossophora kunthii (Agardh, 1882) \\
\hline & Glossophora kunthii (Agardh, 1882) & Halopteris filicina (Grateloup, 1806) \\
\hline & Leathesia difformis (Areschoug, 1847) & Leathesia difformis (Areschoug, 1847) \\
\hline & Lessonia variegata (Agardh, 1877) & Lessonia variegata (Agardh, 1877) \\
\hline & Ralfsia verrucosa (Areschoug, 1843) & Ralfsia verrucosa (Areschoug, 1843) \\
\hline & Splachnidium rugosum (Linneus, 1771) & Splachnidium rugosum (Linneus, 1771) \\
\hline & Undaria pinnatifida & Unknown Brown Branched \\
\hline & Unknown Brown Branched & \\
\hline & Zonaria aureomarginata (Agardh, 1817) & \\
\hline \multirow[t]{5}{*}{ Filter feeders } & Actinia tenebrosa (Farquhar, 1898) & Aulocomya maoriana (Iredale, 1915) \\
\hline & Calantica spinosa (Gray, 1825) & Calantica spinosa (Gray, 1825) \\
\hline & Chamaesipho brunnea (Moore, 1944) & Chamaesipho brunnea (Moore, 1944) \\
\hline & Chamaesipho columna (Spengler, 1790) & Chamaesipho columna (Spengler, 1790) \\
\hline & Epopella plicata (Gray, 1843) & Epopella plicata (Gray, 1843) \\
\hline
\end{tabular}


Mytilus galloprovincialis (Lamarck, 1819)

Limnoperna pulex (Lamarck, 1819)

Serpulidae family

Spirorbidae family
Limnoperna pulex (Lamarck, 1819)

Mytilus galloprovincialis (Lamarck, 1819)

Perna canaliculus (Gmelin, 1791)

Serpulidae family

Spirorbidae family

Asteracmea suteri (Iredale, 1915)

Atalacmea fragilis (Sowerby, 1823)

Austrolittorina cincta (Auoy \& Gaimard, 1833)

Austrolittorina antipodium (Philippi, 1847)

Benhamina obliquata (Sowerby, 1825)

Cantharidus opalus (Martyn, 1793)

Cellana denticulata (Martyn, 1784)

Cellana ornata (Dillwyn, 1817)

Cellana radians (Gmelin, 1719)

Chiton glaucus (Gray, 1828)

Diloma aethiops (Gmelin, 1791)

Diloma coracina (Philippi, 1851)

Epitonium jukesianum (Forbes, 1852)

Eudoxochiton nobilis (Gray, 1828)

Maoricolpus roseus (Quoy \& Gaimard, 1834)

Margarella spp.

Notoacmea spp.

Patelloida corticata (Hutton, 1880)

Siphonaria australis (Quoy \& Gaimard, 1833)

Sypharochiton pelliserpentis (Quoy \& Gaimard, 1834)

Turbo smaragdus (Gmelin, 1791)

Buccinulum linea (Martyn, 1784)

Cominella glandiformis (Reeve, 1847)

Cominella maculosa (Martyn, 1784)

Haustrum haustorium (Gmelin, 1791)

Haustrum lacunosus (Brugiere, 1789)

Haustrum scobina (Quoy \& Gaimard, 1833)

Patiriella regularis (Verill, 1867) 
A BVSTEP analysis of the community composition data revealed that 8 groups explained $95.2 \%$ of the pattern described in the MDS plots. These groups were coralline algae Corallina spp. (encrusting), Corallina spp. (geniculate), the surf barnacle Chamaesipho brunnea, the acorn barnacle C. columna, the blue mussel Mytilus galloprovincialis, the red macroalgae Porphyra spp. and the limpets Cellana ornata and $C$. denticulata (Figure 2.7, Table 2.3). Both coralline algal groups were more abundant in the CS sites compared with the WH sites. $C$. brunnea and $C$. columna showed differing patterns of abundance, with $C$. brunnea being more abundant in the CS while $C$. columna was more abundant in WH. However, $C$. columna had a high relative percent cover at BB, which is near the mouth of WH. M. galloprovincialis was almost exclusively found in WH, with relatively high percent cover at sites within WH and only a few sparse individuals in the CS (Figure 2.7). When present, Porphyra spp. showed a higher percent cover at the CS sites. The percent cover of geniculate Corallina spp., C. brunnea, $C$. ornata and $C$. denticulata, differed significantly between seasons. Corallina spp. (geniculate) was higher in percent cover in the winter than in all other seasons, while the percent cover of $C$. brunnea was significantly greater in the spring compared with other seasons (Table 2.3). The limpets $C$. ornata and $C$. denticulata had a higher percent cover in the winter and spring with significantly lower values in the summer and autumn (Table 2.3). 
Table 2.3. PERMANOVA analysis of the percent covers of intertidal species across coast, site and season. Bold values denote significant differences.

\begin{tabular}{|c|c|c|c|c|c|c|c|c|c|}
\hline & \multirow[b]{2}{*}{ df } & \multicolumn{2}{|c|}{$\begin{array}{l}\text { Corallina spp. } \\
\text { (encrusting) }\end{array}$} & \multicolumn{2}{|c|}{$\begin{array}{l}\text { Corallina spp. } \\
\text { (geniculate) }\end{array}$} & \multicolumn{2}{|c|}{$\begin{array}{l}\text { Chamaesipho } \\
\text { brunnea }\end{array}$} & \multicolumn{2}{|c|}{$\begin{array}{l}\text { Chamaesipho } \\
\text { columna }\end{array}$} \\
\hline & & Pseudo F & $\mathrm{P}($ perm $)$ & Pseudo F & $\mathrm{P}($ perm $)$ & Pseudo F & $\mathrm{P}($ perm $)$ & Pseudo F & $\mathrm{P}($ perm $)$ \\
\hline Coast & 1 & 25.10 & $<0.001$ & 56.46 & $<0.001$ & 89.02 & $<0.001$ & 203.34 & $<0.001$ \\
\hline Season & 3 & 1.57 & 0.09 & 13.17 & $<0.001$ & 4.85 & 0.004 & 2.45 & 0.06 \\
\hline Site (Coast) & 10 & 7.01 & $<0.001$ & 5.77 & $<0.001$ & 8.65 & $<0.001$ & 11.51 & $<0.001$ \\
\hline Coast x Season & 3 & 1.65 & 0.07 & 2.21 & 0.0964 & 2.01 & 0.12 & 0.91 & 0.45 \\
\hline \multirow[t]{3}{*}{ Site (Coast) x Season } & 30 & 0.93 & 0.65 & 1.64 & 0.0542 & 0.54 & 0.96 & 0.58 & 0.95 \\
\hline & & \multicolumn{2}{|c|}{$\begin{array}{l}\text { Mytilus } \\
\text { galloprovincialis }\end{array}$} & \multicolumn{2}{|c|}{ Porphyra spp. } & $\begin{array}{l}\text { Cellana } \\
\text { ornata }\end{array}$ & & \multicolumn{2}{|c|}{$\begin{array}{l}\text { Cellana } \\
\text { denticulata }\end{array}$} \\
\hline & df & Pseudo F & $\mathrm{P}($ perm $)$ & Pseudo F & $\mathrm{P}($ perm $)$ & Pseudo F & $\mathrm{P}($ perm $)$ & Pseudo F & $\mathrm{P}($ perm $)$ \\
\hline Coast & 1 & 43623.00 & $<0.001$ & 5.84 & 0.02 & 96.14 & $<0.001$ & 215.27 & $<0.001$ \\
\hline Season & 3 & 0.86 & 0.47 & 2.16 & 0.09 & 19.11 & $<0.001$ & 8.44 & $<0.001$ \\
\hline Site (Coast) & 10 & 38.38 & $<0.001$ & 1.79 & 0.08 & 23.56 & $<0.001$ & 31.12 & $<0.001$ \\
\hline Coast x Season & 3 & 0.75 & 0.56 & 0.41 & 0.78 & 0.41 & 0.75 & 0.89 & 0.45 \\
\hline Site (Coast) x Season & 30 & 1.18 & 0.29 & 0.75 & 0.82 & 2.61 & 0.001 & 1.28 & 0.20 \\
\hline
\end{tabular}




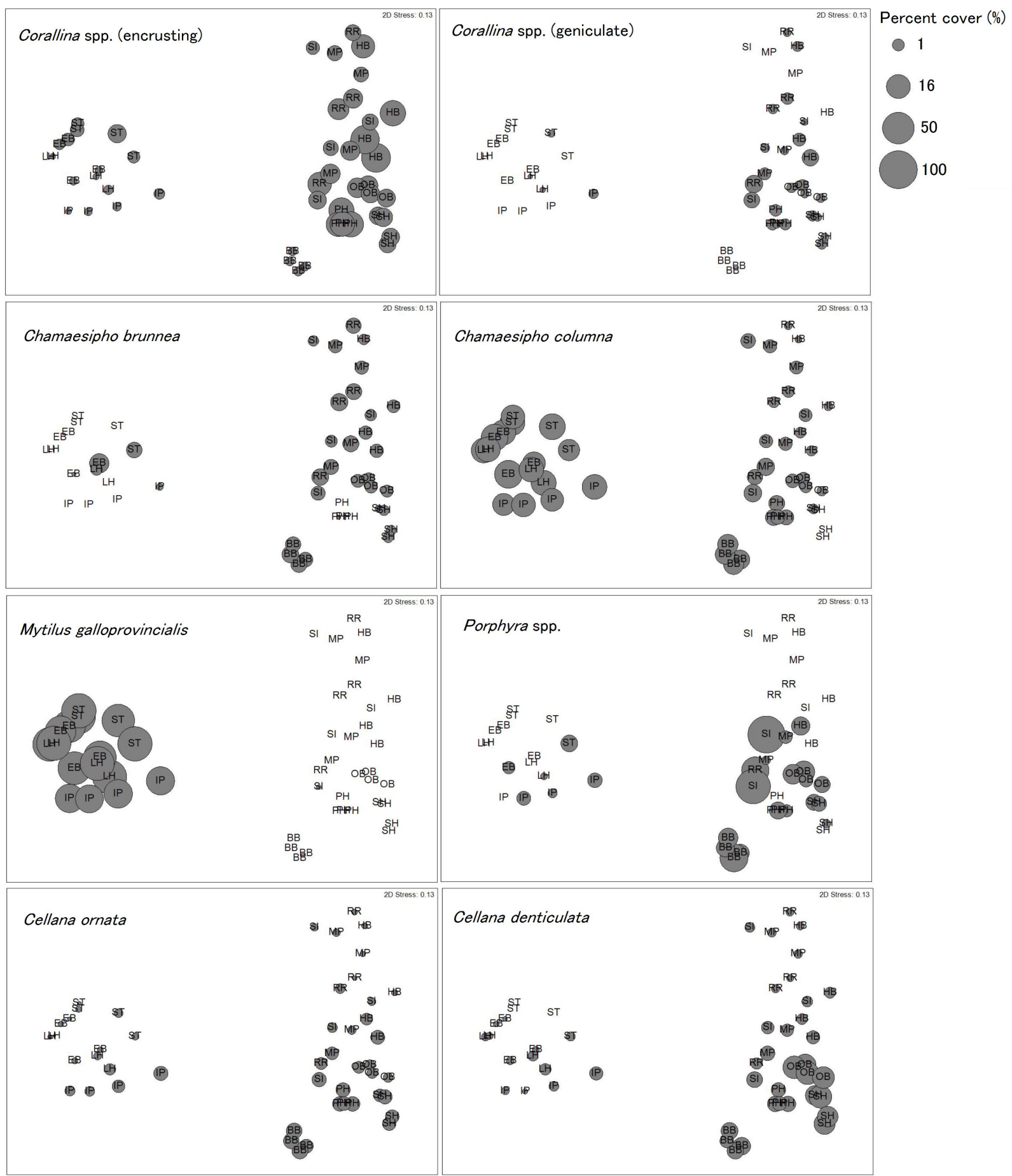

Figure 2.7 Bubble plots on MDS ordinations describing the percent cover of key intertidal species determined through BVSTEP analysis from 12 sites, 8 sites in the Cook Strait (SH: Sinclair head, RR: Red Rocks, OB: Owhiro Bay, SI: Sirens, HB: Houghton Bay, MP: Moa Point, PH: Palmer Head, BB: Breaker Bay) and 4 sites in Wellington Harbour (ST: Seatoun, EB: Evans Bay, LH: Lambton Harbour, IP: Inconsistent Point). 


\subsubsection{Environmental factors}

The DistlM analysis revealed there were 5 environmental variables contributing to $41 \%$ of the overall pattern in community composition. These environmental variables were $\mathrm{NO}_{3}$, PCOM, POM, chl $a$, and SST. Further PERMANOVA analysis revealed that $\mathrm{NO}_{3}$ was significantly different between seasons and had a significant interaction effect between coast and season (Table 2.4). Summer values of $\mathrm{NO}_{3}$ were significantly higher in the $\mathrm{CS}$ (mean \pm $\mathrm{SE}=0.29 \pm 0.06)$ than in $\mathrm{WH}($ mean $\pm \mathrm{SE}=0.09 \pm 0.07)(\mathrm{t}=2.70, \mathrm{p}($ perm $)=0.02)$, while there were no significant differences between the CS and WH during the other seasons (Figure 2.8).

The PCOM was generally significantly higher in the CS (mean $\pm \mathrm{SE}=37.69 \pm 2.91)$ than in WH (mean $\pm \mathrm{SE}=28.33 \pm 4.86$ ) (Table 2.4), but did not differ among seasons or sites within each coast.

Coast-wise comparisons indicated that the POM in WH (mean $\pm \mathrm{SE}=4.15 \pm 1.21$ ) was generally higher than in the $\mathrm{CS}$ (mean $\pm \mathrm{SE}=1.98 \pm 0.34$ ). The POM was significantly higher in WH at IP when compared with $\mathrm{LH}$ and EB, while sites in the CS were not significantly different from each other (Table 2.4). The POM in the winter and autumn was significantly lower in the CS compared with the winter concentration of POM in WH $(\mathrm{t}=$ $8.59, \mathrm{p}(\mathrm{perm})=0.003)$. However, within the CS, the autumn POM concentration was significantly higher than in the winter (Figure 2.8). 

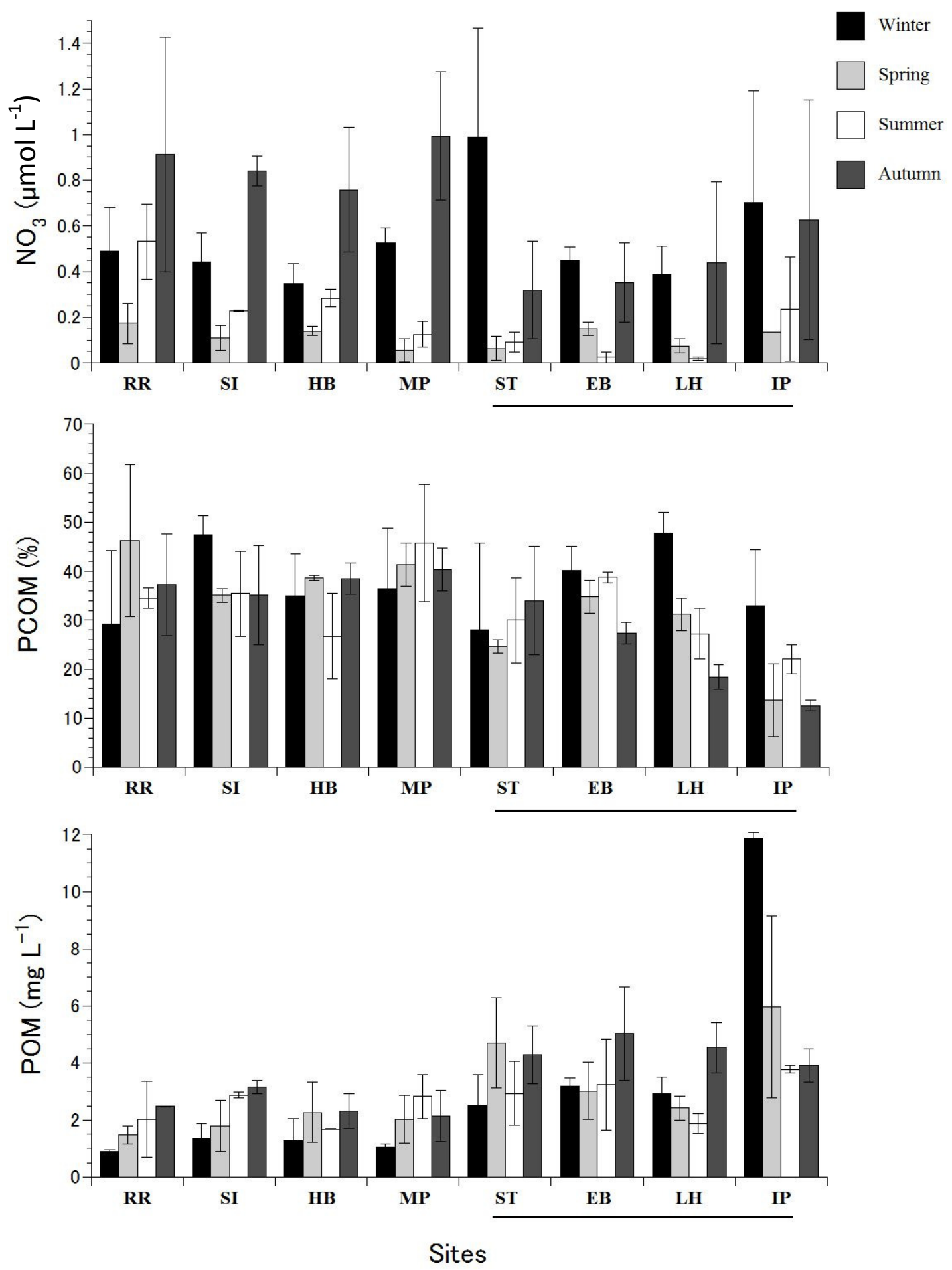

Figure 2.8 Measurements of $\mathrm{NO}_{3}$, percent organic matter (PCOM) and particulate organic matter (POM) from 8 sites (Mean $\pm \mathrm{SE}$ ). Sites within Wellington Harbour are indicated by a line to differentiate from those in Cook Strait. 
Table 2.4. PERMANOVA analysis of key environmental variables by coast, site and season determined through DistlM analysis. Bold values denote significant differences.

\begin{tabular}{|c|c|c|c|c|c|c|c|}
\hline & \multirow[b]{2}{*}{ df } & \multicolumn{2}{|l|}{$\mathrm{NO}_{3}$} & \multicolumn{2}{|l|}{ PCOM } & \multicolumn{2}{|l|}{ POM } \\
\hline & & Pseudo F & $\mathrm{P}($ perm $)$ & Pseudo F & $\mathrm{P}($ perm $)$ & Pseudo F & $\mathrm{P}($ perm $)$ \\
\hline Coast & 1 & 1.41 & 0.24 & 12.09 & 0.002 & 32.30 & $<0.001$ \\
\hline Season & 3 & 14.28 & $<0.001$ & 0.45 & 0.71 & 0.93 & 0.44 \\
\hline Site (Coast) & 6 & 1.08 & 0.39 & 1.89 & 0.11 & 4.71 & 0.004 \\
\hline Coast x Season & 3 & 4.41 & 0.01 & 1.48 & 0.24 & 3.09 & 0.04 \\
\hline Site (Coast) x Season & 18 & 0.48 & 0.95 & 0.68 & 0.80 & 1.89 & 0.06 \\
\hline
\end{tabular}

The concentrations of $c h l a$ in the water column were significantly different among seasons (Table 2.5), with both the CS and WH showing higher levels in the spring and summer than in the autumn and winter (Figure 2.9). Winter concentrations of $c h l a$ were significantly lower in the CS than in WH $(\mathrm{t}=14.10, \mathrm{p}(\mathrm{perm})=0.002)$. Spring, summer and autumn concentrations of $c h l a$ were not significantly different between coasts.

Sea surface temperature (SST) was significantly different among seasons (Table 2.5) with nearly all seasons being significantly different from each other $(\mathrm{p}($ perm $)<0.001)$, except for SST between summer and autumn (Figure 2.9). During the winter, summer and autumn temperatures were significantly lower in the CS than in $\mathrm{WH}(\mathrm{p}(\mathrm{perm})<0.05)$, while in the spring temperatures were similar (Figure 2.9). 

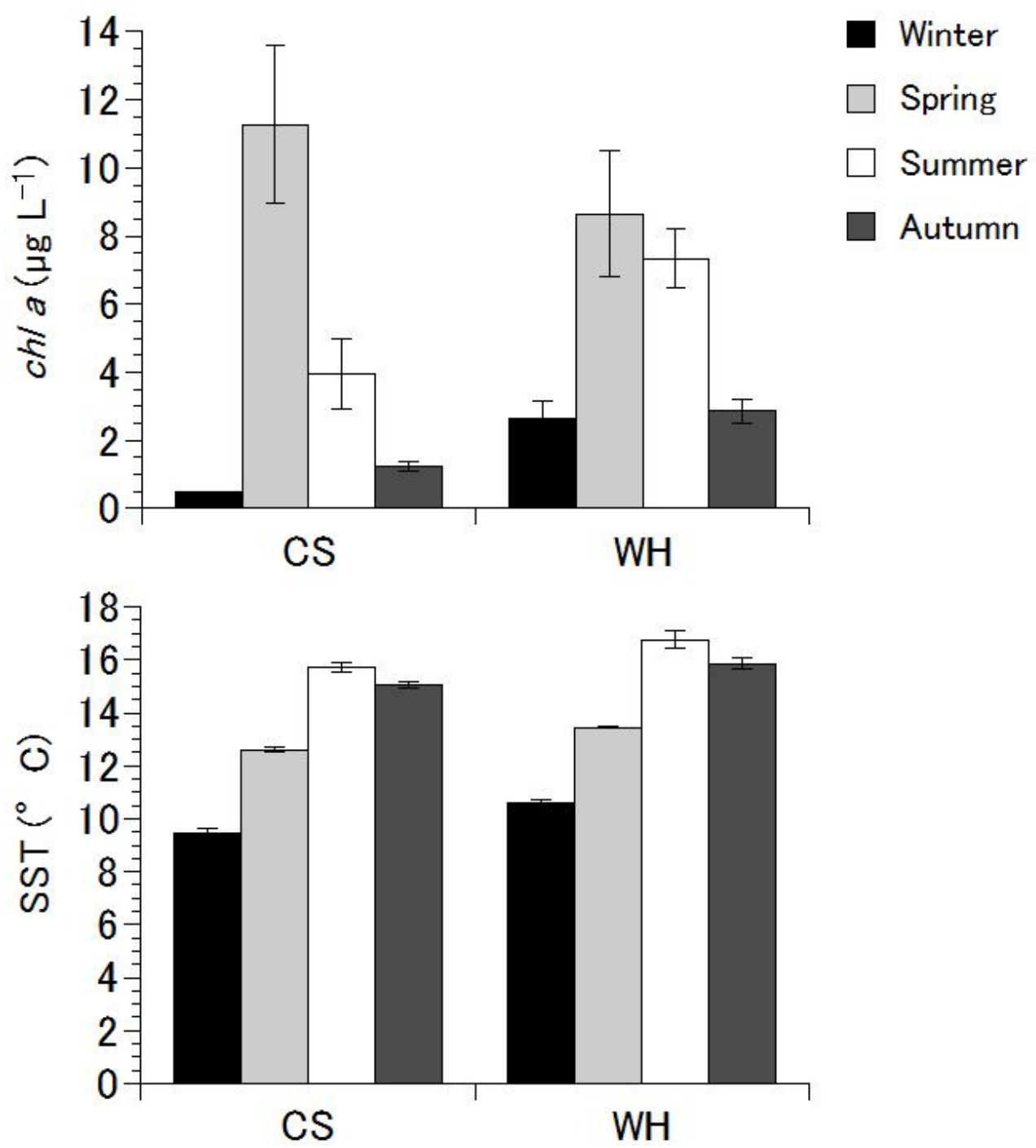

Figure 2.9 Seasonal chlorophyll a (chl $a$ ) and sea surface temperature (SST) in the Cook Strait and Wellington Harbour (mean \pm SE) $n=24$. 
Table 2.5. PERMANOVA analysis of key environmental variables by coast and season determined through DistlM analysis. Bold values denote significant differences.

\begin{tabular}{|c|c|c|c|c|c|}
\hline & \multicolumn{2}{|r|}{ chl $a$} & \multicolumn{3}{|c|}{$\mathrm{SST}$ (from CTD) } \\
\hline & $\mathrm{df}$ & Pseudo F & $\mathrm{P}($ perm $)$ & Pseudo F & $\mathrm{P}($ perm $)$ \\
\hline Coast & 1 & 0.02 & 0.90 & 1.48 & 0.23 \\
\hline Season & 3 & 24.33 & $<0.001$ & 164.85 & $<0.001$ \\
\hline Coast x Season & 3 & 5.07 & 0.003 & 6.15 & 0.002 \\
\hline
\end{tabular}

\subsection{Discussion}

\subsubsection{Community composition in the Cook Strait vs. Wellington Harbour}

The species composition of rocky intertidal biota it the mid-intertidal zone showed substantial geographic differences around the southern coast of the North Island of New Zealand. While several previous biogeographic studies have examined similar differences across widespread geographic areas which include state-wide, country-wide and intercontinental examinations of the differences in intertidal species composition (Bustamante and Branch 1996a, Menge et al. 1999, 2003, Blanchette et al. 2008, Navarrete et al. 2008, Smith et al. 2009), this study focused on a disparate shoreline within a relatively short distance (a few $\mathrm{km}$ ) and the potential environmental factors causing these differences. The quantitative differences examined in this study have determined a clear-cut division between the Cook Strait (CS) and Wellington Harbour (WH), with WH having a similar species composition between sites and season than the CS.

Community composition data suggested that the mid intertidal zone in the Taputeranga Marine Reserve (TMR) is similar to other coasts along the CS. In other marine reserves in New Zealand there has been a negative impact on intertidal assemblages due to 
human trampling (Brown and Taylor 1999, Schiel and Taylor 1999). Because community members and tourists often use marine reserves to view marine life, intertidal species are (unavoidably) trampled. These effects have not been observed in the TMR as it is a relatively new marine reserve (established in August 2008) and the often large swells and topography (jagged greywacke outcrops) of the area are not often suitable for walking. Thus, changes between the sites on the CS outside and inside the TMR were not apparent in this study.

Species diversity was higher in the CS than in WH across seasons with species having a greater evenness across CS sites. This indicates that in the CS, the occupied space in the intertidal zone is shared among different species, with lower occurrence of a dominant species (as was for M. galloprovincialis in WH). This was consistent between seasons. The species richness values were higher in the $\mathrm{CS}$ than in $\mathrm{WH}$, but the species accumulation curves revealed that there is a greater number of species in WH than in the CS across all seasons. These changes in species richness indicate that many species in $\mathrm{WH}$ come and go with the seasons which is proven to be common in other temperate countries (Lubchenco 1983, Jernakoff 1985). Several studies have linked mussels (the dominant species in the WH mid-intertidal zone) with increasing invertebrate abundances which is consistent with the species richness patterns in WH (Bertness and Leonard 1997, Bertness et al. 1999, Gutierez et al. 2003, Crain and Bertness 2006, Erwin 2008). Mussels often provide a greater spatial heterogeneity as well as protection from physical (desiccation, wave exposure and wind exposure) and physiological (high/low temperatures) factors (Archambault and Bourget 1996, Ansart and Vernon 2003, Bertness et al. 2006). The greater number of macroalgal species in the CS is not well understood, in many cases it is attributed to low turbidity and high wave exposure (Morton and Miller 1968, Morton 2004, Nelson 2008). The lack of thermal and irradiance stress may also account for the high abundances of macroalgae in the midintertidal zone of the CS as the southern facing CS shores are exposed to less sunlight than 
many sites in $\mathrm{WH}$, Therefore, macroalgae in the CS will experience less damage from high UV (Morelissen and Harley 2006).

Much of the difference in intertidal community composition at the mid-intertidal zone between the CS and WH is explained by a few dominant species, with coralline algal species and Chamaesipho brunnea being more abundant in the CS and Mytilus galloprovincialis and Chamaesipho columna being more abundant in WH (and in the case of M. galloprovincialis, nearly entirely absent from the CS). Menge et al. (1999) in their cross-coastal study of New Zealand's South Island intertidal community differences, found that mid-intertidal zones across both the east and west coast of the South Island were dominated by $M$. galloprovincialis. In the low-intertidal zones, the percent cover of M. galloprovincialis was nearly zero on the west coast of the South Island, but still high on the east coast of the South Island. They attributed this difference to higher predator numbers on the west coast causing top-down pressure on mussel populations. The current study emphasizes that the lack of mussel abundance is not always explained by higher predator abundances and that the variation in bottom-up factors can appear to control assemblages in intertidal communities.

\subsubsection{Mussel abundances in the Cook Strait vs Wellington Harbour}

While a few other filter feeder and grazer species were limited to WH in the mid-intertidal zone (Table 2.2), the disparity in mussel abundances between the CS and WH is the most notable (Gardner 2000, Gardner and Thompson 2001b, Helson and Gardner 2004, Helson et al. 2007, Gardner and Bell 2008). Two of the four mussel species (Aulacomya maoriana, Perna canaliculus, Limnoperna pulex) were found exclusively on WH shores, and only the occasional M. galloprovincialis individual was found at CS sites. Often, when describing shorelines with fewer mussels, top-down models are used to explain the observed pattern (Paine 1969, Hunt and Scheibling 1998, Menge et al. 1999, Bertness et al. 2004, Griffen and 
Delaney 2007). Common intertidal predators (whelks, crabs, seastars) often cause the distinct lack of mussels. Fewer predatory species were found in the CS than in WH and they are not thought to be the major cause of low mussel numbers in the CS. Thus, it seems as though the CS might be limited by bottom-up factors rather than controlled by top-down pressures.

\subsubsection{Seasonality of bottom-up factors}

Many of the environmental factors examined showed strong seasonal changes. There is some evidence that the seasonal change in the important environmental factors is shaping the longterm community compositional differences between the CS and WH. It was initially anticipated that nutrients in the water column would be low during times of low POM and $c h l$ a. Elevated nitrate levels during the winter and autumn in the CS and WH indicate that there is enough nitrate in the water column to promote healthy phytoplankton blooms during those months on both coasts (0.1-0.19 $\mu \mathrm{M})$ (Carpenter and Guillard 1971, Menge et al. 1997). In the spring and summer months at most sites (except RR), the nitrate levels were lower and in some cases went below the level necessary to promote phytoplankton blooms (ST, EB and LH). However, for most of the year, phytoplankton does not appear to be nitrate limited on either shore.

The environmental factors that would have a more direct impact on filter feeder and grazer abundances, also showed seasonal changes. Only PCOM did not change seasonally, however, across nearly all sites and seasons the PCOM was greater than $20 \%$ which is necessary for mussels to overcome metabolic faecal loss which is when the amount of energy in the faeces is greater than the energy consumed by the organism (Gardner 2000, 2002, Gardner and Thompson 2001b, Helson and Gardner 2007, Helson et al. 2007). The POM was particularly low in the winter and chl $a$ was low in both the winter and autumn in the CS. Helson and Gardner (2007) found that there was a size dependent relationship between food 
supply and survival over time. Filter feeders (mussels) with smaller maximum body size lived longer under food-limited conditions. This may be why the little black mussel (Limnoperna pulex) survives in large numbers on the CS along with the two species of barnacle $(C$. brunnea and C. columna).

The impacts of phytoplankton concentrations on intertidal community composition have been thoroughly examined across both small and large scales (Menge et al. 1997, 1999, 2009, Navarrete et al. 2006, Blanchette et al. 2008). The POM concentrations presented here are consistent with a bottom-up hypothesis, suggesting that in general, the filter feeders in WH sites have more organic material in the water column to feed on during all seasons and the CS has less. This result, however, is confounded by seasonal variation in both POM and chl $a$, which might also play an important role. Prolonged periods of starvation in the CS over the autumn and winter months could be limiting mussels to $\mathrm{WH}$ and there is evidence to suggest that early stage mortality could be the result of low food availability (Phillips 2004, Helson and Gardner 2004). Larval and juvenile mussels tend to be present, but at very low numbers in the CS indicating that they likely originate from $\mathrm{WH}$ or are in fact little black mussels which occur in the upper intertidal zone in the CS (Helson and Gardner 2004, Demello and Phillips 2011). The timing of larval and juvenile mussels in the CS water column observed by Helson and Gardner (2004b) appears to coincide with the seasonally low POM and chl $a$ in the winter months. This could explain the near absence of mussels in the CS, but would need to be further examined.

\subsubsection{Phytoplankton community differences between Cook Strait and Wellington Harbour}

While other studies suggest that larval transport can be mediated by coastline configuration (Mckindsey and Bourget 2000, McQuaid and Phillips 2006, Demello and Phillips 2011), few studies have examined differences in phytoplankton diversity between bays and open ocean 
and how this difference might impact intertidal communities. Phytoplankton densities are heavily impacted by zones of upwelling in the open ocean (Furnas and Mitchell 1986, Froneman et al. 1995, Menge et al. 1997, Blanchette et al. 2009), but there is little information on how local phytoplankton species differ between upwelling and non-upwelling zones. Furthermore, local changes in the phytoplankton community due to seasonal upwelling are not understood. This study adds to the evidence that seasonal boundaries in water column characteristics can have a large impact on shaping coastal communities. Further research into the seasonal changes in nearshore phytoplankton community dynamics between the CS and WH would enhance the current understanding of why the intertidal communities between the two shores are so different.

\subsection{Conclusion}

Patterns of intertidal organisation on temperate rocky intertidal shorelines have been well studied, and for the most part do not vary much from this pattern (Stephenson and Stephenson 1949). However, the shoreline in the CS region and surrounding areas (the outer Marlborough Sounds in the South Island, Paekakariki to the west and Cape Palliser to the east) appear to be an exception to that rule (Morton and Miller 1968, Morton 2004, Gardner 2008) with a very different assemblage in the mid-intertidal zone (CS) to an example of a typical temperate rocky intertidal shore (WH). The results from this study suggest that the differences in community composition between the CS and WH are largely reflected by the differences in nearshore pelagic primary productivity. Other studies have suggested that there are strong links between food supply in the water column and mussel survival and growth (Bustamante and Branch 1996b, Menge et al. 1997, McQuaid and Lawrie 2005, Blanchette et al. 2009), but few have found consistent seasonal differences in environmental factors that might cause a stark difference in intertidal communities at a small scale (10s of $\mathrm{km})$. The 
relatively fine scale effect of phytoplankton input may suggest strong benthic-pelagic coupling and reduced connectivity between the CS and WH. 


\section{Chapter 3. Does wave exposure limit the distribution of mussels along Cook Strait shores?}

\subsection{Introduction}

Temperate rocky intertidal shores are commonly characterised by vertical zonation patterns of the same types of organisms (Stephenson and Stephenson 1949, Menge and Sutherland 1976). Mussels play an important role as dominant species in these shoreline descriptions, often occupying much of the mid intertidal zone. As filter feeders, mussels ingest both microalgae and macroalgal detritus (Bayne et al. 1993, Riera 2007) and thus, are a link between primary productivity in the water column and secondary production on shore (Menge et al. 1997, 1999). On many shores mussels also facilitate species richness, acting as ecosystem engineers by providing space and shelter for smaller invertebrates (Bertness and Leonard 1997, Bruno et al. 2003, Crain and Bertness 2006).

Marine mussels can withstand a wide range of environmental variability, including temperature (Seed 1969a, Ansart and Vernon 2003, Jansen et al. 2007), desiccation (Bertness et al. 2006) and extended aerial exposure (Finke et al. 2007, Helmuth et al. 2007, Tam and Scrosati 2011). Wave exposure is an important factor in shaping the population dynamics of mussels with both negative and positive trade-offs. Intertidal mussels have greater abundances and larger sizes at intermediate levels of wave exposure which is thought to deliver more food to shore (Bustamante and Branch 1996b, Dahlhoff and Menge 1996, Steffani and Branch 2003). In wave exposed habitats there are greater maximum wave velocities, drag forces and pounding where common predators (sea stars, crabs and whelks tend to be dislodged) are lower in abundance (Bertness et al. 2004). Thus, sessile 
invertebrates (barnacles and mussels) are likely to dominate wave exposed shorelines as they are seldom preyed upon in these habitats. In wave sheltered habitats, mussel populations are controlled by predators (top-down control) allowing seaweeds to dominate (Paine 1969, Hunt and Scheibling 1996, Hunt and Scheibling 1998, Bertness et al. 2004). In contrast, intense wave action imposes large hydrodynamic forces on mussels increasing the risk of damage to their shells and dislodgement (Hunt and Scheibling 2001a, Helmuth and Denny 2003, Petraitis and Dudgeon 2004). In addition, mussel size and distribution can be severely limited by abrasive forces on shore, such as ice scour (McCook and Chapman 1993, Guichard et al. 2001, Gouhier and Guichard 2007, Heaven and Scrosati 2008). Mussels are able to withstand remarkable environmental variation and ecological stressors and this is why they are so widely distributed across temperate rocky intertidal environments worldwide.

The coast of Wellington Harbour (New Zealand) has a mussel species distribution that matches a typical temperate intertidal coastline with two species of mussels occupying the mid intertidal zone, the endemic ribbed mussel, Aulacomya maoriana (Iredale, 1915) and the blue mussel, Mytilus galloprovincialis (Lamarck 1819). A short distance away $(<10 \mathrm{~km})$ on Cook Strait, which separates the North and South islands of New Zealand, the shores are almost completely devoid of mussels from the mid intertidal, with no other plant or organism occupying that space (Gardner 2008). Several studies have attempted to determine which factors are causing this extreme disparity in mussel abundance (Gardner 2000, 2002, Gardner and Thompson 2001b, Helson and Gardner 2004, Helson et al. 2007), however none have yet excluded wave exposure as a factor in explaining the differences in mussel abundances between the two shores.

The shores of the southern tip of the North Island of New Zealand are characterised by large outcroppings of greywacke rock surrounded by cobble and large boulders. Due to its geographical position, it is heavily impacted by southern winds that can reach speeds well 
over 70 knots $\left(130 \mathrm{~km} \mathrm{hr}^{-1}\right.$ ). During storms, the swell can reach $10 \mathrm{~m}$ (Stephens and Ramsay 2006, Gardner and Bell 2008). Both Wellington Harbour and Cook Strait shores are impacted by these high winds and storms, with the Cook Strait shores thought to be the more heavily affected of the two. Thus, the resulting heavy wave forces are thought to be the factor which best explains the lack of mussels along the Cook Strait. Other environmental differences between Cook Strait and Wellington Harbour shores that have also been suggested to explain coastal differences are seston quality and nutrient availability (Gardner 2000, Helson et al. 2007). These are indicators of bottom-up control that greatly affect sessile filter feeders as they are an indication of the available food that supports mussel populations. In South Africa, heavy wave exposure increases mussel abundances by creating localised areas of upwelling that promote phytoplankton productivity and subsequently higher abundances of mussels than wave sheltered shores (McQuaid and Lindsay 2000, McQuaid et al. 2000). These conflicting ideas about how wave exposure levels affect mussel populations have made it difficult to fully understand why mussels are absent from Cook Strait shores.

The present study aimed to determine if high wave exposure is limiting the mussels, A. maoriana and M. galloprovincialis, on Cook Strait shores. The purpose of this experiment was to determine if wave exposure is affecting survival, growth and condition index of the two species of mussels along Cook Strait and Wellington Harbour through long-term mussel transplants at both sites. Because the water column differences between the two shores can change over time, this experiment includes a seasonal examination of water column differences that may impact mussel abundances along the two shores. Few manipulative field experiments have been performed on either Wellington Harbour or the Cook Strait shores due to the severe hydrodynamics of the south coast. Thus, an experiment of this nature is rarely attempted or successfully completed on these shores. 


\subsection{Methods}

\subsubsection{Location and site selection}

A small-scale experiment was performed at two locations: one in Wellington Harbour at Evans Bay (WH: S $41^{\circ} 17.983$ E 174²9.028) and the other on Cook Strait at Breaker Bay (CS: S $41^{\circ} 19.612 \mathrm{E} 174^{\circ} 49.028$ ) (Figure 3.1). These two locations represent distinct WH (typical rocky intertidal mussel beds) and CS coastline (distinct lack of mussels in the mid intertidal zone).

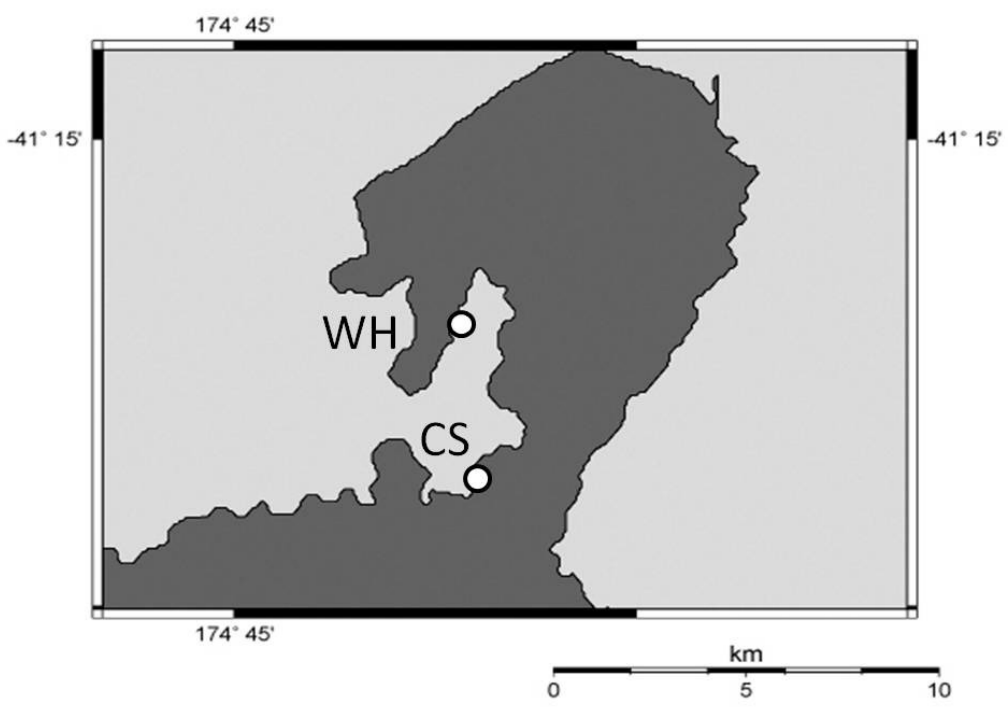

Figure 3.1. Map of locations in Wellington Harbour (WH) and on Cook Strait (CS).

This experimental field manipulation examined the relationship between environmental variables (nutrients, particulate food supply, temperature, salinity, dissolved oxygen and wave-exposure) and the presence/absence of mussels. The level of wave exposure on mussels was manipulated by transplanting at two wave exposure levels in two representative sites in $\mathrm{WH}$ and along the CS. The impact of wave exposure at $\mathrm{WH}$ and the CS 
in the water column was determined by measuring mussel survival, growth and condition index over time.

\subsubsection{Quantification of wave exposure}

At both locations, the wave-sheltered sites were habitats on rocky outcrops facing, but not directly in contact with, open water. Direct contact with waves was buffered by large boulders at sheltered sites which had good drainage (not tidepools). The exposed sites were habitats on rocky outcrops directly facing open water. To ensure that these two treatment levels are in fact significantly different between wave exposure and significantly similar between coasts, the maximum wave velocity at each wave exposure level of each site in the mid intertidal zone was quantified by use of dynamometer (Palumbi 1984, Bell and Denny 1994, Figure 3.2a) and clod card (Gerard 1982, Koehl and Alberte 1988, Figure 3.2b) measurements to ensure sites were equally sheltered or exposed along both coasts across all seasons (September -November: autumn, December - February: summer, March - May: spring, June - August: winter).
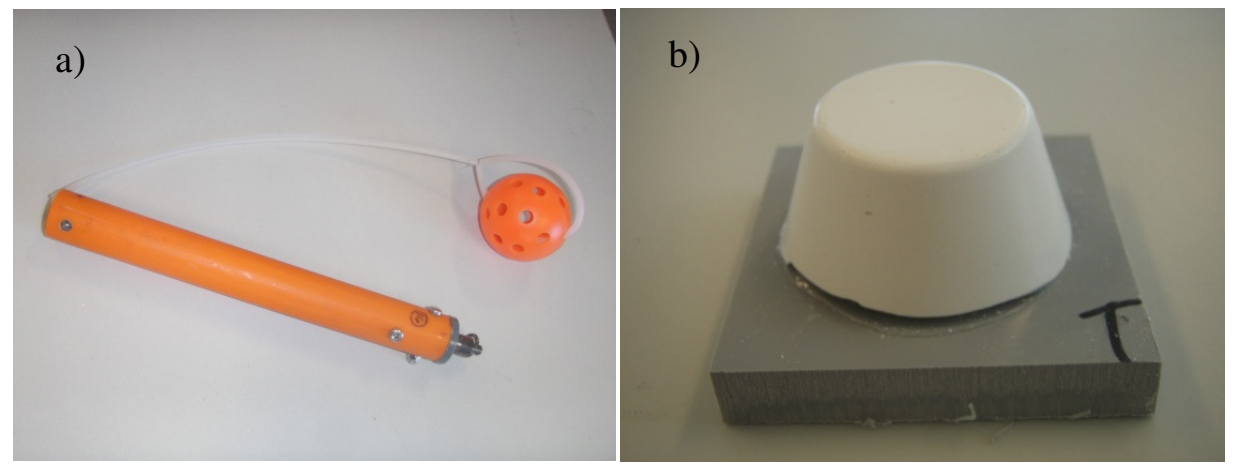

Figure 3.2. Devices used to measure levels of wave exposure a) dynamometer and b) clod card. 
One dynamometer per location per exposure level (4 total) was deployed and monitored at weekly intervals for 3 weeks randomly over 4, 3-monthly seasons $(n=48)$. Prior to deployment, each dynamometer had the rubber indicator placed at zero and after a week, the distance from the zero mark was recorded. Using calculations found in Bell and Denny (1994) it was possible to determine the maximum wave velocity for each week.

Plaster clod cards were made from durable plaster (hydrostone) purchased from TopMark (Auckland, NZ). Each clod measured $3 \mathrm{~cm}$ in diameter and $2 \mathrm{~cm}$ in height (Figure 3.2b). Each clod card was dried at $40{ }^{\circ} \mathrm{C}$ and weighed to the nearest $0.0001 \mathrm{~g}$ before and after deployment of 4 days. These measurements were taken with the intention of having a relative comparison between sheltered and wave exposed sites between locations. That is, weight loss over time was related to wave exposure. Upon each deployment, 3 clod cards were placed at each wave exposure level at each location (12 in total). This procedure was done randomly for 3 weeks over 4, 3-monthly seasons $(n=144)$.

\subsubsection{Nutrients and water column properties}

Nutrient concentrations (nitrite, nitrate, ammonia, phosphate and silicate) and other water column properties (total particulate matter, particulate organic matter, percent organic matter, dissolved oxygen, temperature and salinity) were measured during the experiment from nearshore, surface seawater samples taken at each location. Samples were collected twice per season (3 months) to capture the general nutrient levels at each location. These data are slightly different from water column properties in other chapters due to the exclusive use of sites in Breaker Bay and Evans Bay representing the CS and WH, respectively.

To measure nutrient concentrations at each site, three $50 \mathrm{~mL}$ samples were collected and frozen at $-20^{\circ} \mathrm{C}$ until the time of analysis. Every 6 month period, the nutrients nitrite $\left(\mathrm{NO}_{2}\right)$, nitrate $\left(\mathrm{NO}_{3}\right)$, ammonia $\left(\mathrm{NH}_{3}\right)$ and phosphate $\left(\mathrm{PO}_{4}\right)$ were analysed using the Skalar 
$\mathrm{San}^{++}$System (Breda, The Netherlands), while silicate $\left(\mathrm{SiO}_{2}\right)$ was analysed using the Orbeco Analyst 975MP (Florida, USA) portable water analyser. The Skalar $\mathrm{San}^{++}$System was chosen to analyse nitrite, nitrate, ammonia and phosphate because these nutrients occur at low levels in both the CS and WH which are undetectable by the Orbeco Analyst 975MP (a significantly faster machine than the Skalar $\mathrm{San}^{++}$System at processing samples), while silicate does occur at moderate levels in both locations.

Total particulate matter (TPM), particulate organic matter (POM) and percent organic matter (PCOM) were measured through seasonal collections of surface water. Each season (3 month period) $6 \mathrm{~L}$ of water werecollected from each site and $2 \mathrm{~L}$ samples were filtered onto pre-ashed, pre weighted Macherey-Nagel 47 mm GF/C filters (Düren, Germany). The filters were then dried at $60^{\circ} \mathrm{C}$ for $24 \mathrm{~h}$ and weighed to obtain the TPM and then ashed at $450^{\circ} \mathrm{C}$ for $24 \mathrm{~h}$. The final ashed weights of the filters were determined and POM was calculated as the TPM-ashed weight. PCOM, the percentage of organic matter in the TPM, was calculated as (POM/TPM)*100 (Gardner 2000, 2002, Helson et al. 2007). Temperature, salinity and dissolved oxygen measurements were taken twice each season using a YSI Model 55 salinity and YSI Model 30 dissolved oxygen meter (Ohio, USA).

\subsubsection{Mussel collection}

Mussels (Aulacomya maoriana and Mytilus galloprovincialis; $\mathrm{n}=1120$ sized between 30-50 $\mathrm{mm}$ in length) were collected from Lambton Harbour (S 41 17.194 , E $\left.174^{\circ} 48.165\right)$ between the $8^{\text {th }}$ and $9^{\text {th }}$ of September 2010 and brought back to Victoria University Coastal Ecology Laboratory (VUCEL, Island Bay, Wellington, NZ). Each individual mussel was lightly labeled with a number using an electric rotary tool (Ozito) with an etching bit (Figure 3.3). 


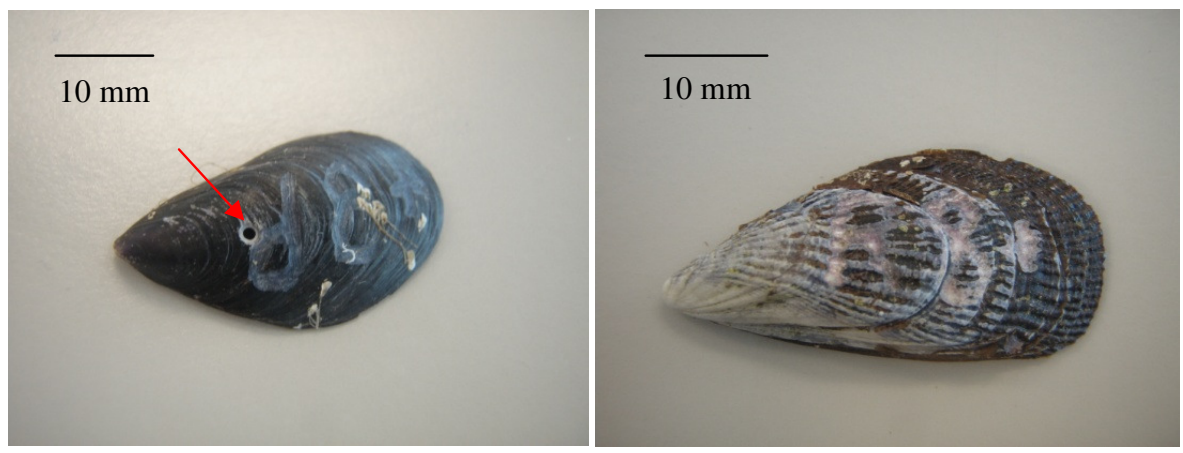

Figure 3.3. Example of etched markings on mussels for individual identification purposes. Arrow is showing an example of a borehole made by a whelk.

Mussels were measured for initial length (distance from umbo to shell margin) and 20 mussels (10 A. maoriana and 10 M. galloprovincialis) were placed in 300 x $300 \mathrm{~mm}$ enclosures constructed from two layers of plastic mesh with a mesh size of $10 \mathrm{~mm}^{2}$. Each enclosure was securely fastened to the substrate by a single $30 \mathrm{~mm}$ stainless steel bolt through the centre of the enclosure secured by a plastic wall plug and $\sim 5 \mathrm{ml}$ of marine putty (Zspar) surrounding the bolt (Figure 3.4).

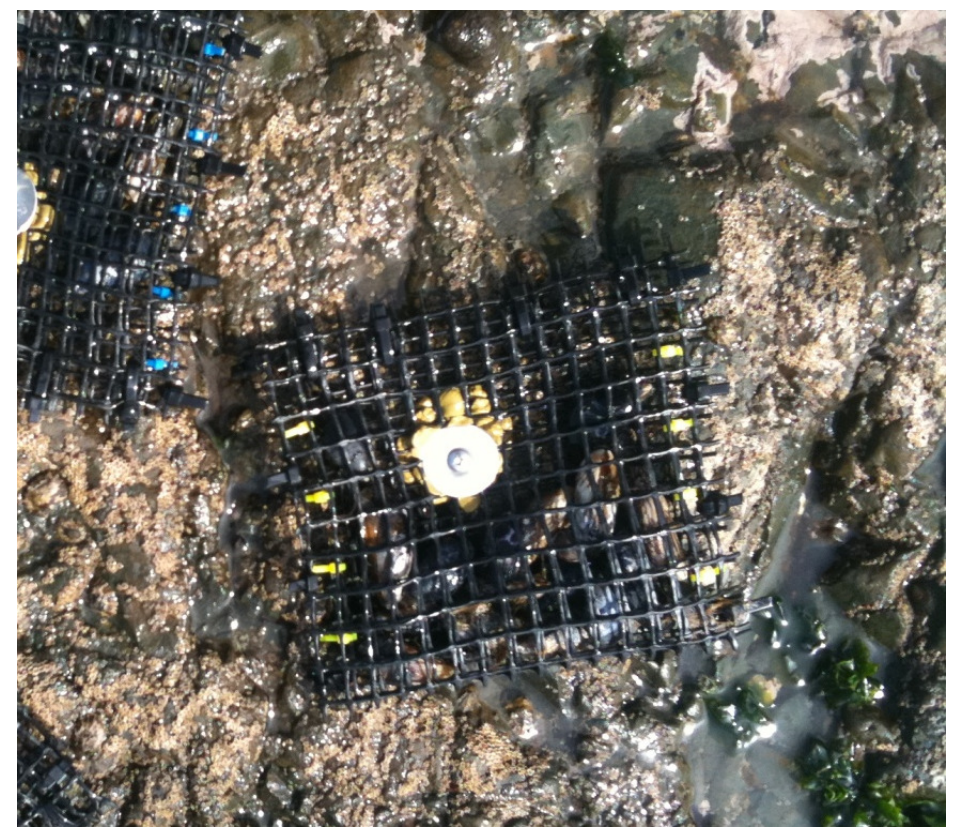

Figure 3.4. Mussel enclosures attached to shore. 
Mussel enclosures were randomly placed in both sheltered and exposed areas at each site in WH and on the CS, on bedrock at the mid intertidal level (between MHHW and MLLW) at a similar aspect, by using a $50 \mathrm{~m}$ transect tape and a random number table. Every month, one mussel enclosure was haphazardly taken from each site (4 enclosures total) to measure growth (addition of new shell length since initial etching) and body condition index (condition index $=$ Dry flesh weight $* 100 /$ whole wet weight - shell weight; as in Hickman and Illingworth 1980). An initial sample of 20 mussels (10 A. maoriana and $10 \mathrm{M}$. galloprovincialis) was measured in September 2010 for condition index as a baseline for either species. Any mortalities from the experimental enclosures (October 2010 onwards) were recorded as a measurement of survival during sampling periods and the general cause of death was documented (broken shell, borehole or missing). The cause of death of mussels was categorised as being missing, empty, broken or with a borehole. Mussels that were missing were presumed to have died and the shell remains broken and fallen through the holes in the plastic mesh of the mussel enclosures. Empty mussels were mussels that had died (from environmental causes) during the experiment and the shells were left in the enclosures. Broken mussels were presumed to have died from rocks or cobbles hitting the mussel enclosure with force during a storm event. Mussels with boreholes (Figure 3.3) were presumed preyed upon by whelks (Buccinulum spp., Cominella spp., Haustrum spp.). The duration of the experiment was 14 months from September 2010 to October 2011.

Due to the nature of the data collected, it was not possible to construct survivorship curves. At the end of each monthly collection, all the mussels in the collected enclosures were shucked to measure condition index. Because of this, it is impossible to determine how long any of the surviving mussels would have lived. 


\subsubsection{Statistical analysis}

To ensure that sheltered and exposed levels within each site (WH and CS) were statistically similar, ANOVA was performed to test for differences in wave velocity measurements made by the dynamometers. ANOVA was also performed on the weight loss $\left(\mathrm{g} \mathrm{day}^{-1}\right)$ of clod cards to determine if sheltered and exposed levels at each site were statistically similar. All data met the assumptions of ANOVA - normal distribution, homoscedasticity and independence.

Site-specific and seasonal differences in nutrient concentrations and water column properties were analysed using a two-way ANOVA with Student's t-test or Tukey's HSD to analyse any differences between coast, season or any interactions. To determine if the initial sizes of the mussels in each mussel enclosure (at the start of the experiment) were similar, i.e. randomly distributed within enclosure as well as randomly distributed across sites/exposure levels, ANOVA analysis was performed on the initial size of all mussels deployed.

Generalised linear models were used to measure the change in size and survival of each species over time at each site and wave exposure level. As adult mussels of a similar size were chosen, the expected trend for growth and survival over the time period of the experiment (14 months) was linear (Seed 1969a). The slopes of each linear regression were compared to examine any differences in growth over time for each species of mussel at each site and wave exposure level. The $95 \%$ confidence intervals of the slopes were compared for any overlap to determine significant differences between the slopes.

Because of unequal numbers of mussels measured each month due to mortalities, a permutational ANOVA (PERMANOVA) was used to analyse the condition index of mussels across each month from each location and site (Anderson et al. 2008). 


\subsection{Results}

\subsubsection{Quantification of site and wave exposure differences}

Dynamometer and clod card data showed that both wave exposure levels (sheltered and exposed) were similar across locations. Both dynamometer measurements $\left(\mathrm{F}_{3}=44.71, \mathrm{p}<\right.$ 0.0001, Figure 3. 5a) and clod card measurements $\left(\mathrm{F}_{3}=88.23, \mathrm{p}<0.0001\right.$, Figure 3.5b) were significantly higher in exposed habitats than sheltered habitats

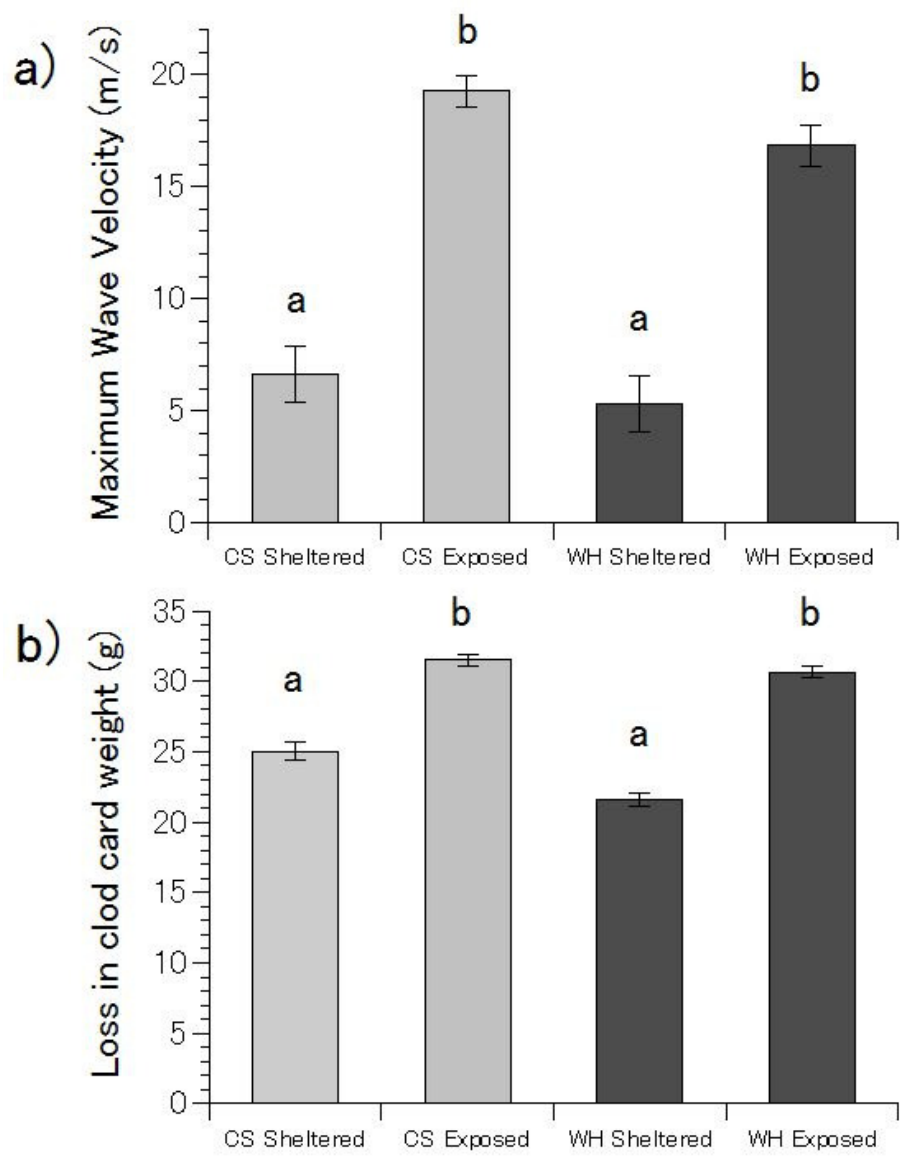

Figure 3.5. Wave exposure measurements from a) dynamometers and b) clod cards. Differing letters indicate significant differences $(n=144)$. 
Salinity and dissolved oxygen (DO) were similar across coast and season with the mean salinity level being 34.012 PSU $\pm 0.482(\mathrm{SEM})$ for both coasts and all seasons $\left(\mathrm{F}_{3}=\right.$ $1.47, \mathrm{p}=0.244)$ and $\mathrm{DO}$ was $128.677 \% \pm 2.843(\mathrm{SEM})$ for both coasts and all seasons $\left(\mathrm{F}_{3}=\right.$ $1.068, \mathrm{p}=0.427)$. Temperature was significantly different as a function of site and season with the spring and summer seasons for CS and WH and the autumn for WH being significantly warmer than the winter season for both coasts $\left(F_{3}=18.26, p<0.0001,3.6\right)$.

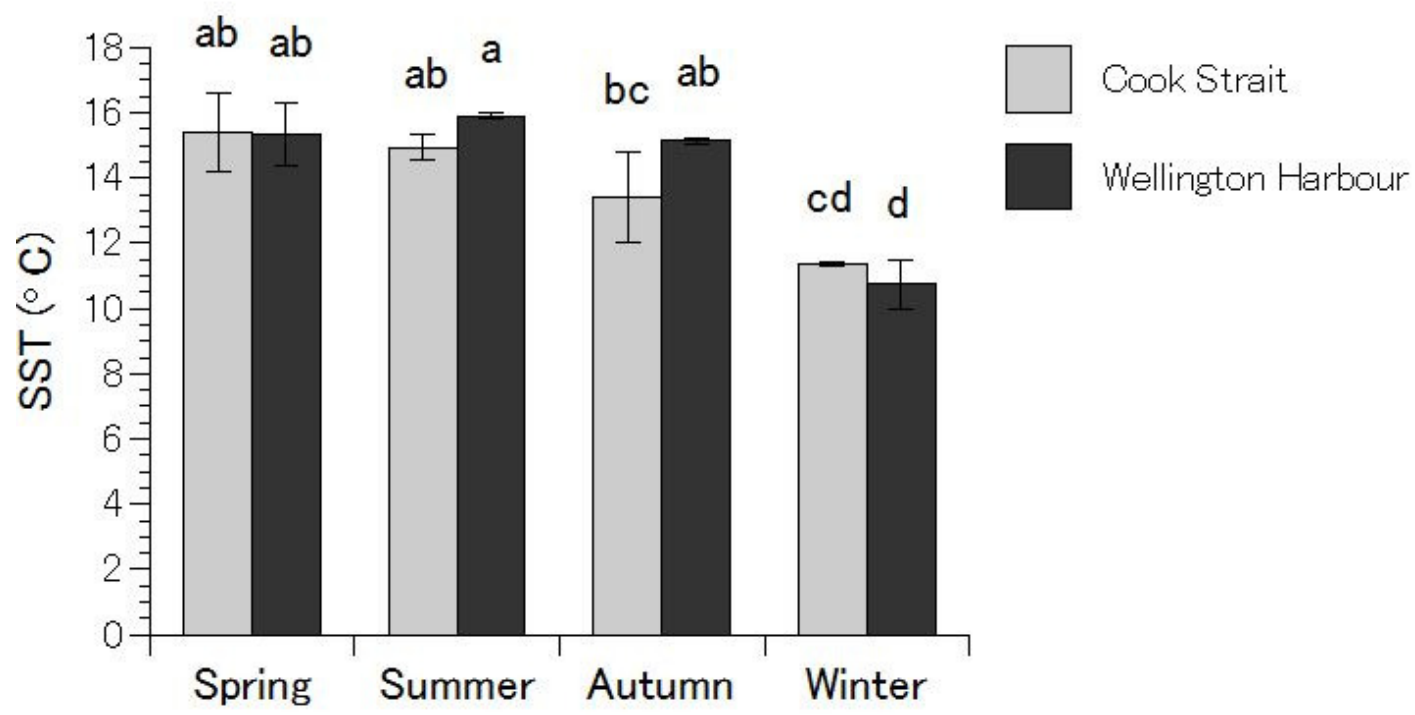

Figure 3.6. Sea surface temperature (SST) for both the Cook Strait and Wellington Harbour. Data were collected from 4 seasons over 2010-2011.

Of the five nutrients, ammonia $\left(\mathrm{NH}_{3}\right)$ and nitrite $\left(\mathrm{NO}_{2}\right)$ did not show significant differences between season or coast. The mean concentration of $\mathrm{NO}_{2}$ at both coasts and for all seasons was $0.097 \mu \mathrm{mol} \mathrm{L}{ }^{-1} \pm 0.028(\mathrm{SEM})$ and the concentration of $\mathrm{NH}_{3}$ was $4.901 \mu \mathrm{mol}$ $\mathrm{L}^{-1} \pm 0.829(\mathrm{SEM})$ across both coast and season. There were significant differences in the nitrate $\left(\mathrm{NO}_{3}\right)$ concentrations between season and coast, with winter and autumn water in the CS significantly higher in $\mathrm{NO}_{3}$ than the spring and summer for both $\mathrm{CS}$ and $\mathrm{WH}\left(\mathrm{F}_{3}=6.78, \mathrm{p}\right.$ $=0.007$, Figure $3.7 \mathrm{a}$ ). There was a trend towards higher $\mathrm{NO}_{3}$ concentration in the autumn and winter for both the CS and WH. Phosphate $\left(\mathrm{PO}_{4}\right)$ concentrations were also significantly 
different between both site and season with summer values in WH higher than those in the CS $\left(\mathrm{F}_{3}=53.51, \mathrm{p}<0.0001\right.$, Figure 3. 7b). Spring $\mathrm{PO}_{4}$ concentrations for both coasts and summer values for CS were lower than the other seasons on both coasts, while summer $\mathrm{PO}_{4}$ concentrations were highest in the WH. Autumn and winter concentrations were intermediate between the $\mathrm{PO}_{4}$ concentration in $\mathrm{WH}$ in the summer and spring in the $\mathrm{CS}$ and $\mathrm{WH}$ (Figure 3. 7b). There were higher silicate $\left(\mathrm{SiO}_{2}\right)$ concentrations in the autumn and winter on the CS, with lower values for both sites in the spring and summer and lower values in the autumn and winter for $\mathrm{WH}\left(\mathrm{F}_{3}=4.22, \mathrm{p}=0.001\right.$, Figure 3. 7c $)$. 

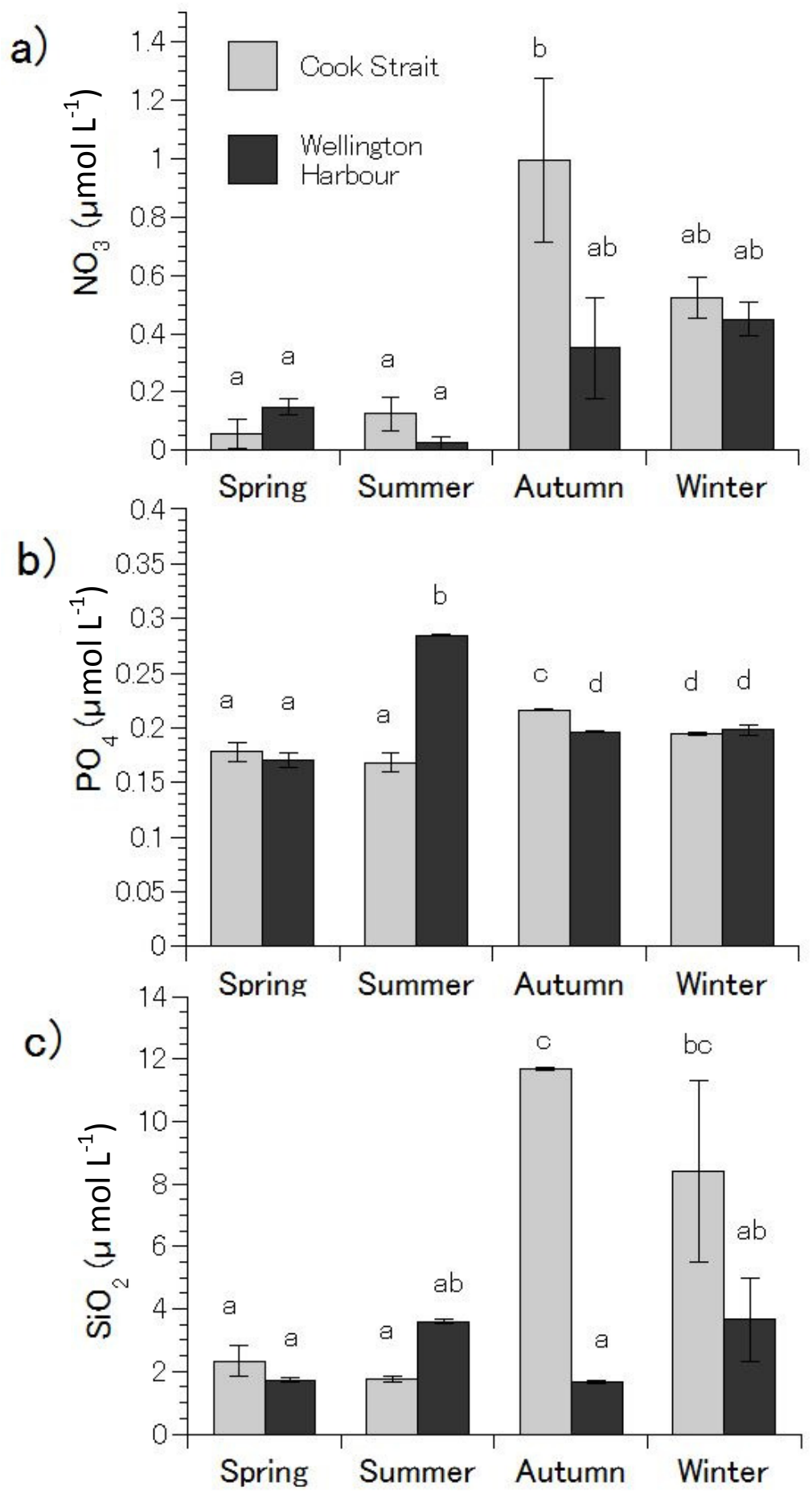

Figure 3.7. Nutrient concentrations (mean \pm SE) along the Cook Strait and Wellington Harbour for a) nitrate, b) phosphate and c) silicate. Measurements were taken during 4 seasons during 2010-2011 ( $\mathrm{n}=48)$. 
The total particulate matter (TPM) concentration in the autumn in WH was the highest and had the largest variability, with the rest of the seasons across both coasts being statistically similar $\left(\mathrm{F}_{3}=4.02, \mathrm{p}=0.002\right.$, Figure $\left.3.8 \mathrm{a}\right)$. The particulate organic matter $(\mathrm{POM})$ concentration was highest in the autumn and winter in WH with significantly lower values in the spring, autumn and winter in the $\mathrm{CS}\left(\mathrm{F}_{3}=3.49 . \mathrm{p}=0.005\right.$, Figure 3. 8b). Percent organic matter $(\mathrm{PCOM})$ was statistically similar across all coasts and seasons $\left(\mathrm{F}_{3}=1.40, \mathrm{p}=0.233\right.$,

Figure 3.8c). 

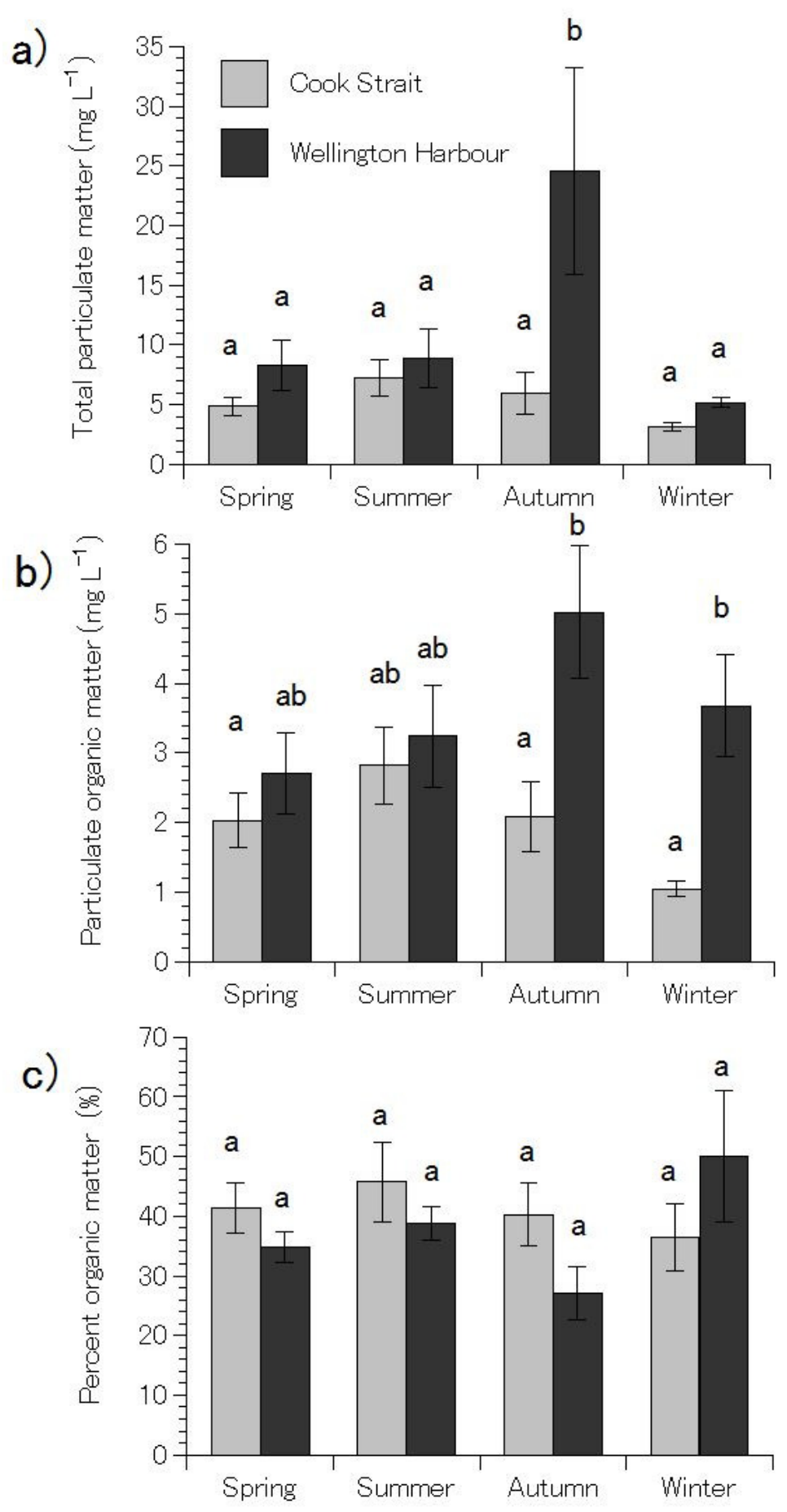

Figure 3.8. Seston measurements (mean \pm SE) from the Cook Strait and Wellington Harbour across 4 seasons during 2010-2011 for a) total particulate matter, b) particulate organic matter, c) percent organic matter. Differing letters denote significant differences $(n=48)$. 


\subsubsection{Mussel survival}

A. maoriana in the exposed habitat in WH had a significantly higher survival rate than that of the WH sheltered habitat and appeared to be higher than both the sheltered and exposed habitats on the CS coast (Figure 3.9a). The survival rate of M. galloprovincialis was also highest in the exposed habitat in WH which was significantly higher than the survival rate of the sheltered habitat in the CS and higher than the sheltered habitat in $\mathrm{WH}$ and the exposed habitat on the CS coast (Figure 3.9b).
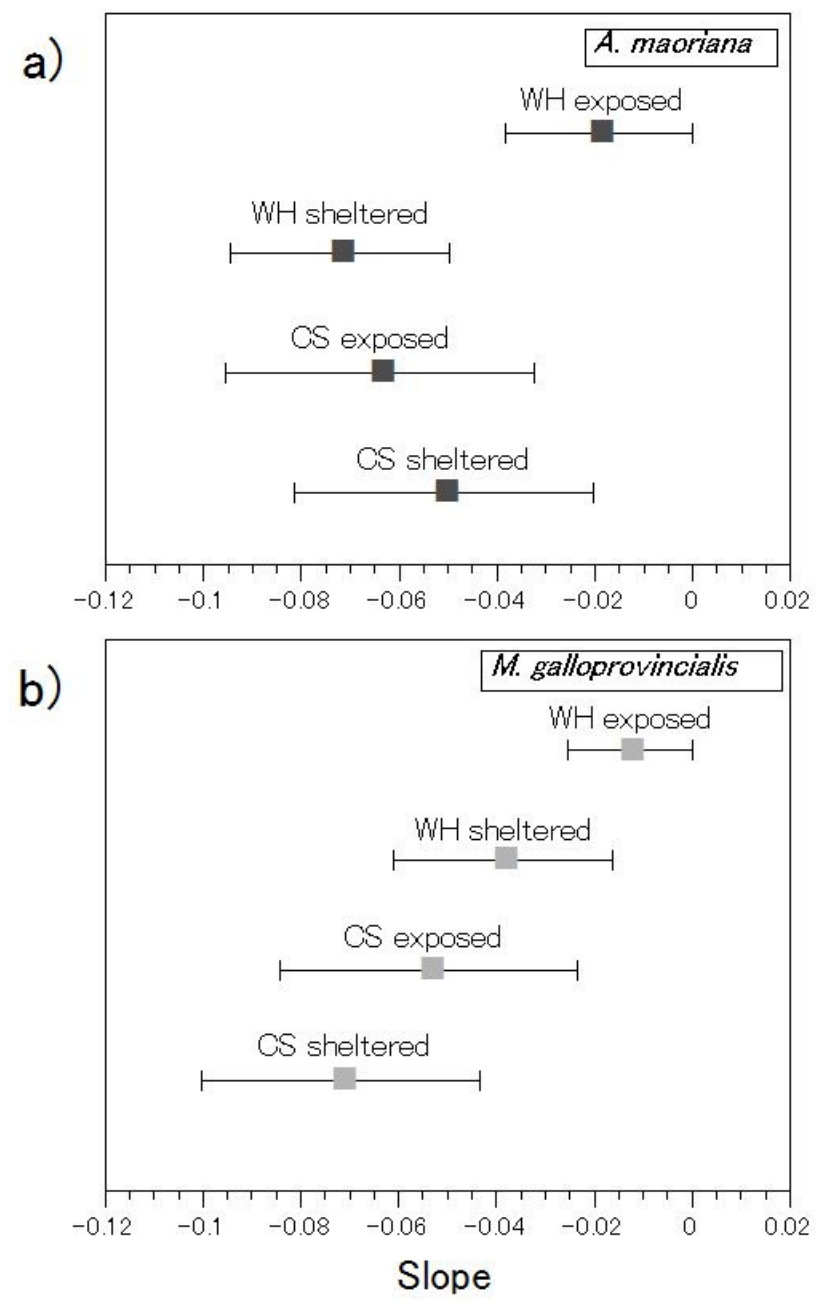

Figure 3.9. Slopes of the survivorship regressions for a) A. maoriana and b) $M$. galloprovincialis from the Cook Strait (CS) and Wellington Harbour (WH) for both wave sheltered and exposed sites. Higher values on the $\mathrm{x}$-axis indicate a higher mean rate of survivorship over time. 
The majority of dead A. maoriana had empty, unbroken shells (Figure 3.10a). In the exposed habitats on both coasts, there were more missing mussels from the enclosures. There were more broken A. maoriana shells found in the exposed habitat of CS. In sheltered habitats on both coasts there were more mussels (both A. maoriana and M. galloprovincialis) with boreholes (Figure 3.10). More M. galloprovincialis had boreholes when compared to the same exposure and coast than A. maoriana. The total number of dead A. maoriana (284) across the 14 month experiment was greater than that of $M$. galloprovincialis (209). More $M$. galloprovincialis were found with boreholes in the sheltered habitat in WH than any other site.

a)
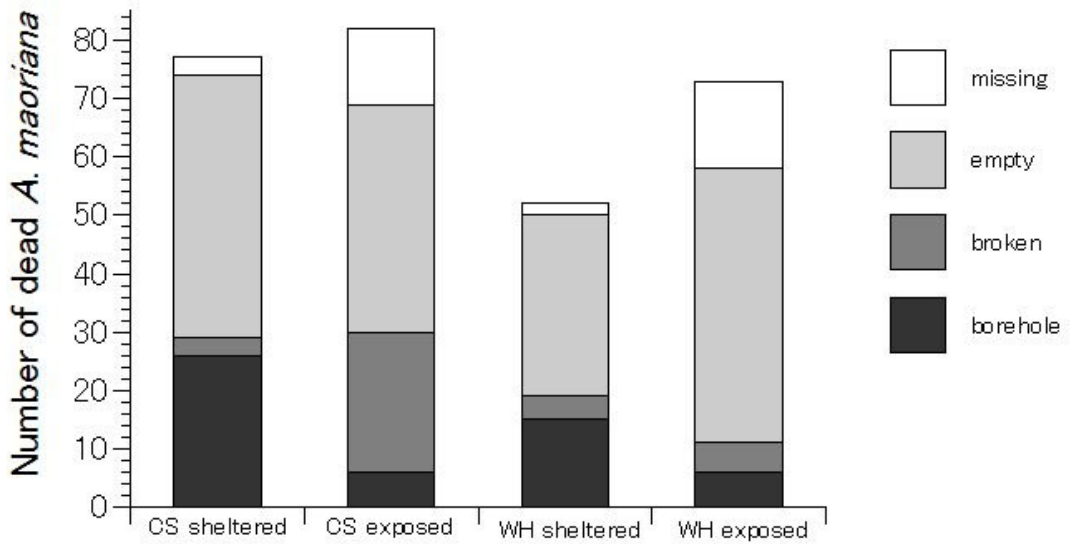

b)

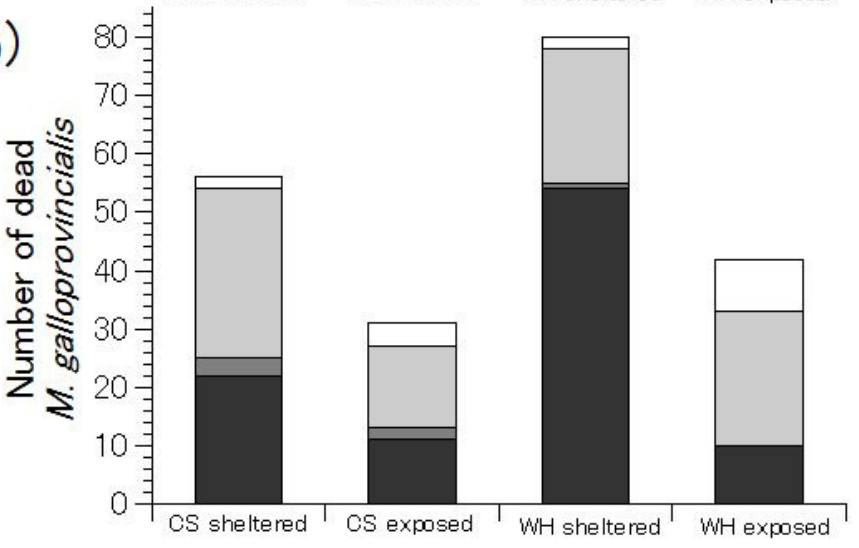

Figure 3.10 Number of dead a) A. maoriana and b) M. galloprovincialis as a function of the cause of death. 


\subsubsection{Growth of mussel shell}

On average, M. galloprovincialis grew more than A. maoriana (Figure 3.11, Table 3.1). Both mussel species in WH had higher rates of growth than those in the CS. From the slopes of the GLM, it is apparent that $A$. maoriana at the sheltered site in WH have a much higher growth rate than either the sheltered or exposed sites on the CS (Figure 3.12a). M. galloprovincialis at both sheltered and exposed habitats in WH grew faster than those in the CS (Figure 3.12b). The lack of overlap in the error bars indicates that regardless of exposure level, $M$. galloprovincialis in WH grew faster than on the CS. 

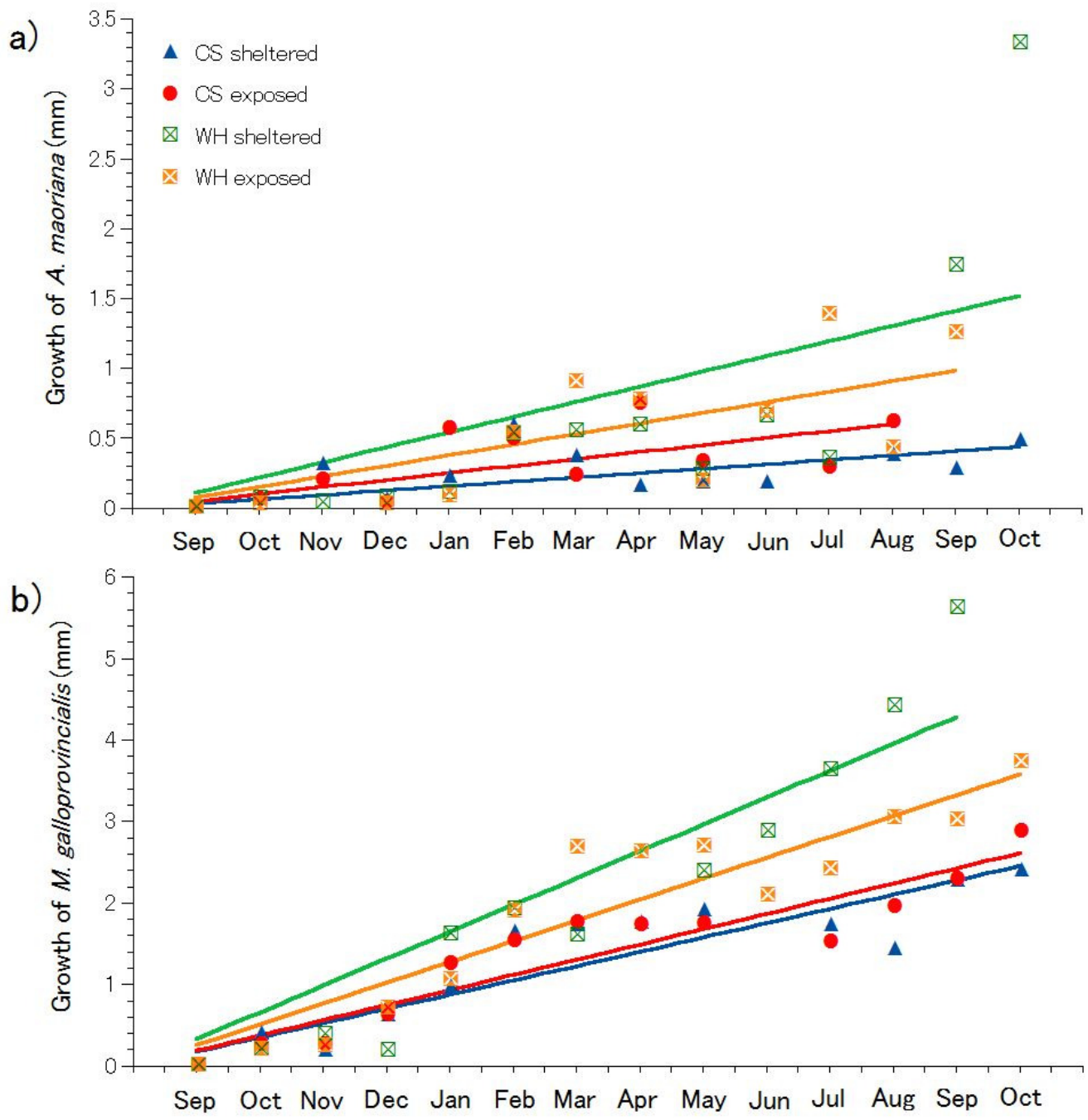

Figure 3.11 Mussel growth (addition of new shell length since etching) for a) A. maoriana and b) M. galloprovincialis along the Cook Strait (CS) and Wellington Harbour (WH) at wave sheltered and exposed sites across each month (September 2010 - October 2011). 
Table 3.1. Generlized Linear Model equations for A. maoriana and M. galloprovincialis at each location and site.

\begin{tabular}{lllrrrr}
\hline & Coast & Wave exposure & slope & intercept & \multicolumn{1}{c}{$\mathrm{p}$} & $\mathrm{R}^{2}$ \\
\hline A. maoriana & CS & sheltered & 0.04 & 0.02 & 0.04 & 0.26 \\
& CS & exposed & 0.09 & 0.01 & 0.05 & 0.41 \\
& WH & sheltered & 0.17 & 0.07 & $<0.001$ & 0.59 \\
& WH & exposed & 0.09 & 0.08 & 0.01 & 0.56 \\
\hline \multirow{4}{*}{ M. galloprovincialis } & CS & sheltered & 0.21 & 0.05 & $<0.001$ & 0.60 \\
& CS & exposed & 0.07 & 0.09 & 0.05 & 0.67 \\
& WH & sheltered & 0.41 & 0.06 & $<0.001$ & 0.52 \\
& WH & exposed & 0.37 & 0.07 & $<0.001$ & 0.67 \\
\hline
\end{tabular}



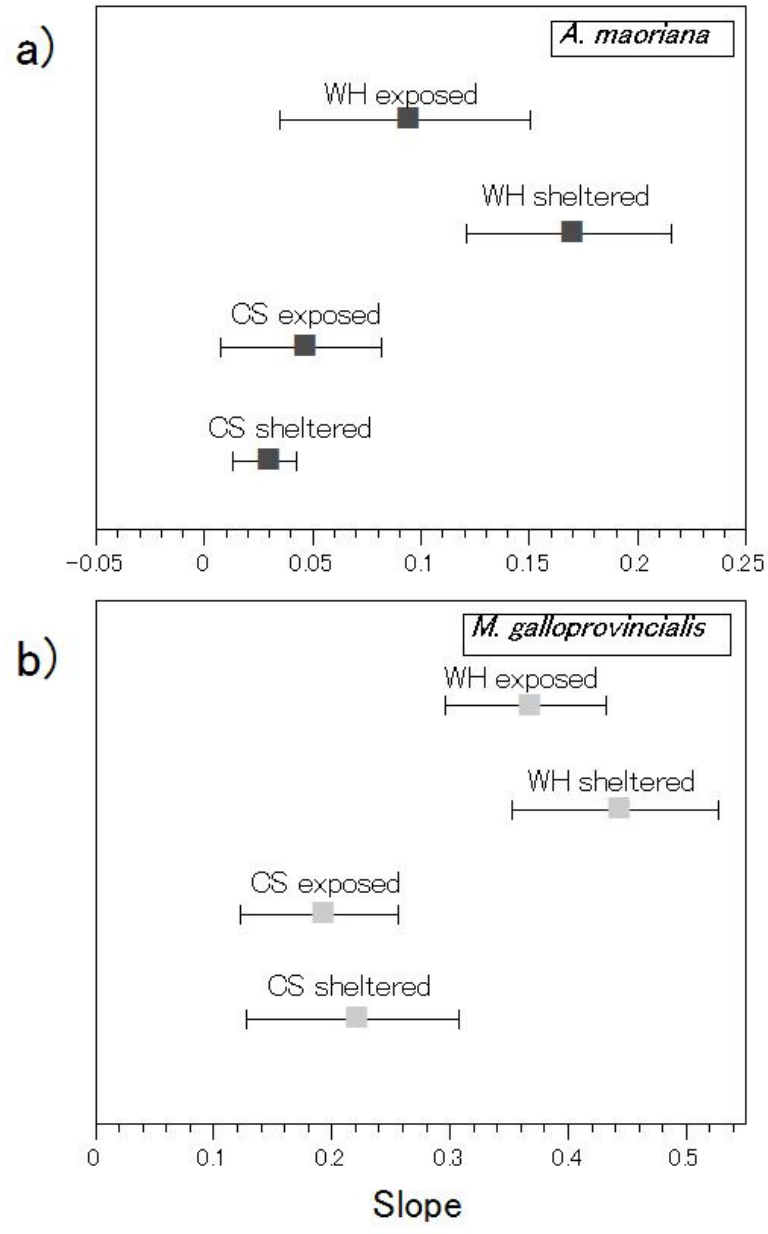

Figure 3.12 Slopes of the growth regressions for a) A. maoriana and b) M. galloprovincialis from Cook Strait (CS) and Wellington Harbour (WH) for both wave-sheltered and exposed habitats.

\subsubsection{Condition index of mussels}

The condition index of both A. maoriana and M. galloprovincialis throughout the 14 month experiment was significantly higher in WH than in the CS at both exposure levels (Table 3.2). Condition index was also more variable at WH than at CS sites for both species over the duration of the experiment (Figure 3.13). There were significant differences in the condition index across months for both species and this was due to natural increases and decreases in somatic tissue during gametogenesis and spawning, respectively(Seed 1969b). While mussel 
condition index was generally lower in the CS compared with $\mathrm{WH}$, it is interesting to note that in both CS sites for both species, they had the lowest condition index in May, but increased by the end of the experiment in October (Figure 3.13).
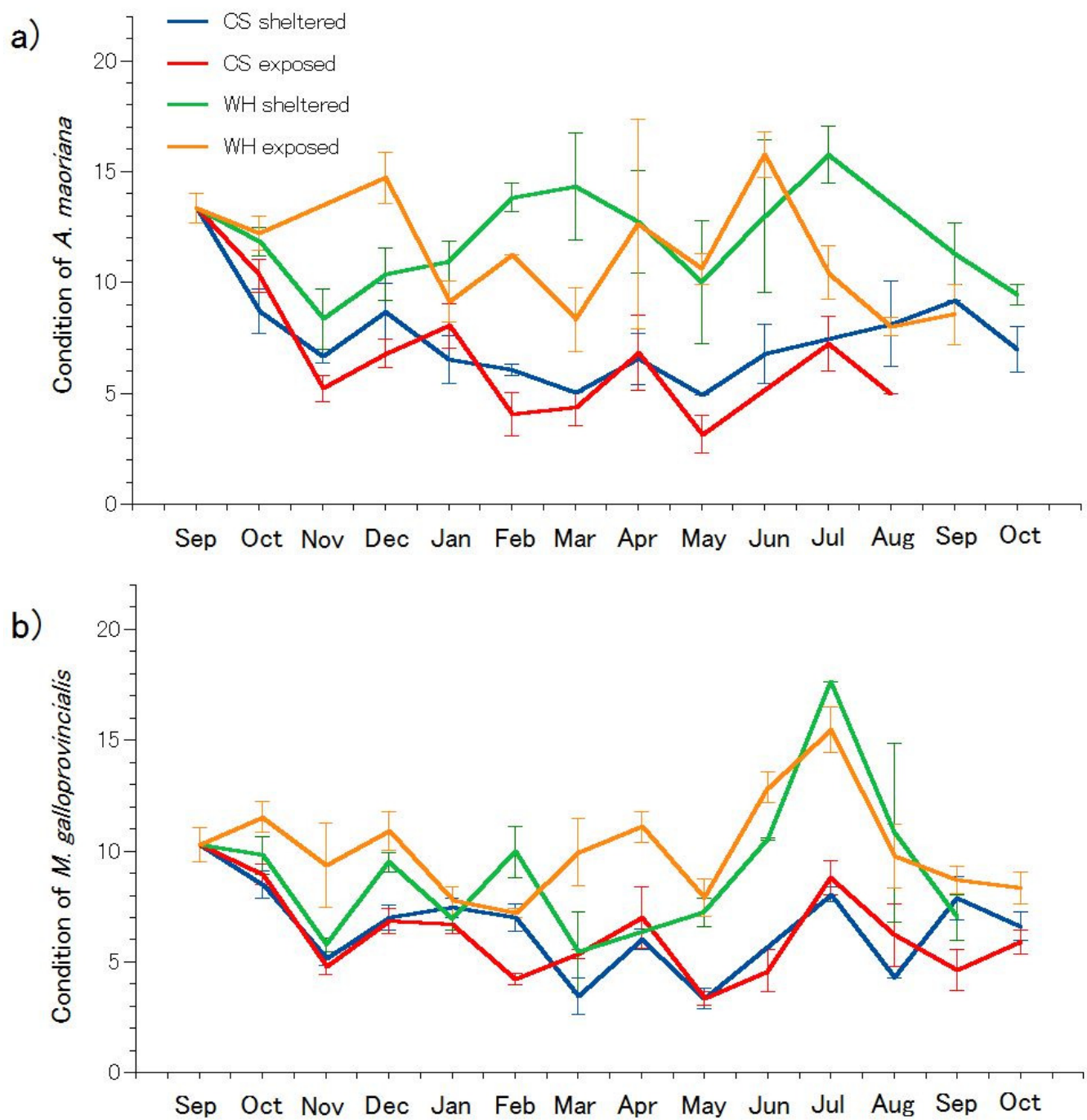

Figure 3.13 Mussel condition index for a) A. maoriana and b) M. galloprovincialis on Cook Strait (CS) and in Wellington Harbour (WH) at wave sheltered and exposed sites as a function of time (September 2010- October 2011) $(n=1120)$. 
Table 3.2 PERMANOVA of mussel condition index between location, exposure level and month. An asterisk denotes a significant difference.

\begin{tabular}{llrrrrrr}
\hline A. maoriana & Source & df & SS & Pseudo-F & P(perm) & \\
& location & & & 12249.00 & 60.09 & $<0.001$ & $*$ \\
& month & 1 & 796.96 & 4.01 & 0.05 & \\
& location x exposure & 13 & 19596.00 & 7.39 & $<0.001$ & $*$ \\
& location x month & 1 & 183.43 & 0.89 & 0.35 & \\
& exposure x month & 13 & 7471.00 & 2.81 & $<0.001$ & $*$ \\
& location x exposure x month & 12 & 1863.30 & 0.76 & 0.71 & \\
\hline M. galloprovincialis & location & 7 & 2442.70 & 1.71 & 0.09 & \\
& exposure & 1 & 13451.00 & 87.67 & $<0.001$ & $*$ \\
& month & 1 & 276.39 & 1.80 & 0.17 & \\
& location x exposure & 13 & 24178.00 & 12.12 & $<0.001$ & $*$ \\
& location x month & 1 & 488.62 & 3.18 & 0.06 & \\
exposure x month & 13 & 8292.90 & 4.16 & $<0.001$ & $*$ \\
& location x exposure x month & 13 & 4182.80 & 2.10 & 0.008 & $*$ \\
\hline
\end{tabular}

\subsection{Discussion}

\subsubsection{Wave exposure}

While wave exposure is considered to greatly impact mussel populations and the invertebrate community that surrounds them (Morton and Miller 1968, McQuaid et al. 2000, Bertness et al. 2006), this study indicates that there is suitable wave-exposed habitat for the survival of adult mussels in the CS. In many other heavily wave-exposed shores such as the Patagonian shores (Bertness et al. 2006), coastline in the NW Atlantic (Tam and Scrosati 2011), west coast of Ireland (Gosling 1992) and South African shores (McQuaid et al. 2000), mussels tend to be small, but still present in large populations under the heaviest of wave-exposure 
stress. In this study there were distinct differences in the survival of mussels across differing levels of wave-exposure (Figure 3.9), but there was no evidence that high levels of waveexposure were exclusively limiting the mussels' survival. The survival of $M$.

galloprovincialis was higher in the exposed habitats in both WH and CS, with mussels in the sheltered habitats at both sites dying primarily from the predation of whelks. Whelks are a significant predator on mussels on other sheltered temperate shores and may shape mid to low intertidal communities through top-down control (Hunt and Scheibling 1998). Prior to this study, there have been few observations of the impact of whelk predation on mussels in the CS or WH. While whelks appear to have an impact on mussels in $\mathrm{WH}$, their predation levels are not strong enough to explain the almost complete absence of mussels on the CS shores.

Wave-exposure does appear to have a negative impact on A. maoriana, with mussels having higher mortality and a lower growth rate and condition index (Figure 3.10a, 3.12a; Table 3.1) at both CS sites and the wave-exposed WH site. A. maoriana has a preference for wave-sheltered habitats (Morton and Miller 1968) and can survive for longer periods than other intertidal mussel species under laboratory conditions (Helson and Gardner 2004, Helson et al. 2007). This could explain why adult A. maoriana tend to be sparsely distributed among the larger M. galloprovincialis within multispecies mussel beds as the larger mussels offer protection from high wave velocities (Morton and Miller 1968). Mussel beds act as facilitators, increasing invertebrate diversity in environmentally harsh conditions on temperate intertidal shores (Crain and Bertness 2006). Although wave-exposure may be impacting A. maoriana, it is not the only factor limiting the ribbed mussels on the CS shore, as the sheltered habitats on that coast had equally high mortality rates compared to exposed habitats on both coasts (Figure 3.9, 3.10a). 
Other studies have found that mussels (Mytilus spp.) tend to be more abundant and have better condition under higher wave exposure (Bertness et al. 2004). Although mussels are competitively dominant species on intertidal rocky shores, they are an important food for several predatory species (Paine 1969, Hunt and Scheibling 1998, Griffen and Delaney 2007, Griffen et al. 2008). In sheltered habitats, mussels tend to be rapidly consumed by predators leaving space on bare rock for competing macroalgae (Bertness et al. 2002). In the CS and WH this does not appear to be the case, with mussels dominating under both sheltered and wave exposed conditions in WH and patches of bare rock on CS shores where mussels would conventionally be found (Gardner 2008). On other wave exposed coastlines such as South Africa, high wave forces significantly shape the growth and condition index of $M$. galloprovincialis, with the mussels experiencing positive effects with higher wave exposure (Steffani and Branch 2003). In the same study, however, higher growth rates and condition indices were found at sites with higher food availability regardless of the level of exposure, which is similar to the results in this experiment. Wave exposure does impact mussels, but the impact of food limitation is much greater than that of high wave forces in the CS.

\subsubsection{Coastal differences in mussel survival, growth and condition}

Many of the water column characteristics along the CS shore are similar to those in WH, with temperature, salinity and dissolved oxygen being similar across sites and across multiple seasons in this and other studies (Helson et al. 2007). Another study along the CS has indicated that multispecies populations of mussels were present in the CS surrounding storm drains (Wightman 2003). The study found that nutrients within the storm drain were higher than in the open water on both the CS and WH shores, but this could not explain the disparity in mussel coverage between the two coasts. Conversely, in this study, there were some differences in the nutrient levels between coasts. Nitrate and silicate appeared to have lower 
spring/summer concentrations compared with the autumn/winter concentrations in the CS, while these nutrients stayed at similar concentrations across seasons in WH. Nitrate is an important and often limiting nutrient in the production of micro- and macroalgae, while silicate is important for the production of diatom frustules (Eppley et al. 1969, Dugdale and Wilkerson 1998).

There is a complex relationship between bottom-up processes and filter feeder abundances. While generally high nutrient concentrations in the water will often result in larger phytoplankton blooms and subsequently greater numbers of filter feeding invertebrates (Dahlhoff and Menge 1996, Menge et al. 1997, 1999, 2009), it is possible that phytoplankton productivity in the CS is limited by nutrients that were not examined, such as iron. Iron is a vital micronutrient for all phytoplankton growth, with small amounts required for fixing carbon atoms in photosynthesis (Geider and Roche 1994, Lewandowska and Kosakowska 2004). In many cases, iron limitation has been used to explain high-nutrient low-chlorophyll (HNLC) zones, particularly in tropical areas of the Pacific and Antarctic waters (Howarth 1988, Pitchford and Brindley 1999, Wells 2003). Eldridge et al. (2004) found that manipulating the amounts of available iron to differing phytoplankton species elicited different results (increases or decreases in abundance), indicating species-specific responses to nutrient limitation. The response in phytoplankton abundance to the addition of iron into HNLC areas can occur within days, indicating that perhaps the phytoplankton community on the CS coast is limited by iron on a seasonal basis. Low iron levels could explain why there are higher nutrient $\left(\mathrm{NO}_{3}\right.$ and $\left.\mathrm{SiO}_{2}\right)$ levels in the CS compared with $\mathrm{WH}$ in the autumn and winter, with proportionately lower POM values in the CS. The outflow from the Hutt River (which would be the major source of iron) into WH has little impact on the CS coast. During instances of high rainfall (autumn and winter) the iron output may facilitate higher phytoplankton blooms in $\mathrm{WH}$, leaving the $\mathrm{CS}$ waters high in nutrients and low in food 
availability. This hypothesis, however, requires significant future research to determine any disparity in the water quality between CS and WH shores.

\subsubsection{Seasonal effects on mussel survival, growth and condition index}

While several studies have examined the effect of phytoplankton concentration on the structure of intertidal communities (Menge et al. 1994, 1997, 1999, Navarrete et al. 2006, Blanchette et al. 2008), there is little research on the effect of seasonal food availability in limiting (almost a complete absence of) any intertidal species. Helson et al. (2007) have indicated that POM, PCOM and chl a concentrations are lower in the CS than in WH, with differences also occurring across seasons. The winter months tended to have lower POM and chl a concentrations, which this study also confirms. This study, however, found that there is a strong component of timing of events that appears to be preventing the establishment of a permanent mussel population in the CS shores.

Past studies have found that a PCOM of $>20 \%$ is required for mussels to overcome metabolic faecal loss (ongoing energy loss resulting from enzyme secretion directly into the gut which is not reabsorbed as well as abrasion of cellular material from the gut passage) (Gardner 2000, 2002, Gardner and Thompson 2001b). In this study, the PCOM was consistently $>20 \%$ across both coasts and all seasons. The POM, however, differed between coasts significantly in the autumn and winter seasons, with relatively low concentrations in the CS compared with WH (Figure 3.8b). This indicates that food limitation may occur for mussels in the CS during the autumn and winter months, while mussels in WH experience a high amount of food.

Lower food availability during critical times of the year may affect adult mussel growth and condition index. Both mussel species had higher growth rates and condition index values in WH compared to the CS. The condition index for both mussel species in the CS 
decreased to $<5$ before slightly increasing, which is a level much lower than Helson et al. (2007) found in a similar study. The lowest condition index for both mussel species at both sheltered and exposed habitats all happened between the months of April and May 2011, which are around the same time as the lower seasonal POM values (lower food availability) in CS. By the end of the 14 month experiment, the mussels in WH had the same or higher condition index as at the start of the experiment where POM values were much higher.

Both mussel species had survivors on the CS at the end of the 14 month study. In Mytilus spp. there are wide variations in growth and resource allocation that can be explained partially by genetics (Suchanek 1981, Steffani and Branch 2003). This indicates that there may be a wide range of individual tolerances between mussels for the particular stressors in the CS. This may explain why there is the occasional blue mussel found stranded in the CS. The distance between the WH entrance and the CS is $<1 \mathrm{~km}$ and it is possible for adult mussels to be moved from WH to the CS during large storm events. Although they might not have as good conditions as mussels in WH, adult mussels found in the CS are able to survive for well over a year.

It is likely that the timing of food limitation may be what is causing the near absence of mussels in the CS. It has been suggested that mussels at the larval and recruitment stage are much more susceptible to negative environmental conditions and food limitation than adult mussels (Phillips 2002, Helson and Gardner 2007). Demello and Phillips (2011) found that mussel recruitment in WH occurred in peaks between the months of April and August (Austral autumn and winter) while in the CS there were much lower numbers of recruits. Helson and Gardner (2004) found a similar peak in planktonic larvae in the autumn (in WH) and winter (in CS), along with a peak in the spring indicating two large spawning events, but only one large recruitment event per year. The timing of high organic matter content in the water column (POM) coincides with a large recruitment event in $\mathrm{WH}$, however in the CS, 
there is much lower POM during this period and both A. maoriana and M. galloprovincialis at the juvenile stage likely experience high mortality due to the low food availability (Helson et al. 2007).

The quality of food also has a significant impact on juvenile mussel survival (Phillips 2002, 2004). Stable isotope studies have revealed that there is a difference in the phytoplankton community during winter on the CS (see Chapter 4). The study also found that phytoplankton was an important part of the diet of mussels in WH throughout both the summer and winter seasons, whereas the phytoplankton in the CS winter may be both less abundant and of low quality to mussel diets. Thus, it would be useful to also examine the quality of the food available to mussels to determine if it is a combination of food quality and food quantity limiting mussels on the CS and not just seasonally low concentrations of food.

\subsection{Conclusions}

While other studies have attempted to determine a single factor limiting the existence of mussels on CS shores (Gardner 2000, Helson and Gardner 2004, Helson et al. 2007), this study indicates that it is likely a complex array of events that is causing the disparity of mussels between the two shorelines rather than simply wave exposure or nutrient levels. It appears that the timing of food availability may be impacting not only adult mussels, but also juveniles on CS shores. Autumn and winter abundances of organic matter in the water column appear to show large differences between the CS and $\mathrm{WH}$, which may indicate a difference in available diet, as well as abundance of food for mussels.

An in depth study into seasonal phytoplankton differences between the CS and WH would be a valuable addition to this study. While research on this topic is revealing the importance of timing and food availability, there have been very few studies examining the possible differences in the phytoplankton communities at each coast. 


\section{Chapter 4. You are where you eat: Seasonal differences in filter feeder diets on two disparate shores}

\subsection{Introduction}

Stable carbon and nitrogen isotopes $\left(\delta^{13} \mathrm{C}\right.$ and $\left.\delta^{15} \mathrm{~N}\right)$ are increasingly used to determine feeding relationships and energy flow through food webs across both large biogeographic areas and over long periods of time (Peterson and Fry 1987, Kling and Fry 1992, Cabana and Rasmussen 1994, Hill et al. 2006, Fukumoiri et al. 2008, Rodgers and Wing 2008, Marín Leal et al. 2008, Hill and McQuaid 2008, Lefebvre et al. 2009b). Use of stable isotope analysis has proven to be a useful tool in marine and freshwater habitats. In the western Mediterranean, stable isotopes have been used to determine intra- and inter-specific resource partitioning among fish species across seasons (Vizzini and Mazzola 2003, 2006). In arctic lakes, Kling and Fry (1992) determined that food webs between macrozooplankton had fewer trophic levels compared to temperate lakes. Stable isotopes have also been used to link seemingly disparate habitats. Stapp et al. (1999) linked marine derived nutrients from seabirds to terrestrial island food webs through the use of stable isotope analysis.

In many marine environments, the importance of primary productivity and bottom-up effects are still poorly understood as the study of these effects incorporates not only environmental factors, but oceanography as well as coastal hydrography (Seitz and Lipcius 2001, Menge et al. 2003, Blanchette et al. 2006a). Where these bottom-up effects are tightly linked, the effects should be detectable along coasts with strongly contrasting environmental conditions (Menge et al. 1999, Nielsen and Navarrete 2003). 
Along the south coast of New Zealand's North Island, there are strong community differences between the Cook Strait (CS) and Wellington Harbour (WH) coasts. WH is a semi-enclosed embayment with a classic rocky intertidal community structure similar to those found on typical temperate shores (Stephenson and Stephenson 1949, Hutchinson 1953). The upper intertidal is largely dominated by honey comb barnacles (Chaemosipha columna), little black mussels (Limnoperna pulex) and small littorinid snails (Austrolittorina antipodium), while the mid-intertidal is dominated by mussels (European blue mussels Mytilus galloprovincialis, ribbed mussels Aulocomya maoriana and the green lipped mussel Perna canaliculus) (Helson and Gardner 2004, Demello and Phillips 2011). The CS coast (less than a few kilometers away) has sparse coverage of barnacles, with an almost complete absence of mussels and a larger diversity of macroalgae (Morton and Miller 1968). Helson \& Gardner (2004) suggest that the shores are different (in particular, the absence of mussels) because less food is available to filter feeders. Other studies have indicated that filter feeders may be seasonally deprived of food and are unable to withstand long periods of starvation (Gardner and Thompson 2001b, Helson and Gardner 2007, Helson et al. 2007).

In marine intertidal environments, filter feeders are particularly useful for studying food webs as they integrate highly variable isotope values among primary producers (Cabana and Rasmussen 1996, Mckinney et al. 2001, Lefebvre et al. 2009a). In addition, since many filter feeders are sedentary, their tissue isotope values reflect the spatial differentiation of their food sources compared to other more mobile consumers (Hill and McQuaid 2008). Often, the presence of intertidal filter feeders (bivalves and barnacles in particular) represent an essential link between primary producers and epibenthic consumers as they filter suspended organic matter from large volumes of water (Shumway et al. 1985).

Modeling flow through food chains is another important step towards understanding trophic relationships, particularly in marine systems (Bustamante and Branch 1996b, Hill et 
al. 2006, Hill and McQuaid 2008, Lefebvre et al. 2009b). Identifying the diet of filter feeders is extremely complex since the available suspended organic matter in the water column originates from multiple sources (e.g. oceanic, riverine, benthic) and is influenced by tide and swell. Seasonal changes in food supply are also known to affect many marine species. Lefebvre et al. (2009b) found that cultivated suspension feeders relied heavily on algal blooms in the spring seasons and observed differing opportunistic feeding behaviour in the winter when food supply was limited.

Combined measurements of $\delta^{13} \mathrm{C}$ and $\delta^{15} \mathrm{~N}$ ratios can provide information on both food web structure and source materials (Fredriksen 2003). Stable isotopes are now widely used to determine trophic interactions among consumers, the food sources contributing to their diets can be identified using isotope mixing models (Phillips and Gregg 2003). Several studies have evaluated trophic partitioning among filter feeders in coastal zones and estuaries (Doi et al. 2005, Yokoyama et al. 2005, Riera 2007), however, few have incorporated spatial and temporal changes to identify trophic relationships among several species of filter feeder (Lefebvre et al. 2009a).

This study aimed to test for differences in qualitative environmental signatures of filter feeders and food sources (micro- and macroalgae) from these two adjacent, but disparate, coastlines across two seasons (summer and winter) using stable isotope analysis. In addition, through species-specific isotopic signatures, the proportion of microalgae and macroalgal detritus in the diets of filter feeders were estimated. Ultimately, this information will help to clarify if the differences in the amounts of food and types of food are determining intertidal community structure on the south coast. 


\subsection{Materials and Methods}

\subsubsection{Study sites and sample collection}

To determine the role of common macroalgal and microalgal (phytoplankton) sources on the diet of common sessile filter feeders and grazers, stable isotope analysis was used (e.g. Environmental Isotopes Pty Ltd). Replicate samples were collected over two seasons in February and July of 2010 (Austral summer 2010 and winter 2010). Five litres of offshore water from the Cook Strait $\left(41^{\circ} 39.927 \mathrm{~S} 174^{\circ} 49.722 \mathrm{E}\right)$ and $5 \mathrm{~L}$ of nearshore water were collected from 4 sites to obtain the isotopic signatures $\left(\delta^{13} \mathrm{C}\right.$ and $\left.\delta^{15} \mathrm{~N}\right)$ of particulate material at different points along the Cook Strait and in Wellington Harbour (Figure 4.1). The 4 sites were, RR: Red Rocks and SI: Sirens along the Cook Strait $\left(41^{\circ} 21.342\right.$ S $174^{\circ} 43.646$ E and $41^{\circ} 20.899 \mathrm{~S} 174^{\circ} 45.841 \mathrm{E}$, respectively) and EB: Evans Bay and IP: Inconsistent Point in Wellington Harbour $\left(41^{\circ} 17.983 \mathrm{~S} 174^{\circ} 49.028 \mathrm{E}\right.$ and $41^{\circ} 19.111 \mathrm{~S} 174^{\circ} 52.322 \mathrm{E}$, respectively). Isotopic signatures from offshore water were considered analogous to microalgae in the water column, while nearshore water gave an isotopic signature for both micro- and macroalgae (Hill et al. 2006, Hill and McQuaid 2008). Samples (3 samples from each site, approximately $30 \mathrm{mg}$ each) of common macroalgae and intertidal invertebrates (Macroalgae - UL: the flat laminate Ulva spp.; CM: Carpophyllum maschalocarpum; MP: Macrocystis pyrifera; LV: Lessonia variegata; UN: Undaria pinnatifida; ZA: Zonaria aureomarginata; DA: Durvillaea antarctica; mussels - PC: Perna canaliculus; AM: Aulacomya maoriana; MG: Mytilus galloprovincialis; LP: Limnoperna pulex; Barnacles CC: Chamaesipho columna; CB: C. brunnea; porcelain crabs - PE: Petrolisthes elongatus) were collected and analysed for stable isotope signatures. Nearshore water ( $2 \mathrm{~L}$ at each site for each season) was also collected and tested using stable isotope analysis as an example of the food available in the water column (microalgae with macroalgal detritus). Offshore water 
samples ( $2 \mathrm{~L}$ for each season) were collected $5 \mathrm{~km}$ off the CS coast and used as an analogue to phytoplankton without the influence of macroalgal detritus.

Due to the disparate nature of the coastlines between $\mathrm{CS}$ and $\mathrm{WH}$, filter feeders were collected from the coastlines where they are naturally able to survive. Thus, LP and PE were collected from both coasts, CB was collected from the CS, and the mussels (AM, MG and PC) as well as CC were collected from WH. The macroalgal species that were collected for this analysis were chosen based on their abundance on either coast (Nelson 2008), while sedentary and low mobility filter feeders were chosen as they reflect changes in the water column over time.

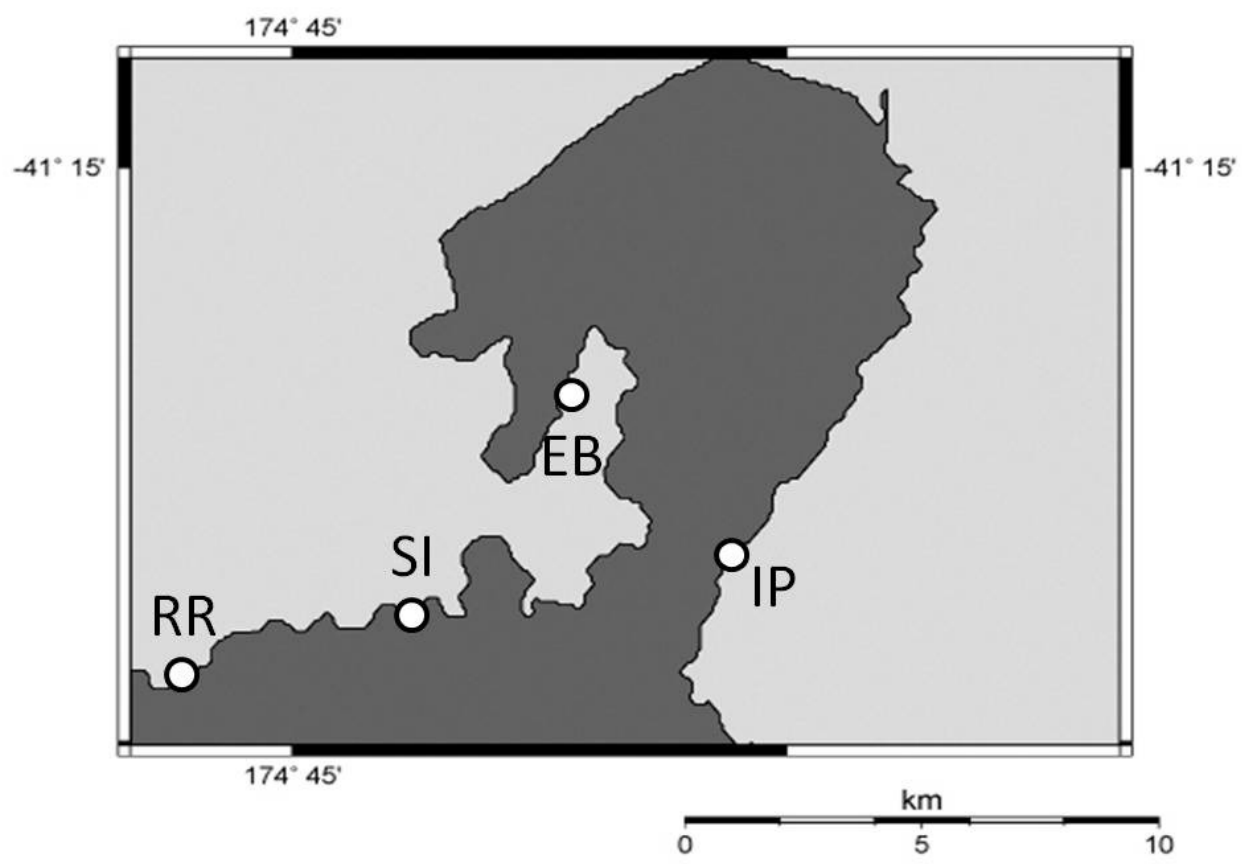

Figure 4.1. Location of study sites along Cook Strait (RR: Red Rocks, SI: Sirens) and Wellington Harbour (EB: Evans Bay and IP: Inconsistent Point). 


\subsubsection{Seston analysis - TPM and POM}

Measurements of total particulate matter (TPM) and particulate organic matter (POM) were collected from each site for both summer and winter. Three $2 \mathrm{~L}$ samples of seawater were collected from the intertidal region at all sites and filtered onto pre-weighted, pre-ashed 47 $\mathrm{mm}$ glass-fibre filters (Macherey-Nagel, Germany). Filters were then dried at $60^{\circ} \mathrm{C}$ for 24 hours and weighed to obtain the total weight of all particulate matter. The filters were then ashed at $450^{\circ} \mathrm{C}$ to obtain the weight of the non-organic carbon.

TPM $\left(\mathrm{mg} \mathrm{l}^{-1}\right)$ is the dry weight of filtered particles divided by the total number of litres of raw seawater collected. POM $\left(\mathrm{mg} \mathrm{l}^{-1}\right)$ is calculated as the TPM - ashed weight of the filters divided by the number of litres of raw seawater collected. Percent organic matter (PCOM) was measured as (POM/TPM) * 100.

\subsection{3. $C$ and $N$ analysis - Sample preparation and analysis}

Invertebrate species were dissected and these samples along with macroalgal samples were individually triple washed with deionized water. Dissection tools were acid washed, rinsed with distilled water and sterilised at $450^{\circ} \mathrm{C}$ for $4 \mathrm{~h}$. Laboratory gloves were used at all times to prevent carbon and nitrogen contamination from handling. Bivalves were prepared by removing the shell. All dissected samples were stored at $-80^{\circ} \mathrm{C}$ and then freeze dried and ground to a fine powder using a clean mortar and pestle which was cleaned with ethanol and triple washed with dionised water between samples.

Organisms with calcareous shells that were too small to dissect (smaller barnacles and crabs) were separated into two sub-samples as in Kolasinski et al. (2008). The first subsample was analysed without any pre-treatment, while the second was treated with $5 \mathrm{~mL} 1 \mathrm{M}$ $\mathrm{HCl}$ until no further $\mathrm{CO}_{2}$ degassing was observed (12-18 h). Acidified samples were 
neutralised with deionised water and centrifuged three times (at $753 \mathrm{x}$ g) with the supernatant discarded between each centrifuge. The samples were then freeze dried and homogenised into a fine powder.

Acidification of samples with dilute hydrochloric acid (1-2 M) has been widely used as the standard treatment for marine organism demineralization (Jacob et al. 2005, Kennedy et al. 2005, Carabel et al. 2006). However, in some cases, acidification can lead to significant decreases in $\delta^{15} \mathrm{~N}$ values. It is assumed that all nitrogen in animal tissue is organically bound and is not removed during the acidification process. To verify this, a portion of both the untreated sample and acidified sample was used to ensure that the $\delta^{15} \mathrm{~N}$ signature was unchanged.

Offshore and nearshore seawater samples (2 L) from each site were filtered onto preweighed, pre-ashed $47 \mathrm{~mm}$ GF filters (Macherey-Nagel, Düren, Germany) and dried at $35^{\circ} \mathrm{C}$ for 24 hours in a drying oven. Offshore and nearshore water samples on GF filters were weighed into 4 x $6 \mathrm{~mm}$ tin capsules. Clean, pre-ashed GF filters were also weighed into 4 × 6 $\mathrm{mm}$ tin capsules as a control for the nitrogen content of the filters.

Powdered macroalgal and invertebrate samples were weighed into 3 x $5 \mathrm{~mm}$ tin capsules. Carbon and nitrogen content and isotopic composition were analysed at the Stable Isotope Laboratory, GNS Science, New Zealand using a Europa Geo 20/20 isotope ration mass spectrometer (PDZ Europa Ltd., Crewe, UK), interfaced to an ANCA-SL elemental analyzer (PDZ Europa Ltd.) in continuous flow mode (EA-IRMS). Carbon dioxide and nitrogen gasses were separated on a GC column at $60^{\circ} \mathrm{C}$, and analysed for isotopic abundance. The ${ }^{13} \mathrm{C} /{ }^{12} \mathrm{C}$ and ${ }^{15} \mathrm{~N} /{ }^{14} \mathrm{~N}$ compositions were expressed in conventional delta notation in per mil (\%o) relative to the levels of ${ }^{13} \mathrm{C}$ in Vienna Pee Dee Belemnite (VPDB) 
and ${ }^{15} \mathrm{~N}$ in atmospheric air. Repeated measurement of an internal standard exhibited a precision of $\pm 0.2 \%$ for $\delta^{13} \mathrm{C}$ and $\pm 0.3 \%$ for $\delta^{15} \mathrm{~N}$.

\subsubsection{Statistical analysis}

Because both $\delta^{13} \mathrm{C}$ and $\delta^{15} \mathrm{~N}$ respond together to some temporal and spatial change in the environment (Marín Leal et al. 2008), multivariate analysis of variance (MANOVA) was used to assess any differences between coast (Cook Strait and Wellington Harbour) and season (Summer and Winter) for both the filter feeders and the potential sources. Sites along the Cook Strait (Red Rocks and Sirens) and Wellington Harbour (Evans Bay and Inconsistent Point) were combined to identify any differences between the two coasts. Pooling of data from sites within coast was justified because separate $t$-test analyses revealed no differences between sites on either coast $(\mathrm{p}>0.05)$.

Separate MANOVA analyses were performed on the $\delta^{13} \mathrm{C}$ and $\delta^{15} \mathrm{~N}$ values of all the sources and filter feeders on each coast to examine any differences between season (Summer and Winter) and species (7 species of invertebrate filter feeder). Because only two of the filter feeder species live on both coasts (LP and PE were found at all sites), MANOVA analyses were performed to examine any differences between species, coast and season. Other invertebrate species were only found on a single coast (CS or WH) and a separate MANOVA analysis was performed on these species due to the absence of certain species on either shore. Thus isotopic signatures for LP and PE were analysed separately for any differences between species, coast and season. Isotopic signatures of species found on the CS (LP, PE and CB) and $\mathrm{WH}$ (LP, PE, CC, AM, MG, PC) were analysed in coastal groupings to examine differences between species and season. The assumptions for ANOVA also hold for MANOVA and were met for this analysis: 1) the standardised residuals (within separate groups of the MANOVA) are normally distributed (tested using normal probability plots with 
square root transformation to meet this assumption) 2) homoscedasticity (tested using residual versus predicted plots) and 3) subjects are independent (Quinn and Keogh 2002). To examine any post hoc relationships, separate MANOVA analyses were performed for each individual species (as species were significantly different in the MANOVA analysis) to determine any coastal or seasonal differences.

\subsubsection{Modelling}

To test contributions to filter feeder diet, the IsoSource model (Phillips 2008) as it estimates the proportional contribution of microalgae and macroalgal detritus in the diet of 7 sessile, intertidal filter feeding species (Phillips and Gregg 2003, Phillips et al. 2005). For this model,

a two isotope system $\left(\delta^{13} \mathrm{C}\right.$ and $\left.\delta^{15} \mathrm{~N}\right)$ was used, with 9 sources to quantify the contribution of micro- and macroalgae in the diet of each species. Each model was calculated using an increment of $1 \%$ for both $\delta^{13} \mathrm{C}$ and $\delta^{15} \mathrm{~N}$. IsoSource models report all possible combinations of each source contribution in small increments $(1 \%)$ that satisfy the isotopic mass balance (the combination of the isotope sources equals that of the mixture) in the mixing model (Phillips and Gregg 2003). The sources occasionally reported a wide range of proportional values to the contribution of the mixture, thus the means were presented in this study.

\subsection{Results}

\subsubsection{Seston analysis - TPM, POM and PCOM}

TPM values in the summer on the CS coast and for the winter and summer on the WH coast were significantly higher than the TPM values recorded during the winter on the CS coast (Figure 4.2, $\mathrm{F}_{3}=4.03, \mathrm{p}=0.02$ ). POM was lowest in the winter in the $\mathrm{CS}$, intermediate in the summer at both locations, and greatest during the winter in WH (Figure 4.2, $\mathrm{F}_{3}=6.81, \mathrm{p}=$ 
0.002). There was no significant difference in PCOM between coast or season $\left(\mathrm{F}_{3}=2.15, \mathrm{p}>\right.$ 0.05), but all values of PCOM were above $20 \%$, which is required for mussels to overcome metabolic faecal loss (Gardner 2000, 2002, Gardner and Thompson 2001b).
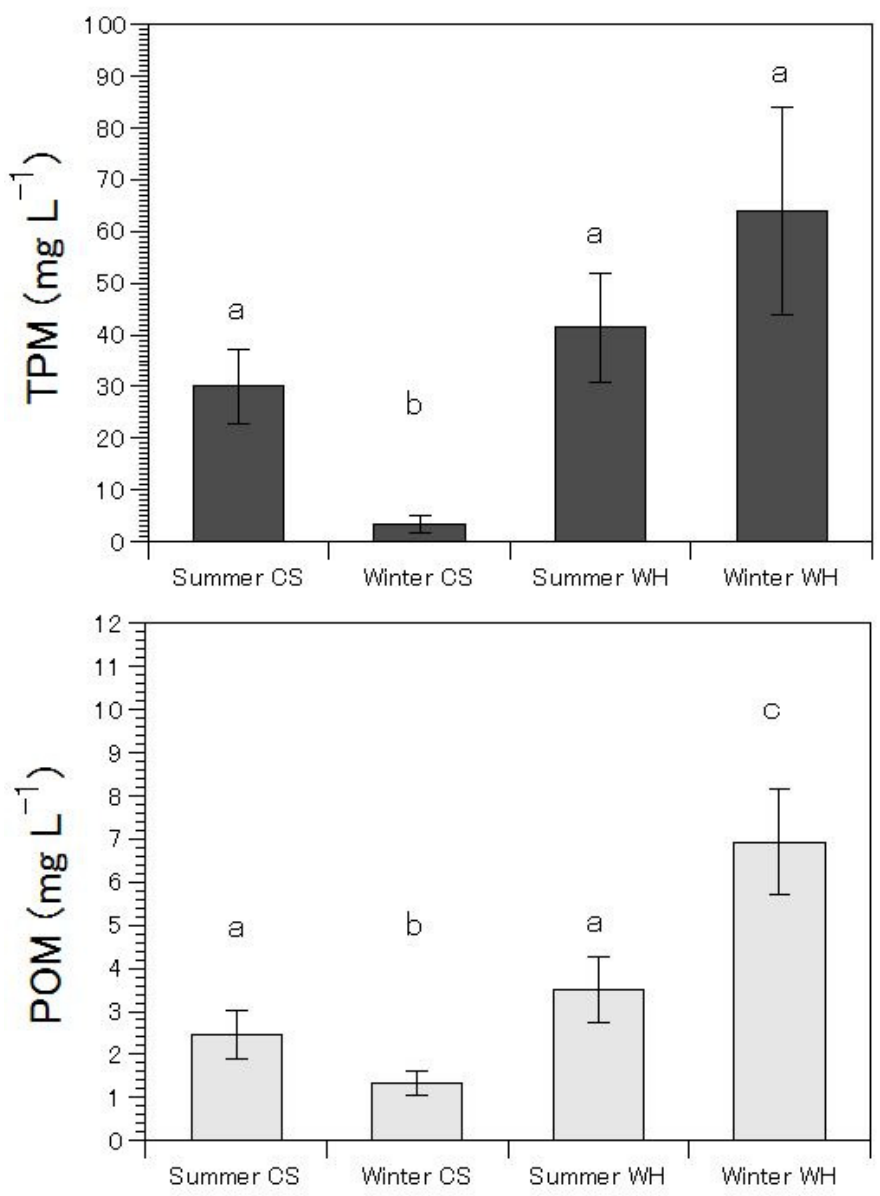

Figure 4.2. TPM: total particulate matter and POM: particulate organic matter (mean $\pm \mathrm{SD}$ ) from the Cook Strait and Wellington Harbour for Summer 2010 and Winter 2010. Differing letters indicate significant differences $(\mathrm{p}<0.05)$. 


\subsection{2. $C$ and $N$ analysis - Isotopic signatures of sources}

Carbon and nitrogen isotopic signatures of all food sources sampled across 2 coasts and at 2 seasons were significantly different between the CS and WH and also between summer and winter (Table 4. 1). Isotope signatures for CM, MP and UL had a significant interaction effect between coast and season (Table 4. 1). There was no consistent pattern between the 3 species with CM having lower $\delta^{15} \mathrm{~N}$ and higher $\delta^{13} \mathrm{C}$ in the CS summer, MP showing higher $\delta^{15} \mathrm{~N}$ in the WH winter, and lowest $\delta^{13} \mathrm{C}$ and $\delta^{15} \mathrm{~N}$ in the $\mathrm{CS}$ winter, and UL showing lower $\delta^{13} \mathrm{C}$ in the WH winter (Figure 4. 3). UN was not significantly different between coast or season.

Other micro- and macroalgal sources were only significantly different between summer and winter (Table 4. 1). DA summer signatures were significantly higher in $\delta^{13} \mathrm{C}$ and lower in $\delta^{15} \mathrm{~N}$ compared with winter values. Both LV and ZA had higher $\delta^{13} \mathrm{C}$ and higher $\delta^{15} \mathrm{~N}$ in the summer compared with the winter season. NW was lower in $\delta^{13} \mathrm{C}$ and higher in $\delta^{15} \mathrm{~N}$ in the summer, while OW showed an opposing pattern with higher $\delta^{13} \mathrm{C}$ and lower $\delta^{15} \mathrm{~N}$ in the summer compared to the winter (Figure 4. 3). 
Table 4.1 MANOVA analysis of sources and post hoc MANOVA analyses for individual species. Individual species are CM: Carpophyllum maschalocarpum, DA: Durvillaea antarctica, LV: Lessonia variegata, MP: Macrosystis pyrifera, UL: laminate Ulva spp., UN: Undaria spp., ZA: Zonaria aureomarginata, NW: nearshore water, OW: offshore water. An asterisk $(*)$ denotes statistical significance $(\mathrm{p}<0.05)$.

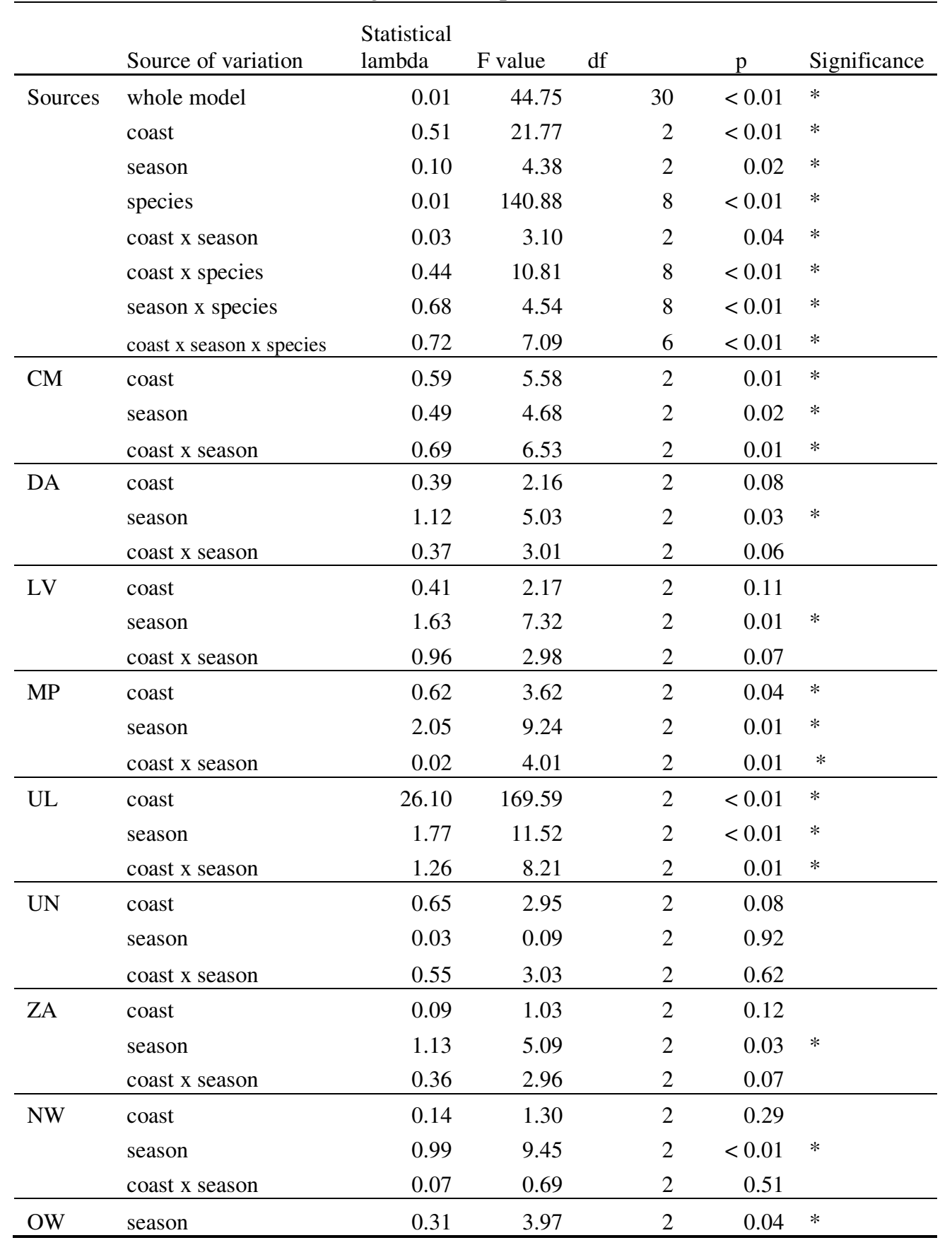




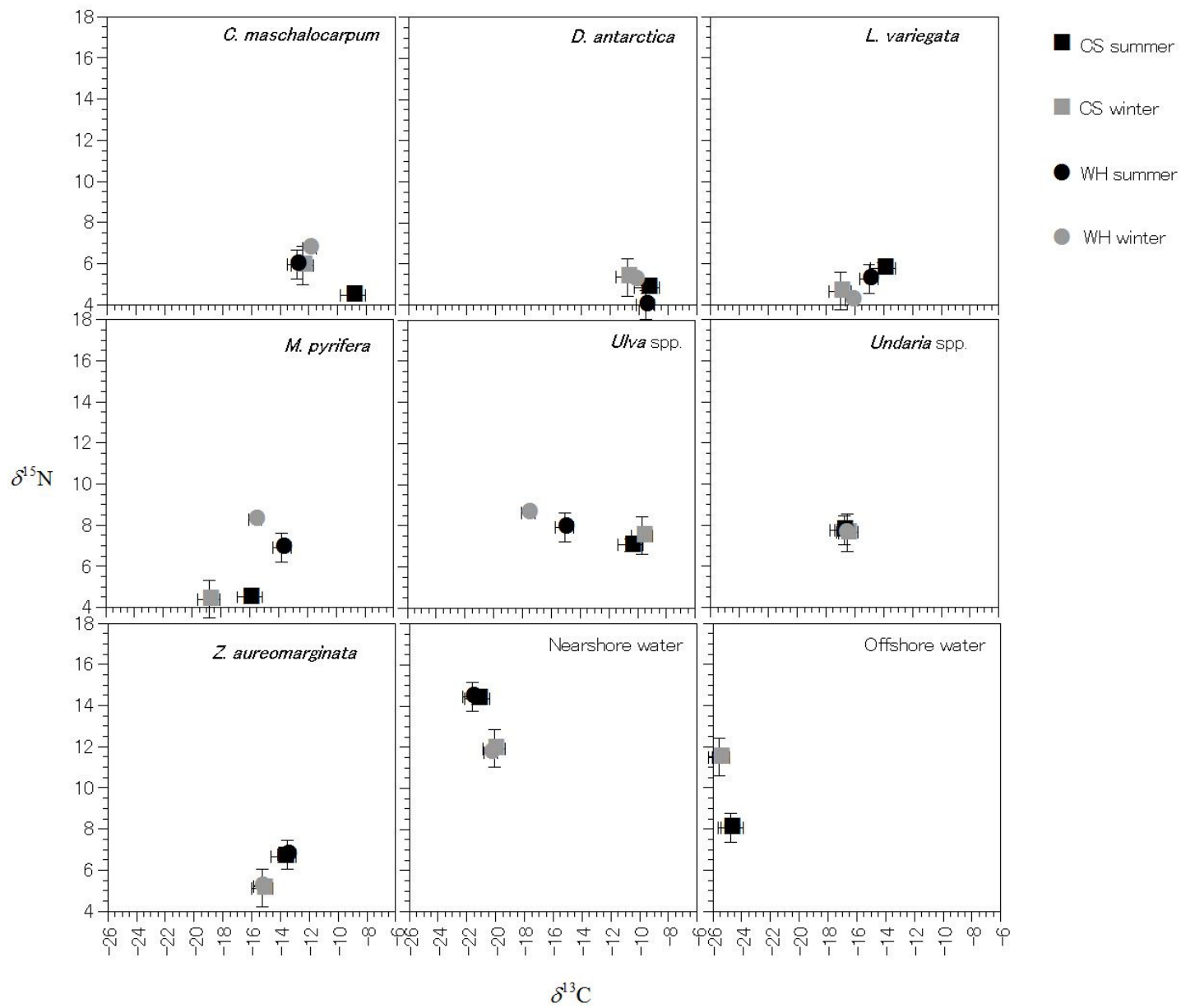

Figure 4.3 Stable carbon and nitrogen isotope signatures (means \pm SD) for micro- and macroalgal sources in the CS and WH in Summer 2010 and Winter 2010 seasons.

\subsubsection{Isotopic signatures of mixtures}

The two filter feeder species that were found on both coasts (LP and PE), had a significant interaction term between species, coast and season (Table 4. 2). LP was found to be significantly different between coast and season with the WH winter values lowest in $\delta^{13} \mathrm{C}$ and $\delta^{15} \mathrm{~N}$ lowest in the CS winter (Figure 4. 4). PE was significantly different between coasts with higher $\delta^{15} \mathrm{~N}$ in WH compared with the CS (Figure 4. 4). Summer isotope values on both coasts for both species were more variable compared with the winter season (Figure 4. 4). 
Table 4.2 MANOVA analysis for filter feeders (mixture samples) that were found on both coasts. Mixtures are LP: Limnoperna pulex and PE: Petrolisthes elongatus. Post hoc MANOVA analyses were performed for individual species. An asterisk (*) denotes significant differences.

\begin{tabular}{|c|c|c|c|c|c|c|c|}
\hline & Source of variation & $\begin{array}{l}\text { Statistical } \\
\text { lambda }\end{array}$ & $\mathrm{F}$ value & df & & $\mathrm{P}$ & Significance \\
\hline \multirow[t]{8}{*}{ LP \&PE } & whole model & 0.08 & 16.23 & & 12 & $<0.01$ & * \\
\hline & coast & 2.03 & 40.77 & & 2 & $<0.01$ & $*$ \\
\hline & season & 0.11 & 2.25 & & 2 & 0.12 & \\
\hline & Species & 0.08 & 1110.57 & & 6 & $<0.01$ & $*$ \\
\hline & coast $\mathrm{x}$ season & 0.03 & 1.69 & & 2 & 0.19 & \\
\hline & coast $\mathrm{x}$ species & 0.81 & 4.82 & & 6 & $<0.01$ & $*$ \\
\hline & season $\mathrm{x}$ species & 0.86 & 3.38 & & 6 & $<0.01$ & $*$ \\
\hline & season $\mathrm{x}$ species $\mathrm{x}$ coast & 0.79 & 3.26 & & 4 & $<0.01$ & $*$ \\
\hline \multirow[t]{3}{*}{ LP } & coast & 0.57 & 3.98 & & 2 & 0.04 & $*$ \\
\hline & season & 1.05 & 7.32 & & 2 & $<0.01$ & $*$ \\
\hline & coast $\mathrm{x}$ season & 2.40 & 16.80 & & 2 & $<0.01$ & $*$ \\
\hline \multirow[t]{3}{*}{$\mathrm{PE}$} & coast & 0.58 & 5.51 & & 2 & 0.01 & $*$ \\
\hline & season & 0.14 & 1.36 & & 2 & 0.28 & \\
\hline & coast $\mathrm{x}$ season & 0.10 & 0.93 & & 2 & 0.41 & \\
\hline
\end{tabular}




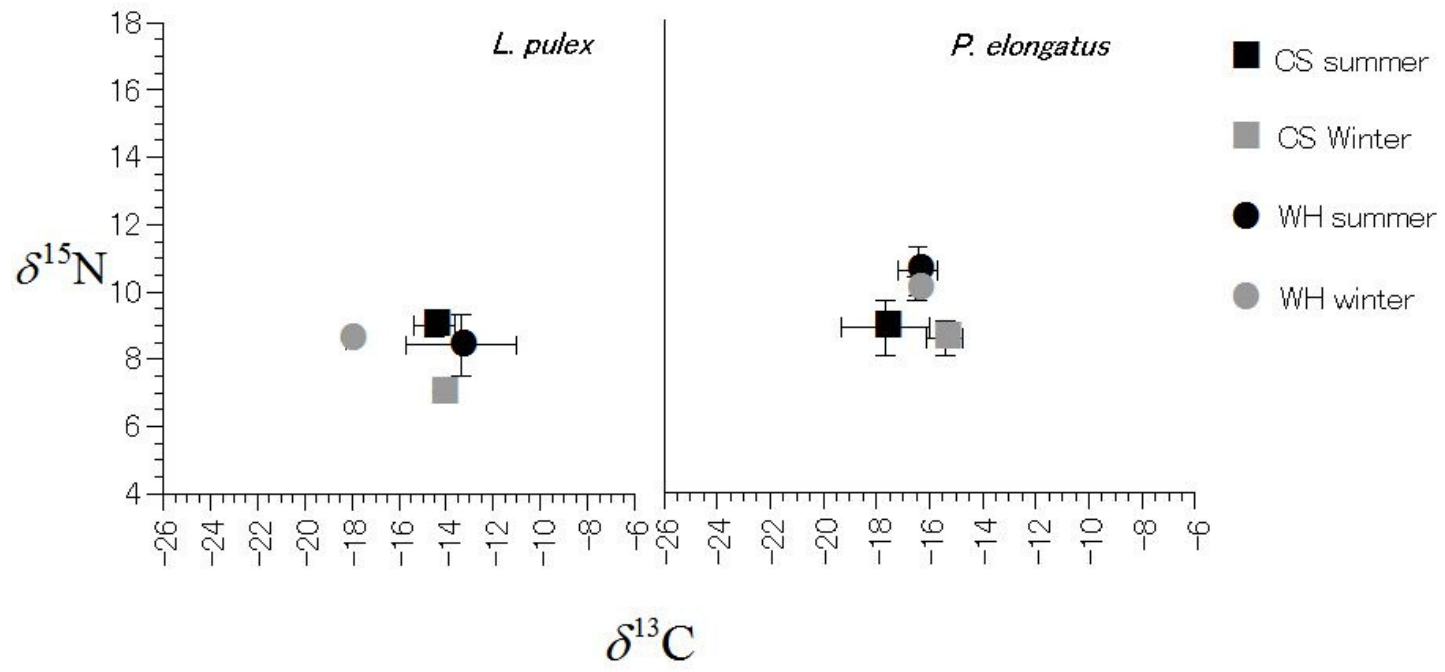

Figure 4.4 Stable carbon and nitrogen isotope signatures (means \pm SD) for Limnoperna pulex and Petroslithes elongatus (mixture signals) that were found in the CS and WH for the Summer 2010 and Winter 2010 seasons.

Species on both the CS and WH coasts had significant interaction terms between species and seasons (Table 4. 3). Summer isotope signatures were more varied compared with winter signatures and, in general, the $\delta^{15} \mathrm{~N}$ was higher in all species during the summer than in the winter months. The stable isotopic signatures of $\mathrm{CB}$, which was the only species found exclusively on the CS, had higher and more varied $\delta^{13} \mathrm{C}$ and $\delta^{15} \mathrm{~N}$ in the summer months than in the winter (Figure 4. 5). CB isotopic signatures were also both higher in $\delta^{15} \mathrm{~N}$ and lower in $\delta^{13} \mathrm{C}$ compared with species from WH (Figure 4. 5). Both CC and PC were not significantly different between seasons. The mussels AM and MG showed similar seasonal patterns in $\delta^{13} \mathrm{C}$ and $\delta^{15} \mathrm{~N}$, with summer values for $\delta^{13} \mathrm{C}$ being lower than winter values and $\delta^{15} \mathrm{~N}$ values being similar between seasons. 
Table 4.3 MANOVA analysis for filter feeders (mixture signals) that were found on either the CS or WH coasts. Mixtures are CB: Chamaesipho brunnea (CS coast), CC: Chamaesipho columna (WH coast), AM: Aulacomya maoriana (WH coast), MG: Mytilus galloprovincialis (WH coast), PC. Perna canaliculus (WH coast). Post hoc MANOVA analyses were performed for individual species. An asterisk $(*)$ denotes significant differences.

\begin{tabular}{|c|c|c|c|c|c|c|}
\hline & $\begin{array}{l}\text { Source of } \\
\text { variation }\end{array}$ & $\begin{array}{l}\text { Statistical } \\
\text { lambda }\end{array}$ & $\mathrm{F}$ value & $\mathrm{df}$ & $\mathrm{P}$ & Significance \\
\hline CS filter feeders & whole model & 0.04 & 22.70 & 10 & $<0.01$ & $*$ \\
\hline \multirow{7}{*}{$\begin{array}{l}\text { WH filter } \\
\text { feeders }\end{array}$} & Season & 0.05 & 3.44 & 2 & 0.04 & $*$ \\
\hline & Species & 0.04 & 53.02 & 4 & $<0.01$ & $*$ \\
\hline & season $\mathrm{x}$ species & 0.09 & 2.69 & 4 & 0.04 & $*$ \\
\hline & whole model & 3.41 & 18.59 & 22 & $<0.01$ & $*$ \\
\hline & Season & 0.11 & 3.28 & 2 & 0.04 & $*$ \\
\hline & Species & 2.93 & 35.21 & 10 & $<0.01$ & $*$ \\
\hline & season*species & 0.38 & 4.58 & 10 & $<0.01$ & $*$ \\
\hline $\mathrm{CB}$ & Season & 4.62 & 16.17 & 2 & $<0.01$ & $*$ \\
\hline $\mathrm{CC}$ & Season & 0.39 & 1.78 & 2 & 0.22 & \\
\hline $\mathrm{AM}$ & Season & 4.08 & 18.36 & 2 & $<0.01$ & $*$ \\
\hline MG & Season & 20.11 & 90.50 & 2 & $<0.01$ & $*$ \\
\hline $\mathrm{PC}$ & Season & 0.30 & 1.34 & 2 & 0.31 & \\
\hline
\end{tabular}




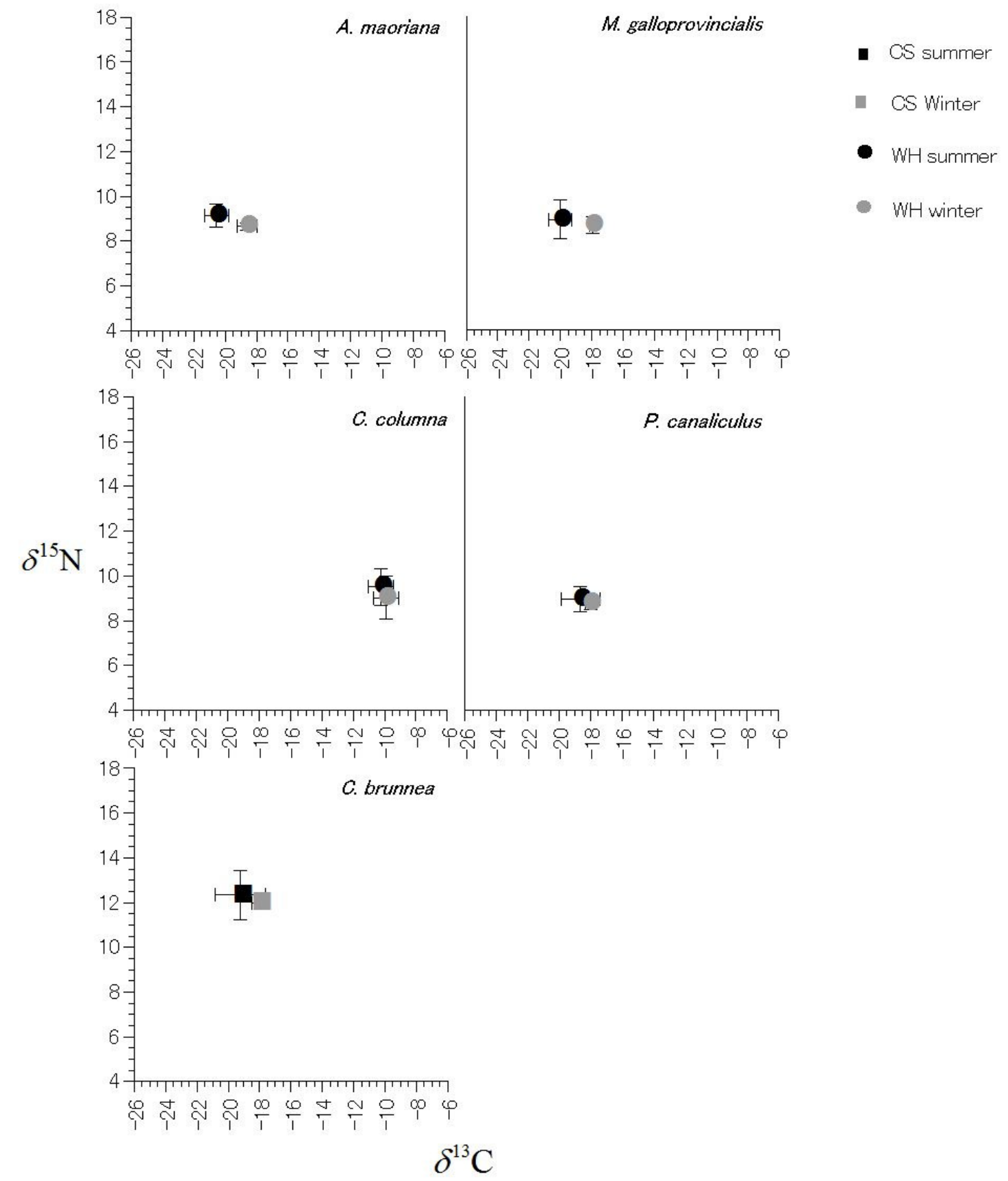

Figure 4.5 Stable carbon and nitrogen isotope signatures (means \pm SD) for filter feeder (mixture signals) that were found in either the CS or WH for the Summer 2010 and Winter 2010 seasons. 


\subsubsection{Contributions to filter feeder diet}

Many of the filter feeders in both the CS and WH have particulates from offshore and nearshore water sources as a large proportion of their diet (mean of $19.4 \%-95.9 \%)$. In the summer, on both the CS and WH coasts, the proportion of offshore water particulates in the diet is larger than that in the winter (Figure 4.6). There were no macroalgal species that consistently contributed more than others to the isotopic signatures of the mixtures.

The two filter feeders that have a prominent presence on both coasts (LP and PE) show proportionally even contributions from micro- and macroalgal sources in the winter on both coasts (Figure 4.6). In the summer, both taxa have fewer sources making up their total diet according to the IsoSource model. LP and PE also have similar proportional contributions of UL to their diets according to the model. During summer on the CS coast LP and PE appear to have less variety in their diet, with only 2 or 3 sources making up over $70 \%$ of the total diet.

Of the 3 filter feeders examined on the CS coast, a large proportion of the summer diet was composed of offshore and nearshore water with fewer and smaller contributions from other macroalgal sources (Figure 4.6). During the winter, these sources contribute more evenly to the diet of LP, PE and CB. In WH there is an opposing trend to that of the CS coast in the diet of filter feeders. Thus, organisms that live primarily or exclusively in WH (CC, $\mathrm{AM}, \mathrm{MG}$ and $\mathrm{PC}$ ) have a more even contribution of sources in their summer diet compared to their winter diet. For the mussels that live exclusively on the WH coast, UL and MP are the major macroalgal contributors to their diet (AM: 39.6\%; MG: 62.0\%; PC: $67.1 \%$ of the total diet). 

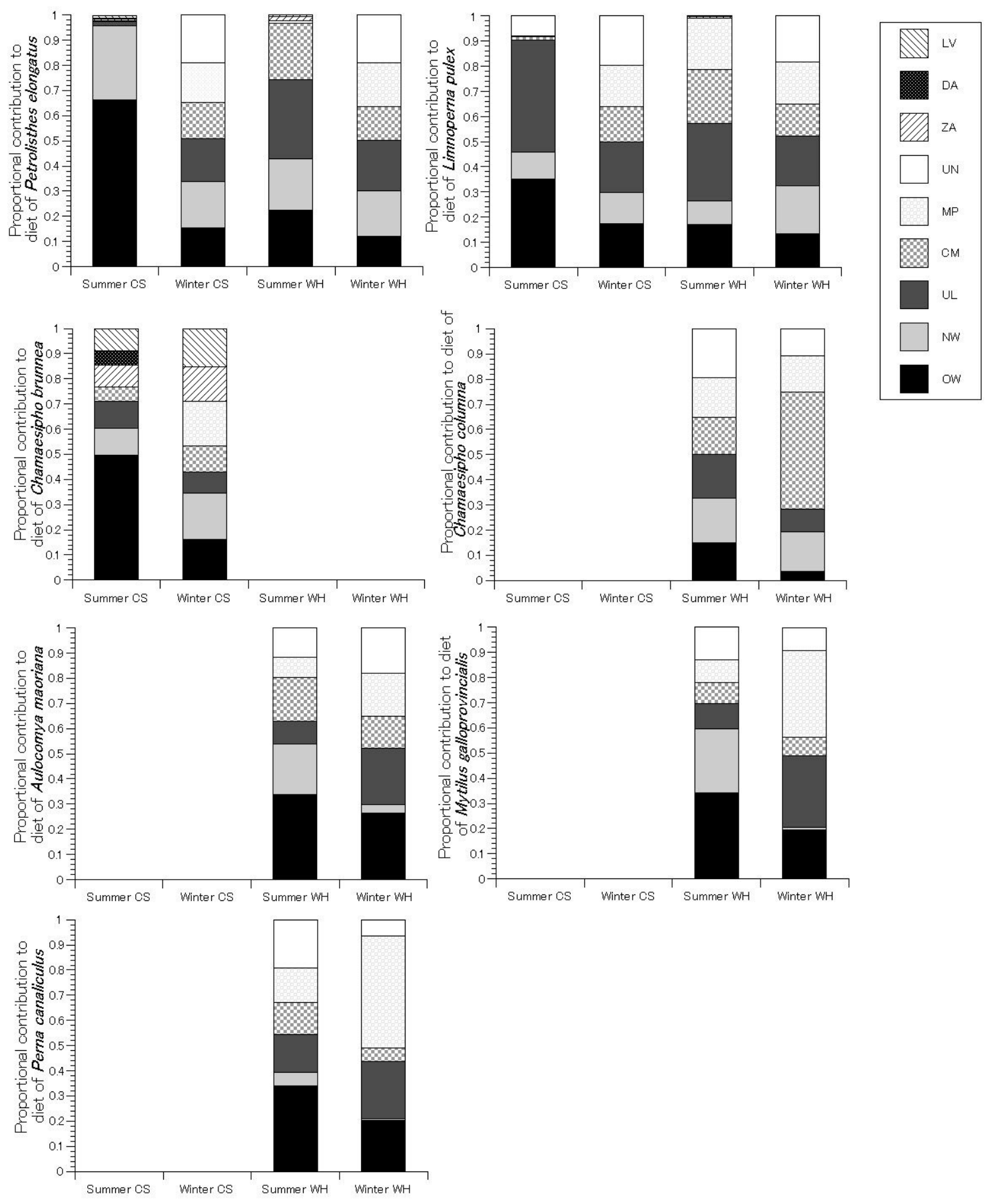

Figure 4.6 Proportional contribution of differing micro- and macroalgal sources to the diets of filter feeders for the Summer and Winter of 2010. Source species are LV: Lessonia variegata, DA: Durvillaea antarctica, ZA: Zonaria aureomarginata, UN: Undaria spp., MP:

Macrosystis pyrifera, CM: Carpophyllum maschalocarpum, UL: laminate Ulva spp., NW: nearshore water and OW: offshore water. 


\subsection{Discussion}

Stable isotopes are becoming an increasingly useful tool in understanding trophic flow directions and their magnitudes in marine ecosystems (Marín Leal et al. 2008, Lefebvre et al. 2009b) and in examining trophic linkages between multiple species and populations (Rodgers and Wing 2008, Hill and McQuaid 2008). This study utilised $\delta^{13} \mathrm{C}$ and $\delta^{15} \mathrm{~N}$ signatures for both purposes; to examine the diet of a group of filter feeders on two disparate shores.

\subsubsection{Seasonality in $C$ and $N$ isotopes of filter feeders and their food sources}

Seasonality of micro- and macroalgae in both the CS and WH is strong with all species except Undaria spp. Microalgal species are dependent on weather patterns and seasonal upwelling to produce blooms within the water column (Kang et al. 1999, Savoye et al. 2003, Vizzini and Mazzola 2003). Many macroalgal species are sensitive to summer UV levels and water temperatures and many can become bleached near the surface of the water column or if they are attached to north facing rocks in the Southern Hemisphere (Nelson 2008). This study succeeded in capturing the characteristics of the food sources by the use of a dual C and $\mathrm{N}$ isotope approach as there were clear differences between the summer and winter seasons in both the CS and WH. Other, more long-term studies have also shown that micro- and macroalgal species making up the diet of filter feeders varied between seasons (Marín Leal et al. 2008, Lefebvre et al. 2009b).

The two species of filter feeder that exist on both the CS and WH coast (Limnoperna pulex and Petrolisthes elongatus), showed lower $\delta^{15} \mathrm{~N}$ in the CS winter indicating lower food availability during that time. This fits with the changes in TPM and POM across season and site. There was a decrease in the amount of food available during the winter in the CS, whereas WH had more food available in the winter from different sources than in the summer. 
In summer on both the CS and WH coasts, the filter feeders are generally more enriched in nitrogen than in the winter and the values for carbon were more varied. This indicates a lower competition for resources in the summer months during higher phytoplankton availability. Bivalves sort and process particles by the use of mucus and ciliary processes prior to ingestion, suggesting that during times of high POM in the water column, they are able to select preferential food particles by both quality and size (Barille et al. 1997, Bougrier and Hawkins 1997). Thus, in times of high food availability (high POM), filter feeders are able to ingest more (higher $\delta^{15} \mathrm{~N}$ ) and be selective (wider range of $\delta^{13} \mathrm{C}$ ). This is further confirmed by the IsoSource model which showed an increase in the contribution of offshore water (analogue for phytoplankton without influence of macroalgal detritus) in the summer diets of nearly all the species, but in particular for species living on the CS coast (Figure 4.6). These results are similar to those of Lefebvre et al. (2009b) in Normandy, France, where they found trophic competition between suspension feeders in autumn and winter, when phytoplankton blooms did not occur.

\subsubsection{Trends in diet composition of filter feeders from $\mathrm{CS}$ and $\mathrm{WH}$}

Many of the filter feeding invertebrates sampled had a large variety of microalgae and macroalgal detritus in their diets according to the IsoSource data. For species that occurred in both the CS and WH, the winter diets showed an even proportion of all the possible sources. Summer diets for both L. pulex and P. elongatus showed a much higher dependence on offand nearshore water in the CS than in $\mathrm{WH}$, but with similar amounts of POM available in the water column in the summer. The smaller size of these organisms compared to $M$. galloprovincialis and P. canaliculus may allow them to take advantage of food sources if they are limited in the water column. The mobility of PE may also be a factor in its survival 
on the CS coast because they are able to move to areas with increased food availability (Johnston and Freeman 2005).

\subsubsection{Coastal trends in stable isotope signatures}

The $\delta^{13} \mathrm{C}$ and $\delta^{15} \mathrm{~N}$ signatures throughout this study showed larger differences between the CS and WH coast than by season. This indicates an increased seasonal variability in the quality and quantity of food sources compared to Marín Leal et al. (2008) who found $\delta^{13} \mathrm{C}$ and $\delta^{15} \mathrm{~N}$ to change less with time than between coasts. It is clear that there are differences in the assemblages of micro- and macroalgae between the CS and WH coasts (Morton and Miller 1968, Nelson 2008) The TPM and POM from both sites across season indicates that there is a substantial difference in the winter values. Winter seston concentrations in WH are known to be high ( 60\%) (Gardner 2000, Helson et al. 2007). The increased availability of food in the form of phytoplankton, zooplankton, microphytobenthos and macroalgal detritus in the winter months in WH is contrasted by the small amounts of POM available in the winter months along the CS coast. It is possible that the filter feeding species that survive on the CS coast are able to withstand long periods of starvation or survive on a different diet than those in WH (Helson and Gardner 2007).

Macroalgal assemblages differ markedly between the CS and WH coasts. There is an increased number of macroalgal species in the CS compared to WH (Morton and Miller 1968, Nelson 2008). There is a greater species richness of large kelp in the CS that can withstand consistently high abrasion from sand and small cobble (Morton 2004). While there are differences in the factors that are controlling microalgal abundances and assemblages in the $\mathrm{CS}$ and $\mathrm{WH}$, it is unclear how the species-specific phytoplankton community differs between these coasts (Bradford et al. 1986). 
The importance of macroalgal detritus to the diets of marine filter feeders has been reported from several coastal ecosystems (Langdon and Newell 1990, Wiedemeyer and Schwamborn 1996, Adin and Riera 2003, Johnston and Freeman 2005, Laurand and Riera 2006, Dubois et al. 2007). While in other studies macroalgal detritus appears to be less important in bivalve diets (Lefebvre et al. 2009b), this study has shown that macroalgae makes up a significant part of mussel diet in WH (over 50\% in both seasons). Mussels are dependent on algae that are more abundant during the winter season. The influences of these species on the diet of the filter feeders was clear, as M. pyrifera and Ulva spp. appeared to contribute more to the diet of all filter feeders in the winter season when the species are known to be more abundant (Reed and Foster 1984).

The two barnacle species had very different $\delta^{13} \mathrm{C}$ and $\delta^{15} \mathrm{~N}$ values (Figure 3). The barnacle found on the CS coast (Chamaesipho brunnea - CB) had a higher $\delta^{15} \mathrm{~N}$ and lower $\delta^{13} \mathrm{C}$ signature than C. columna which is found on the WH coast. The compositions of their diets are also quite different, with $C$. brunnea consuming a larger proportion of phytoplankton (from offshore water) in both seasons compared to C. columna which consumed more macroalgal detritus. Large macroalgal species (LV, DA) constituted a significant proportion of the diet of $C$. brunnea which is unique to this species when compared to the other filter feeders examined in this study. These macroalgal species secrete large amounts of mucilage (a slimy protective layer on the seaweeds surface) that sloughs off and enters the food chain (Leppard 1995). Other studies have found that temperate, rocky intertidal food webs are heavily dependent on kelp-derived organic carbon where these large macroalgal species are in high abundance (Bustamante and Branch 1996b). The two species of barnacle are also very different sizes. C. columna is much smaller than C. brunnea with average size being $\sim 4 \mathrm{~mm}$ and $\sim 10 \mathrm{~mm}$, respectively. This size difference may allow $C$. brunnea to attach more firmly to the substrate or to withstand stronger storm events than $C$. 
columna (Morton and Miller 1968). A larger size might also give C. brunnea a greater capacity to store energy allowing it to withstand longer periods of starvation in either the adult or juvenile stage. Gosselin and Qian (1996) suggested that energy reserves at time of settlement are crucial to the survival of barnacles. The barnacle species differences between the CS and WH shores may be due to their ability to store food as well as the type of food that they are consuming at the time of settlement (Moyse 1963, Gosselin and Qian 1996).

The filter feeders that occurred only on WH coasts had very different $\delta^{13} \mathrm{C}$ and $\delta^{15} \mathrm{~N}$ signatures. Contrary to findings of Marin Leal et al. (2008), the diets of bivalves in WH do not appear to rely more heavily in the summer on phytoplankton contributions to their diet than other filter feeders living on the CS. What is apparent, however, is that the contribution of phytoplankton (offshore water) to the winter diets of A. maoriana, M. galloprovincialis and $P$. canaliculus is comparable to that of the summer months. This indicates that phytoplankton may be an important contributor to the diet of bivalves in $\mathrm{WH}$ in the sense that phytoplankton are more available and more abundant across time rather than as a singular pulse event in the summer. Helson and Gardner (2007) found that all three mussel species from WH that were kept in CS water died after several months. This, in combination with the findings from this study, indicates factors limiting mussels to $\mathrm{WH}$ are the quality and quantity of food available to them as well as long periods of starvation that occur around the winter months in the CS.

Rogers (1999) performed a study on a small population of mussels found on the CS that occurred near a site where filtered raw sewage was discharged close to shore. The sewage treatment plant has since been upgraded to a tertiary sewage treatment station (with milli-screening and UV light treatment) which releases the discharge $1.8 \mathrm{~km}$ further out to sea. The population of small M. galloprovincialis has since disappeared (pers. observation). This indicates that there is some connection between the higher nutrient load of the sewers 
output and the presence of mussels on the CS. While that study was conducted during the spring of one year, the continual presence of higher $\mathrm{NO}_{3}$ and $\mathrm{NH}_{4}$ (and presence of associated micro- and macroalgal species throughout the year) from the raw sewage output may have allowed the mussels to survive on the CS.

\subsection{Conclusions}

This study demonstrates the complexity of filter feeder diets on temperate, rocky intertidal shores. The $\delta^{13} \mathrm{C}$ and $\delta^{15} \mathrm{~N}$ values of the sources show clear dietary differences between species living in the CS and those in WH. It is likely that a combination of factors in the diet of filter feeders is affecting their ability to survive. It is clear that the organic matter available to filter feeders in the CS is much lower in the winter compared to summer and the CS winter concentration of POM is lower than both seasons in WH which has been shown in other studies (Helson and Gardner 2007, Helson et al. 2007).

What is unclear is how specific food sources (particularly phytoplankton) are affecting the survival of filter feeder species. Many studies have suggested that diet at the time of settlement is crucial for intertidal filter feeders (Gosselin and Qian 1996, Phillips 2002, 2004). This, in combination with periods of low food availability may be what is structuring the filter feeder community in the CS and may explain why the CS community is so strikingly different from the WH coast. 


\section{Chapter 5. Does reduced availability of particulate food limit mussels from the Cook Strait shores?}

\subsection{Introduction}

Like many temperate intertidal rocky shores, Wellington Harbour (WH) shoreline is composed of vertical zones of typical functional groups of species determined by daily changes in tidal height (Stephenson and Stephenson 1949, Lubchenco 1980, Jensen and Armstrong 1991, Harley and Helmuth 2003, Gardner 2008). The upper intertidal zone is dominated by small littorinid snails, followed by barnacles, mussels in the mid-intertidal zone and macroalgae in the low zone. WH supports a large diversity of filter feeders with two mussel species dominating the mid-intertidal zone: the ribbed mussel (Aulacomya maoriana) and the blue mussel (Mytilus galloprovincialis). Other mussel species are also present: the little black mussel (Limnoperna pulex) lives in the high intertidal, while the green-lipped mussel (Perna canaliculus) lives lower down on the shore. In the nearby Cook Strait (CS), which is less than a few kilometres from the mouth of $\mathrm{WH}$, the filter feeder abundances are quite limited compared to WH. More striking is that the entire mid-intertidal zone in the CS is largely devoid of mussels.

Mussels are an important trophic link between primary productivity in coastal waters and secondary production on the shore, as they filter particles from the water and provide food for whelks, crabs, seastars, fish and seabirds (Paine 1969, Frechette and Bourget 1985, Hunt and Scheibling 1998, Menge et al. 1999, Bertness et al. 2004, Griffen and Delaney 2007, Helson and Gardner 2007). Intertidal mussels are also characteristically dominant and provide space and shelter for other invertebrate species (Bertness and Leonard 1997, Bertness et al. 1999, Menge et al. 1999, Crain and Bertness 2006). Furthermore, mussel beds enrich 
sediment with organic material (biodeposits) and modify microbial activity which affects oxygen consumption, sulphate reduction and denitrification rates (Langdon and Newell 1990, Smaal 1991). Thus, given their importance in coastal waters, it is remarkable that mussels are almost entirely absent from the CS shores, yet so dominant in the nearby WH.

There are, however, a few species of filter feeders that exists on both the WH and CS shores. One of them is the false crab (Petrolisthes elongatus), a small filter feeding crab that occurs in the mid- intertidal zone in sheltered habitats (Steger and Gardner 2007). It resides under cobbles and is present year round on both shores. It is not known to move far from where it settles and is adapted to survive out of water during low tide (Jensen and Armstrong 1991, Stillman 2002, 2003). Their survival and abundance in the CS is interesting, because they share feeding methods with mussels and are adapted to eating particles in the water column with their modified maxillipeds, yet are not restricted to WH (Johnston and Freeman 2005, Gardner 2008).

There is a growing body of evidence that mussels are to some degree limited to $\mathrm{WH}$ by food availability (Gardner and Thompson 2001b, Gardner 2002, Helson and Gardner 2007). The importance of bottom-up community regulation has long been recognised in intertidal communities and has been reported at sites in North and South America, South Africa, Spain and New Zealand (Bradford and Roberts 1978, Froneman et al. 1995, Menge et al. 2009, 1997, 1999, McQuaid et al. 2000, Nielsen and Navarrete 2003, Broitman and Kinlan 2006, McQuaid and Lindsay 2007, Blanchette et al. 2008, 2009, Bode et al. 2009). Increases in primary productivity have been linked to increases in the abundances of mussels on shore and there has been a focus on top-down regulation (predation) causing decreased mussel abundances in the intertidal zone (Paine 1969, Menge et al. 1999, Bertness et al. 2002). The coast surrounding the CS, however, tells a different story as there is a distinct decrease in 
mussel abundance and an associated invertebrate community that is bottom-up driven (Helson and Gardner 2007, Helson et al. 2007, Gardner 2008, Chapter 2).

It is well known that temperate marine habitats exhibit strong seasonality of primary production in the water column (Chapman and Craigie 1977, Habib et al. 1997, Sasai et al. 2012). Often algal blooms occur in the spring and phytoplankton abundances tend to be low during the winter months. Evidence of lower particulate organic matter and chlorophyll $a$ production is apparent in the CS during the winter months (Helson et al. 2007a, see Chapter 3). Thus food abundances in CS waters during the winter months are thought to contribute to the very low abundances of mussels, but it is still unclear as to how other filter feeder species survive throughout the year in the CS.

The purpose of this study was to examine differences between the feeding habits of two mussel species that are mostly limited to WH (A. maoriana and M. galloprovincialis ) and a filter feeder from the same tidal height that occurs in both the WH and CS ( $P$. elongatus). Here, a laboratory feeding experiment was conducted in both $\mathrm{WH}$ and on the CS coast in both summer and winter for all three species to determine if there are any differences in how the three species are eating and if there are any size preferences of the food consumed. This study will give insight into why mussels are dominant in WH and mostly absent from the CS, while other filter feeders can survive in large numbers in both the CS and WH.

\subsection{Methods}

\subsubsection{Study facilities and holding conditions}

Mussels (Aulacomya maoriana and Mytilus galloprovincialis) and false crabs (Petrolisthes elongatus) were collected from Evans Bay, Wellington Harbour (S 41 17.983' E 174'49.028') in February 2011 and August 2011. Forty individuals of each species were 
collected and held at the National Institute for Water and Atmosphere (NIWA) aquaculture facilities at Mahanga Bay in Wellington Harbour and at the Victoria University Coastal Ecology Laboratory (VUCEL) at Island Bay which is situated along the Cook Strait. Mussels were cleaned of epibionts before being placed in plastic aquaria supplied with unfiltered water from the respective coasts. Mussels and crabs were acclimated to ambient conditions (Table 5.2) for 2-3 days prior to the beginning of the experiment. Mussels ranged in size from $30 \mathrm{~mm}$ to $50 \mathrm{~mm}$ for both species, while the carapace width of the crabs ranged from $9 \mathrm{~mm}-$ $12 \mathrm{~mm}$.

\subsubsection{Water column and seston characteristics}

Water samples were taken 3 times per $24 \mathrm{~h}$ sampling period. The total amount of water sampled each day was $6 \mathrm{~L}$ (3 replicate samples of $2 \mathrm{~L}$ to measure total particulate matter (TPM) and particulate organic matter (POM) and to calculate percentage organic matter $(\mathrm{PCOM}=\mathrm{POM} / \mathrm{TPM} \times 100) . \mathrm{TPM}, \mathrm{POM}$ and PCOM were measured by filtering $2 \mathrm{~L}$ samples onto a pre-ashed, pre-weighted Macherey-Nagel GF/C filter (Düren, Germany) and dried at $60^{\circ} \mathrm{C}$ for $24 \mathrm{~h}$. Filters and seston were weighed after drying to determine TPM and ashed at $450^{\circ} \mathrm{C}$ for $\approx 24 \mathrm{~h}$. The final ashed weight of the filters plus seston was determined and POM was calculated as TPM - ash weight. PCOM was calculated as (POM/TPM)*100 and is the percentage of TPM that is organic. Temperature $\left({ }^{\circ} \mathrm{C}\right)$, salinity (PSU) and dissolved oxygen (\%) were also measured using a YSI salinity and dissolved oxygen meter (Ohio, USA).

\subsubsection{Clearance rate $(C R)$}

CR experiments were carried out at both WH and CS facilities (NIWA and VUCEL, respectively) in the summer (February 2011) and winter (August 2011) with 20 of each 
species used to estimate clearance rates (the volume of water cleared of particles animal ${ }^{-1} \mathrm{~h}^{-}$

${ }^{1}$ ). The experimental setup and protocol followed Gardner (2002) and consisted of a header tank that feeds simultaneously into each of $1 \mathrm{~L}$ chambers through $1 \mathrm{~L}$ individual flow restrictors with a flow rate through each chamber of between $100-150 \mathrm{~mL} \mathrm{~min}^{-1}$. Ten individuals were tested each day with one chamber left empty as the control. The volume of each individual chamber was $0.5 \mathrm{~L}$ for the mussels and $0.25 \mathrm{~L}$ for the false crabs (Gardner 2002, Steger and Gardner 2007). Outflow from each of the chambers was through a plastic, 1 $\mathrm{cm}$ diameter tube at the opposite end of the chamber from the inflow.

During each experimental period, water samples $(\sim 10 \mathrm{~mL})$ were collected 3 times at equal intervals from the outflow of each chamber to determine particle counts and sizes using a Beckman-Coulter Multisizer ${ }^{\mathrm{TM}} 3$ Coulter Counter (Auckland, NZ). The machine was fitted with a $100 \mu \mathrm{m}$ aperture tube, which recorded all the particles in the size range between $2 \mu \mathrm{m}$ $-59 \mu \mathrm{m}$ (equivalent in spherical diameter) in $1 \mathrm{~mL}$ of the water sample.

Clearance rates (CR) for each organism at each time of sampling were calculated as the number of particles removed from the water per unit volume with reference to the number of particles in the control sample. Mean clearance rate per individual was calculated as:

$$
\mathrm{CR}=\left[\frac{C_{c}-C_{s}}{C_{c}}\right] * F R
$$

where $\mathrm{CR}$ is the clearance rate (in $\mathrm{L} \mathrm{h}^{-1}$ ), $C_{c}$ is the number of particles from the outflow of the control chamber, $C_{s}$ is the number of particles from the sample chamber and $F R$ is the flow rate (in $\mathrm{L} \mathrm{h}^{-1}$ ). Mean $\mathrm{CR}$ per organism per $24 \mathrm{~h}$ period was calculated and used for statistical analysis. At the end of each experimental period, the mussels were shucked, dried (at $60{ }^{\circ} \mathrm{C}$ for $\sim 24 \mathrm{~h}$ ) and dry body weights were measured to an accuracy of $0.1 \mathrm{mg}$. CR values were 
then standardised $\left(\mathrm{CR}_{\mathrm{s}}\right)$ to mass specific rates for organisms of $1 \mathrm{~g}$ dry body weight using the weight exponent:

$$
Y=a X^{b}
$$

where $Y$ is the physiological rate process, $X$ is the dry body weight (g) and $a$ and $b$ are fitted parameters as calculated in Gardner (2002), Helson and Gardner (2007) and Steger and Gardner (2007).

\subsubsection{Absorption efficiency (AE)}

During each $24 \mathrm{~h} \mathrm{CR}$ experiment, a subsample of faecal material was collected using a pipette from each of the 10 chambers containing a study animal. Faecal samples were filtered onto pre-ashed, pre-weighed Macherey-Nagel GF/C filters (Düren, Germany) and dried at $60^{\circ} \mathrm{C}$ for $24 \mathrm{~h}$. Filters plus faeces were weighed after drying to determine their dry weight and ashed at $450^{\circ} \mathrm{C}$ for $\approx 24 \mathrm{~h}$ to determine the weight loss on ignition.

$\mathrm{AE}$ was determined for each individual using the equation:

$$
\mathrm{AE}=(F-E) /[(1-E) * F]
$$

where $F$ is the ash-free dry weight to dry weight ratio of the seston supplied to the animal, and $E$ is the ash-free dry weight to dry weight ratio of the animal's faeces.

\subsubsection{Net Energy Budget (NEB)}

Individual net energy budget (NEB) values were calculated using parameters according to Widdows (1985) and Widdows and Johnson (1988) with the exception that ammonia excretion was not measured here because it represents only a small proportion of energy 
expenditure (c. $1-2 \%$ ). NEB represents the energy that is available for somatic and reproduction growth and was calculated as:

$$
\mathrm{NEB}=(C * \mathrm{AE})-R
$$

where $C$ is the total energy consumed, $R$ is the respiratory energy and AE is absorption efficiency. The calculation of $C$ and $R$ follows Widdows and Johnson (1988):

$$
\begin{gathered}
C=\mathrm{CR}_{\mathrm{s}}\left(\mathrm{lg}^{-1} \mathrm{~h}^{-1}\right) * \operatorname{POM}\left(\mathrm{mg} \mathrm{l}^{-1}\right) * 23\left(\mathrm{~J} \mathrm{ml}^{-1}\right) \\
R=\mathrm{VO}_{2 \mathrm{~s}}\left(\mathrm{ml} \mathrm{O}_{2} \mathrm{~g}^{-1} \mathrm{~h}^{-1}\right) * 20.33\left(\mathrm{~J} \mathrm{ml}^{-1} \mathrm{O}_{2}\right)
\end{gathered}
$$

Values of $\mathrm{VO}_{2 \mathrm{~s}}$ were used from previous published work (Helson and Gardner 2007, Steger and Gardner 2007). A positive NEB reflects energy available for growth whereas a negative NEB reflects a net energy loss.

\subsubsection{Particle size distributions}

The seawater samples collected from the outflow of each chamber containing an individual during the $\mathrm{CR}$ experiment were used to calculate the total number of particles consumed by each individual for a range of particle sizes. The Multisizer ${ }^{\mathrm{TM}}$ was used to measure the number of particles in a $1 \mathrm{ml}$ sample from $2 \mu \mathrm{m}$ to $59 \mu \mathrm{m}$. The particle size concentrations from the outflow of the chambers containing either a mussel or crab were subtracted from the control chamber.

\subsubsection{Statistical analysis}

For each of the above sections ANOVAs were performed for the factors: coast (between WH and CS), season (between summer and winter), species (between M. galloprovincialis, A. maoriana and P. elongatus) and particle size (between sizes from $2 \mu \mathrm{m}$ to $60 \mu \mathrm{m}$ ) with 
relevant interaction terms. Student's t- tests and Tukey's HSD were used to analyse significant post hoc differences. All data met the assumptions of normality, homoscedacticity and independence for ANOVA analysis.

\subsection{Results}

\subsubsection{Water column and seston characteristics}

Temperature, salinity and DO all differed significantly with season, with higher temperatures, higher salinity and lower DO in the summer compared with the winter (Table 5.1). The WH coast had a higher summer temperature, but lower winter temperature than the CS (Table $5.2)$.

Table 5.1 ANOVA results of temperature, salinity and dissolved oxygen. An asterisk denotes significant differences.

\begin{tabular}{llrrrr}
\hline & & df & \multicolumn{1}{c}{ F } & \multicolumn{1}{c}{$p$} & \\
\hline Temperature & Season & 1 & 1408.13 & $<0.001$ & $*$ \\
$\left({ }^{\circ} \mathrm{C}\right)$ & Coast & 1 & 4.64 & 0.034 & $*$ \\
& season x coast & 1 & 74.94 & $<0.001$ & $*$ \\
Salinity (PSU) & Season & 1 & 9.52 & 0.003 & $*$ \\
& Coast & 1 & 0.26 & 0.606 & \\
& season x coast & 1 & 0.65 & 0.420 & \\
DO $(\%)$ & Season & 1 & 128.80 & $<0.001$ & $*$ \\
& Coast & 1 & 4.76 & 0.032 & $*$ \\
& season x coast & 1 & 4.28 & 0.042 & $*$ \\
\hline
\end{tabular}


Table 5.2 Mean ( \pm SE) temperature $\left({ }^{\circ} \mathrm{C}\right)$, salinity (PSU) and dissolved oxygen $(\%)$ from the laboratory experiment in Wellington Harbour (WH) and Cook Strait (CS). Differing letters denote a significant difference within factor (Tukey's HSD).

\begin{tabular}{|c|c|c|c|c|}
\hline & Coast & Season & Mean & $\pm \mathrm{SE}$ \\
\hline \multirow[t]{4}{*}{$\begin{array}{l}\text { Temperature } \\
\left({ }^{\circ} \mathrm{C}\right)\end{array}$} & CS & Summer & 15.91 & $0.19 \mathrm{~A}$ \\
\hline & WH & Summer & 17.77 & $0.13 \mathrm{~B}$ \\
\hline & $\mathrm{CS}$ & Winter & 10.92 & $0.21 \mathrm{C}$ \\
\hline & WH & Winter & 9.80 & $0.12 \mathrm{~B}$ \\
\hline \multirow[t]{4}{*}{ Salinity (PSU) } & $\mathrm{CS}$ & Summer & 33.50 & $0.30 \mathrm{~A}$ \\
\hline & WH & Summer & 33.83 & $0.12 \mathrm{~B}$ \\
\hline & $\mathrm{CS}$ & Winter & 32.94 & $0.22 \mathrm{~A}$ \\
\hline & WH & Winter & 32.87 & $0.29 \mathrm{~A}$ \\
\hline \multirow[t]{4}{*}{ DO (\%) } & $\mathrm{CS}$ & Summer & 86.60 & $1.37 \mathrm{~A}$ \\
\hline & WH & Summer & 86.76 & $0.70 \mathrm{~A}$ \\
\hline & $\mathrm{CS}$ & Winter & 100.08 & $1.49 \mathrm{~B}$ \\
\hline & WH & Winter & 106.27 & $1.95 \mathrm{C}$ \\
\hline
\end{tabular}

All three measures of seston quantity and quality were generally higher in $\mathrm{WH}$ than in the CS (Table 5.3). POM and PCOM differed between seasons as well, with the summers having higher POM and PCOM than during the winter experiment. The POM in the CS was particularly low during the winter compared to the summer in the CS and both winter and summer in the WH (Table 5.4). 
Table 5.3 ANOVA of total particulate matter (TPM), particulate organic matter (POM) and percent organic matter (PCOM) by season (summer and winter), coast (Wellington Harbour and Cook Strait). An asterisk (*) denotes significance.

\begin{tabular}{lllrrl}
\hline & & df & \multicolumn{1}{c}{$\mathrm{F}$} & \multicolumn{1}{c}{$\mathrm{P}$} & \\
\hline TPM & Season & 1 & 0.002 & 0.96 & \\
& Coast & 1 & 4.75 & 0.03 & $*$ \\
& season x coast & 1 & 10.94 & 0.001 & $*$ \\
POM & Season & 1 & 9.19 & 0.003 & $*$ \\
& Coast & 1 & 61.23 & $<0.001$ & $*$ \\
& season x coast & 1 & 4.83 & 0.03 & $*$ \\
& Season & 1 & 12.11 & $<0.001$ & $*$ \\
& Coast & 1 & 26.14 & $<0.001$ & $*$ \\
& season x coast & 1 & 1.50 & 0.22 & \\
\hline
\end{tabular}

Table 5.4 Mean $( \pm \mathrm{SE})$ total particulate matter $(\mathrm{TPM})$, particulate organic matter $(\mathrm{POM})$ and percent organic matter (PCOM). Differing letters indicate significant differences within factor (Tukey's HSD).

\begin{tabular}{lllrrl}
\hline & Coast & Season & \multicolumn{1}{l}{ Mean } & \pm SE & \\
\hline TPM & CS & Summer & 18.04 & 0.71 & AB \\
$\left(\mathrm{mg} \mathrm{l}^{-1}\right)$ & CS & Winter & 22.80 & 0.83 & A \\
& WH & Summer & 26.05 & 2.65 & AB \\
& WH & Winter & 21.16 & 0.50 & B \\
POM & CS & Summer & 4.06 & 0.24 & A \\
$\left(\mathrm{mg} \mathrm{l}^{-1}\right)$ & CS & Winter & 3.85 & 0.27 & B \\
& WH & Summer & 6.60 & 0.28 & C \\
& WH & Winter & 5.27 & 0.20 & C \\
PCOM & CS & Summer & 22.86 & 1.49 & A \\
$(\%)$ & CS & Winter & 16.72 & 1.07 & B \\
& WH & Summer & 27.93 & 1.65 & C \\
& WH & Winter & 24.99 & 0.83 & AC \\
\hline
\end{tabular}




\subsubsection{Clearance rate}

Mean $\mathrm{CR}_{\mathrm{s}}$ differed significantly between coast and between species (Table 5.5). $\mathrm{CR}_{\mathrm{s}}$ values were higher in WH compared to the CS. The false crab (Petrolisthes elongatus) had the lowest $\mathrm{CR}_{\mathrm{s}}$ in both $\mathrm{WH}$ and CS, as well as across seasons (Table 5.6). During both seasons in the CS and the summer in WH, Mytilus galloprovincialis had a higher CR than Aulacomya maoriana.

Table 5.5 ANOVA table of size standardised clearance rates $\left(\mathrm{CR}_{\mathrm{S}}\right)$, absorption efficiency (AE) and net energy budget (NEB) by season (summer and winter), coast (Wellington Harbour and Cook Strait), and species (A. maoriana, M. galloprovincialis and P. elongatus). An asterisk (*) denotes significance.

\begin{tabular}{|c|c|c|c|c|c|c|}
\hline & & df & & & $\mathrm{p}$ & \\
\hline \multirow[t]{7}{*}{$\mathrm{CR}_{\mathrm{s}}$} & Season & & 1 & 0.02 & 0.63 & \\
\hline & Coast & & 1 & 30.08 & $<0.001$ & $*$ \\
\hline & Species & & 2 & 15.72 & $<0.001$ & $*$ \\
\hline & species $\mathrm{x}$ coast & & 2 & 12.41 & $<0.001$ & $*$ \\
\hline & coast $\mathrm{x}$ season & & 1 & 1.20 & 0.27 & \\
\hline & species x season & & 2 & 8.80 & $<0.001$ & $*$ \\
\hline & species $\mathrm{x}$ coast $\mathrm{x}$ season & & 2 & 5.18 & 0.006 & $*$ \\
\hline \multirow[t]{7}{*}{$\mathrm{AE}$} & Season & & 1 & 0.22 & 0.63 & $*$ \\
\hline & Coast & & 1 & 2.55 & 0.11 & \\
\hline & Species & & 2 & 9.19 & $<0.001$ & \\
\hline & species $\mathrm{x}$ coast & & 2 & 3.41 & 0.03 & $*$ \\
\hline & coast $\mathrm{x}$ season & & 1 & 15.28 & $<0.001$ & $*$ \\
\hline & species x season & & 2 & 10.80 & $<0.001$ & * \\
\hline & species $\mathrm{x}$ coast $\mathrm{x}$ season & & 2 & 0.71 & 0.48 & \\
\hline \multirow[t]{7}{*}{ NEB } & Season & & 1 & 11.01 & 0.001 & $*$ \\
\hline & Coast & & 1 & 0.056 & 0.81 & \\
\hline & Species & & 2 & 8.28 & $<0.001$ & $*$ \\
\hline & species $\mathrm{x}$ coast & & 2 & 4.71 & 0.009 & * \\
\hline & coast $x$ season & & 1 & 1.81 & 0.17 & \\
\hline & species $x$ season & & 2 & 6.08 & 0.003 & $*$ \\
\hline & species $\mathrm{x}$ coast $\mathrm{x}$ season & & 2 & 4.32 & 0.01 & $*$ \\
\hline
\end{tabular}


Table 5.6 Size standardised clearance rates $\left(\mathrm{CR}_{\mathrm{s}}\right)$, absorption efficiencies (AE) and net energy budget (NEB) (Mean \pm SE). Differing letters indicate significant differences within factor (Tukey's HSD).

\begin{tabular}{lllccccccccc}
\hline Season & Coast & Species & $\begin{array}{l}\mathrm{CR}_{\mathrm{s}} \\
\left(\mathrm{L} \mathrm{g}^{-1} \mathrm{~h}^{-1}\right)\end{array}$ & $\pm \mathrm{SE}$ & & $\mathrm{AE}$ & $\pm \mathrm{SE}$ & & $\begin{array}{c}\mathrm{NEB} \\
\left(\mathrm{J} \mathrm{g}^{-1} \mathrm{~h}^{-1}\right)\end{array}$ & $\pm \mathrm{SE}$ & \\
\hline Summer & CS & AM & 2.96 & 0.34 & $\mathrm{~A}$ & 0.80 & 0.05 & $\mathrm{~A}$ & 219.52 & 36.56 & $\mathrm{~A}$ \\
Summer & CS & MG & 5.84 & 0.54 & $\mathrm{~B}$ & 0.87 & 0.02 & $\mathrm{~A}$ & 466.27 & 45.90 & $\mathrm{~B}$ \\
Summer & CS & PE & 1.87 & 0.28 & $\mathrm{~A}$ & 0.21 & 0.12 & $\mathrm{~B}$ & 14.30 & 7.89 & $\mathrm{C}$ \\
Winter & CS & AM & 2.85 & 0.41 & $\mathrm{~A}$ & 0.44 & 0.07 & $\mathrm{~A}$ & 177.61 & 40.15 & $\mathrm{~A}$ \\
Winter & CS & MG & 5.15 & 0.64 & $\mathrm{~B}$ & 0.19 & 0.14 & $\mathrm{~A}$ & 90.58 & 85.75 & $\mathrm{~A}$ \\
Winter & CS & PE & 2.31 & 0.33 & $\mathrm{~A}$ & -0.12 & 0.22 & $\mathrm{~A}$ & -58.57 & 82.66 & $\mathrm{~A}$ \\
Summer & WH & AM & 5.83 & 0.74 & $\mathrm{AB}$ & 0.63 & 0.07 & $\mathrm{~A}$ & 386.06 & 102.30 & $\mathrm{~A}$ \\
Summer & WH & MG & 7.18 & 1.26 & $\mathrm{~A}$ & 0.24 & 0.09 & $\mathrm{~A}$ & 104.96 & 155.40 & $\mathrm{~A}$ \\
Summer & WH & PE & 3.39 & 0.37 & $\mathrm{~B}$ & 0.12 & 0.28 & $\mathrm{~A}$ & 20.84 & 71.22 & $\mathrm{~A}$ \\
Winter & WH & AM & 5.21 & 0.70 & $\mathrm{AB}$ & 0.80 & 0.08 & $\mathrm{~A}$ & 585.38 & 107.44 & $\mathrm{~A}$ \\
Winter & WH & MG & 7.86 & 0.37 & $\mathrm{~A}$ & 0.22 & 0.18 & $\mathrm{~A}$ & 92.70 & 80.57 & $\mathrm{~B}$ \\
Winter & WH & PE & 4.75 & 0.33 & $\mathrm{~B}$ & 0.79 & 0.07 & $\mathrm{~B}$ & 413.54 & 62.08 & $\mathrm{C}$ \\
\hline
\end{tabular}

\subsubsection{Absorption efficiency}

Of all the mean AE observations, there was only one negative mean observation for $P$.

elongatus in the CS winter (Table 5.6). Of the 80 observations for each species, 5 were negative for A. maoriana, 16 were negative for $M$. galloprovincialis and 25 were negative for P. elongatus (Table 5.7). There were more negative AE values in the CS winter for all species compared with the other coasts and other seasons, with the exception of $M$. galloprovincialis which had an equal number of negative AE values in both the CS winter and WH summer. The highest AE occurred in the CS summer and the WH winter. Across both seasons and coasts, A. maoriana had the highest AE, while $M$. galloprovincialis and $P$. elongatus were significantly lower (Table 5.5). 
Table 5.7 Percentage (\%) of individuals who had a negative absorption efficiency (-AE) and negative net energy budget (-NEB).

\begin{tabular}{lllrr}
\hline & & & $\begin{array}{c}\text { AE } \\
(\%)\end{array}$ & $\begin{array}{r}\text {-NEB } \\
(\%)\end{array}$ \\
\hline CS & Summer & AM & 5 & 5 \\
CS & Summer & MG & 0 & 0 \\
CS & Summer & PE & 35 & 40 \\
CS & Winter & AM & 10 & 10 \\
CS & Winter & MG & 30 & 35 \\
CS & Winter & PE & 50 & 45 \\
\hline WH & Summer & AM & 5 & 5 \\
WH & Summer & MG & 30 & 30 \\
WH & Summer & PE & 35 & 30 \\
\hline WH & Winter & AM & 5 & 5 \\
WH & Winter & MG & 20 & 20 \\
WH & Winter & PE & 5 & 5 \\
\hline
\end{tabular}

\subsubsection{Net Energy Budget}

All mean values for NEB were positive across both seasons and coasts for each species, with or exception of one negative NEB for P. elongatus in the CS winter. This was associated with the mean negative AE for the crab. Of the 80 observations for each species, 5 were negative for A. maoriana, 17 were negative for M. galloprovincialis and 24 were negative for $P$. elongatus (Table 5.7). There were more negative NEB values in the CS winter for all 3 species. The NEB of all the species differed between coasts with higher values in WH compared to the CS (Table 5.5). Both $M$. galloprovincialis and P. elongatus had significantly lower NEB values than A. maoriana.

\subsubsection{Particle size concentration}

Most particles cleared by all 3 species were between $2 \mu \mathrm{m}$ and $7 \mu \mathrm{m}$ in size (equivalent spherical diameter). The greatest number of particles consumed was at $2 \mu \mathrm{m}$ and decreased 
for all species compared to the control (Figure 5.1). In the WH winter and CS summer, $P$. elongatus consumed greater numbers of particles at sizes between $8 \mu \mathrm{m}$ and $14 \mu \mathrm{m}$ than the two mussel species (Figure 5.2). In general, P. elongatus consumed fewer particles than either mussel species (Table 5.8), but at the larger particle size range (15 $\mu \mathrm{m}-59 \mu \mathrm{m})$ they consumed significantly more than the mussels (Figure 5.3).

In general, there were fewer particles available for organisms to feed on in the winter seasons and consequently all three species consumed less in the winter (Table 5.8). The two mussel species consumed higher numbers of smaller particles $(2 \mu \mathrm{m}$ to $7 \mu \mathrm{m})$ than the false crab in the WH winter, but in the CS winter they consumed less of the smaller particles. 


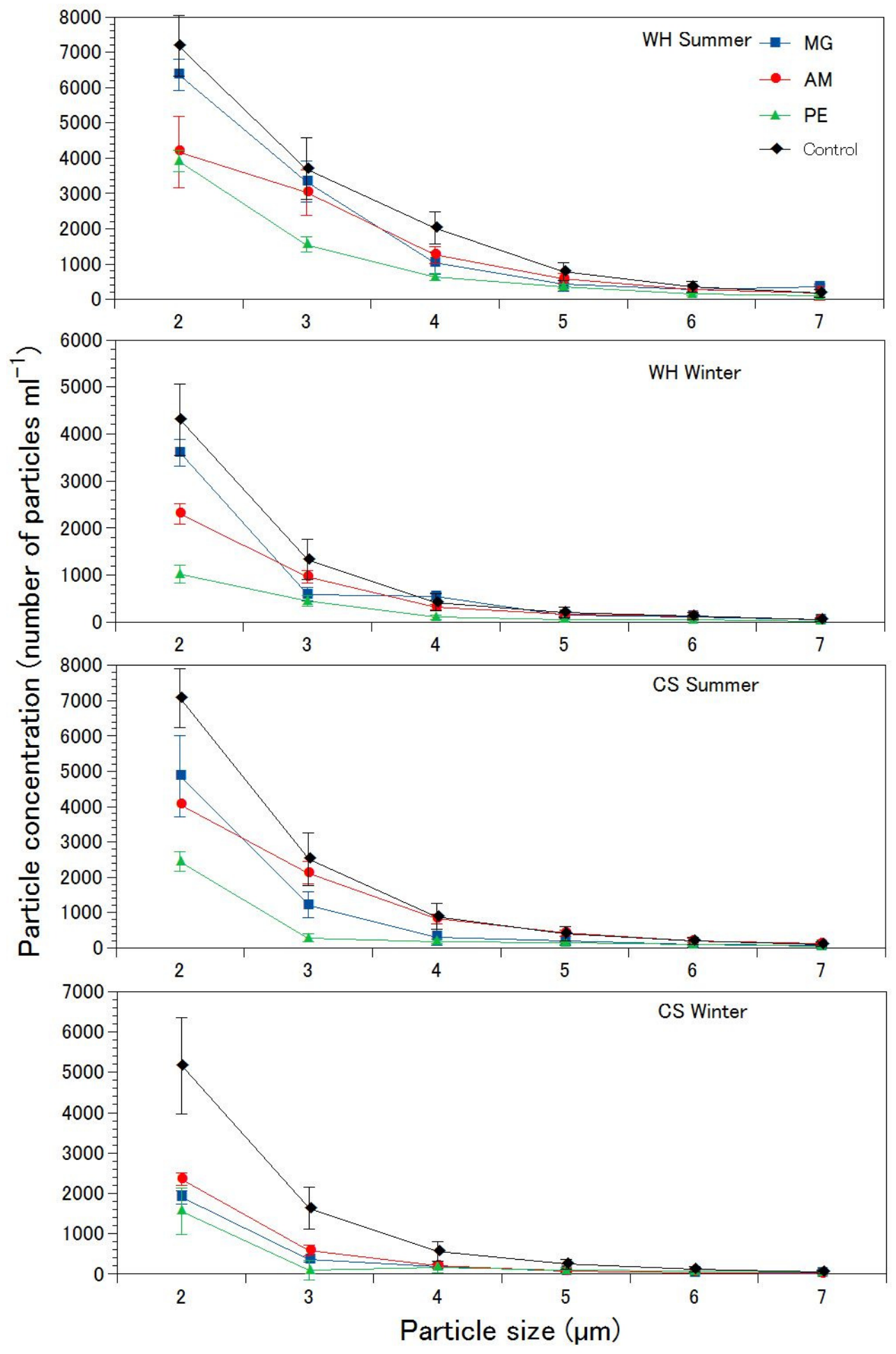

Figure 5.1. Concentration of particles consumed (mean $\pm \mathrm{SE}$ ) in the size range of $2 \mu \mathrm{m}$ to 7 $\mu \mathrm{m}$ spherical diameter for Mytilus galloprovincialis (MG), Aulacomya maoriana (AM) andPetrolisthes elongatus (PE) compared to the control $(\mathrm{n}=240)$. 

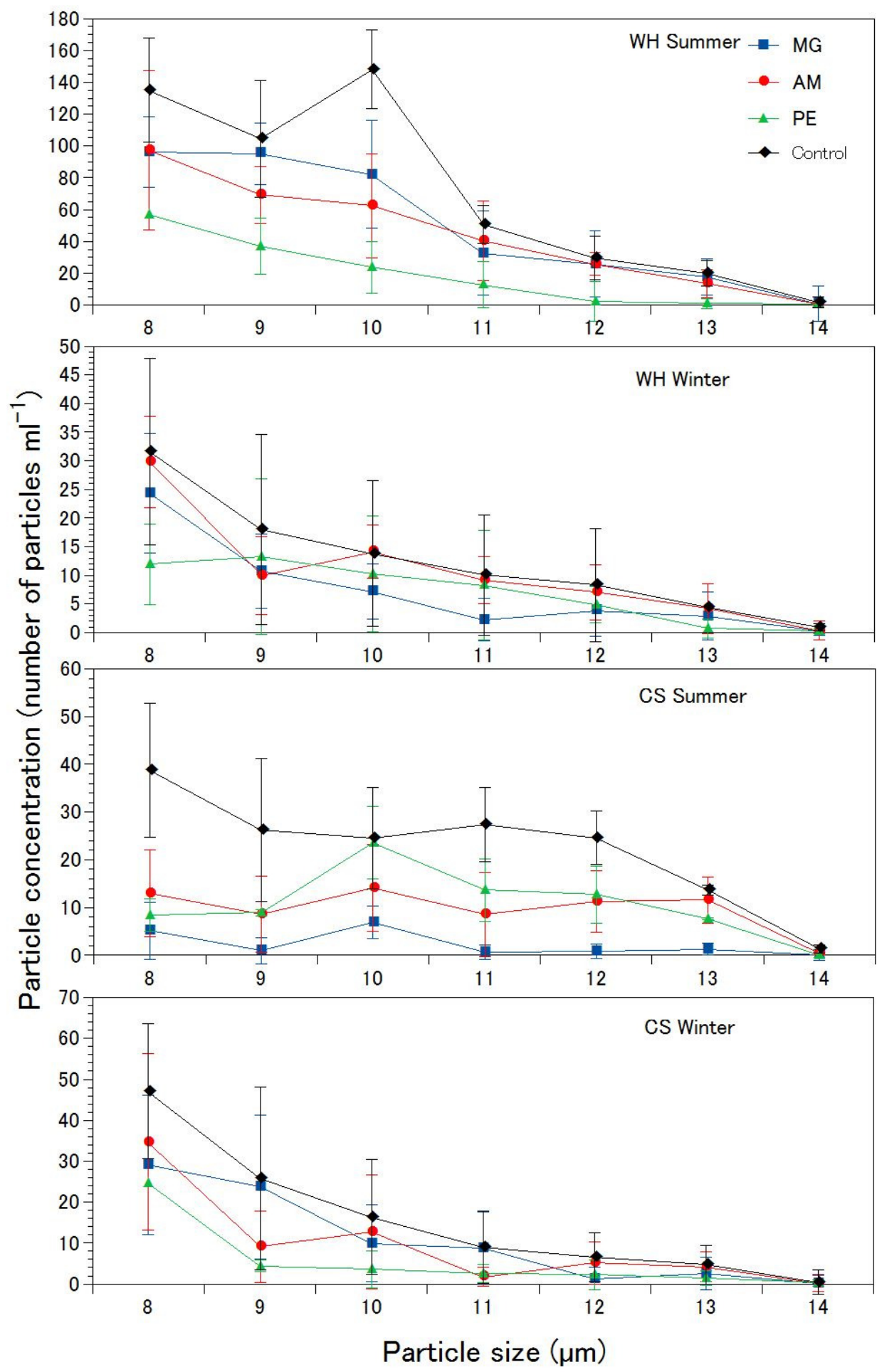

Figure 5.2 Concentration of particles consumed (mean \pm SE) in the size range of $8 \mu \mathrm{m}$ to 14 $\mu \mathrm{m}$ spherical diameter for Mytilus galloprovincialis (MG), Aulacomya maoriana (AM) and Petrolisthes elongatus (PE) compared to the control $(\mathrm{n}=240)$. 


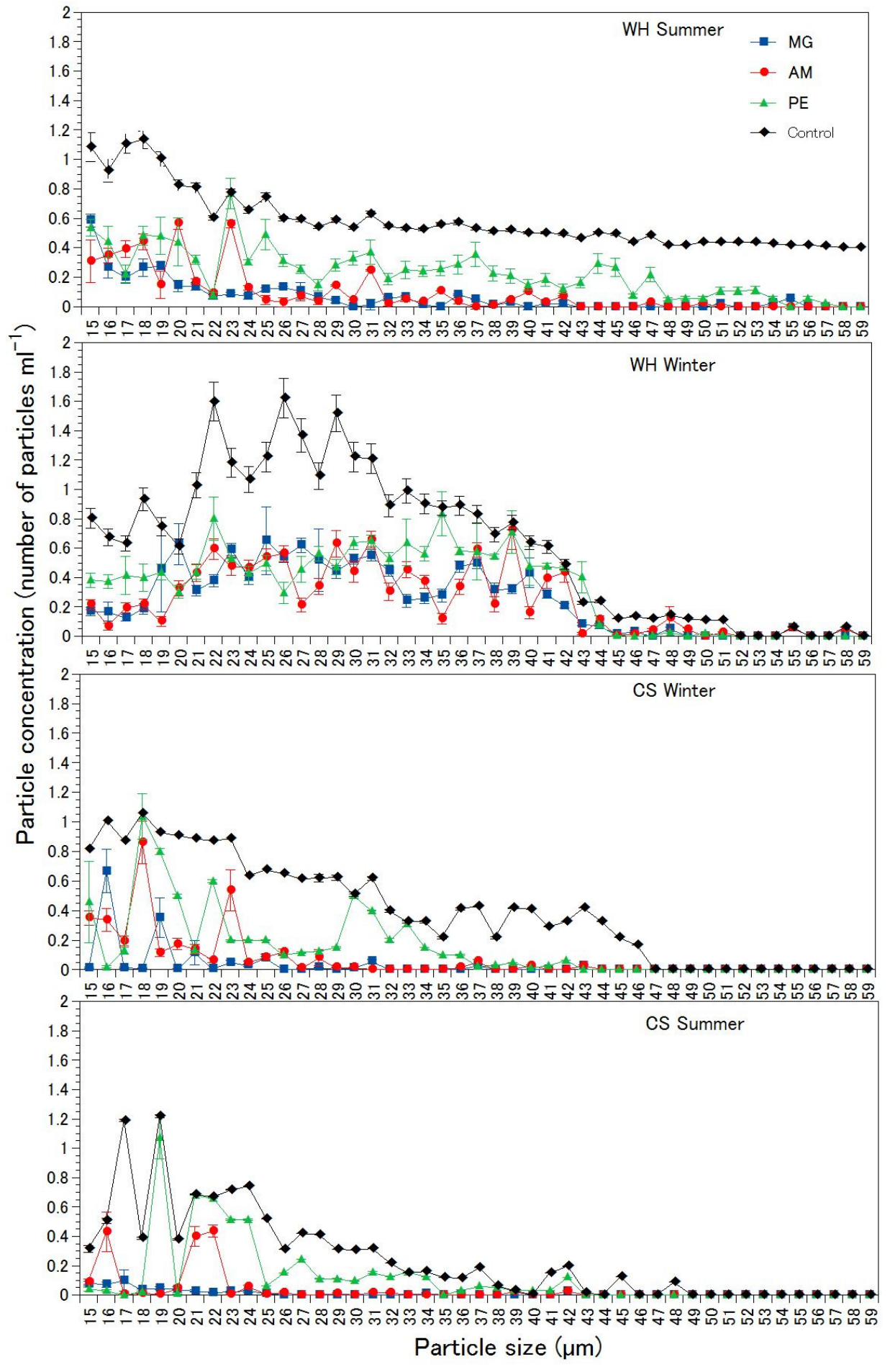

Figure 5.3 Concentration of particles consumed (mean \pm SE) in the size range of $15 \mu \mathrm{m}$ to 59 $\mu \mathrm{m}$ spherical diameter for Mytilus galloprovincialis (MG), Aulacomya maoriana (AM) and Petrolisthes elongatus (PE) compared to the control $(\mathrm{n}=240)$. 


\subsection{Discussion}

\subsubsection{Clearance rates}

Size standardised clearance rates $\left(\mathrm{CR}_{\mathrm{s}}\right)$ of all three species were generally lower when individuals were exposed to CS compared to $\mathrm{WH}$ water, which was consistent with previous studies by Gardner (2002) and Helson and Gardner (2007). The CR advantage for $M$. galloprovincialis could be the result of an increased gill (feeding) surface area per unit body mass, a more efficient gill particle filtering mechanism or an inherently greater CR compared with the other two species (Gardner 2002). In these studies, the variation in mussel $\mathrm{CR}_{\mathrm{S}}$ was explained by the amount of particulate organic matter (POM) in the water column. This association was also found for the false crabs, which have increasing $\mathrm{CR}_{\mathrm{s}}$ with greater POM to a maximum of $70 \mathrm{mg}^{-1}$ (Steger and Gardner 2007). Other studies on mussel CR have reported varying responses to the amount of POM in the water indicating a negative relationship of CR to POM in the tropical mussel Perna viridis (Hawkins et al. 1998), while filtration rates of the cold, temperate mussel Mytilus edulis were positive as a function of increasing POM (Bayne et al. 1993). These varying results indicate a high degree of plasticity among differing mussel species based on feeding physiology. In the current study, $\mathrm{CR}_{\mathrm{s}}$ of all species were greater in $\mathrm{WH}$, where higher POM values were observed. This response is consistent with organisms whose feeding mechanisms are not being overwhelmed by particles (Steger and Gardner 2007).

\subsubsection{Absorption efficiency and net energy budget}

On average, A. maoriana had higher AE and NEB than $M$. galloprovincialis and $P$. elongatus. This is consistent with work by Helson et al. (2007), who found that of the 3 intertidal mussel species found in WH (Perna canaliculus, A. maoriana and M. 
galloprovincialis). A. maoriana survived the longest when held over a long period of time in CS (unfiltered) waters under laboratory conditions. A. maoriana survived for up to 12 months while $M$. galloprovincialis survived for 8 months and $P$. canaliculus survived for 6 months. In the field, however, M. galloprovincialis had a higher survival rate in CS coastal conditions and A. maoriana had a higher mortality under exposed conditions (see Chapter 3 ). Thus, while A. maoriana has higher AE and NEB values than other mussels (see Chapter 5), Chapter 3 results indicate they may be inhibited to some degree by physical factors such as wave-exposure.

Negative AE and NEBs are indicative of food limitation in filter feeders, where the energy expenditure is greater than the energy acquisition. While the mean values of AE and NEB for almost all species in both seasons and coasts were positive, there were several individuals who had negative AE and NEB estimates (Table 5.7). During the CS winter, AE and NEBs were lowest for each species and had the highest percentage of negative AE and NEB values, indicating that food was limiting along that coast during the winter months. Due to the short duration of the experiment, higher AE and NEBs were observed in the CS winter than expected. Had the experiment been prolonged over several months, there is an indication that the low POM observed in CS waters over the winter months (see Chapter 2) would result in a mean negative $\mathrm{AE}$ and NEB for all 3 species.

\subsubsection{Body size and metabolic rates}

The organism size also appears to have an impact on AE and NEBs in CS water column conditions. Experiments by Gardner (2002) and Helson et al. (2007) found that mussels with larger adult body sizes tended to have a higher rate of mortality when exposed to unfiltered seawater from the CS. Mussels with the largest adult body size (Perna canaliculus) had lower $\mathrm{CR}_{\mathrm{s}}$ and condition index values than both A. maoriana and M. galloprovincialis (James et al. 
2001). These results suggest body size may be an important factor in the survival of filter feeders in the CS, and can partially explain how smaller organisms such as barnacles (Chamaesipho columa, Chamaesipho brunnea), the black mussel (Limnoperna pulex), and $P$. elongatus are able to survive along the CS shores.

\subsubsection{Feeding habits}

Although A. maoriana, M. galloprovincialis and P. elongatus are all filter feeders, there are several differences in how they feed. Mussels possess a variety of ways to deal with particle size diversity in the seston: a) differential clearance due to a selective retention at the level of the gills, b) pre-ingestive selection on the gills and at the palps associated with the process of pseudofaeces formation and c) selective digestion or differential utilisation of ingested particles within the gut (Shumway et al. 1985, Rouillon and Navarro 2003). False crabs, however, can change between active feeding (where they use their modified maxillipeds to pump water past their feeding structures) and passive feeding (relying on ambient currents for delivery of food particles) depending on flow rates and the availability of particles (Trager and Genin 1993, Achituv and Pedrotti 1999, Yaikin et al. 2002). During slow flow rates $\left(0.267 \mathrm{~L} \mathrm{crab}^{-1} \mathrm{~h}^{-1}\right)$ and low to moderate particle availability $\left(0-1000 \mathrm{mg} \mathrm{L}^{-1}\right)$, false crabs will actively feed at a significantly higher $\mathrm{CR}_{\mathrm{s}}$ (Achituv and Pedrotti 1999, Steger and Gardner 2007). Thus, false crabs have a slight advantage over mussels during times of low food availability as they can more than double their $\mathrm{CR}_{\mathrm{s}}$ during active feeding.

This study highlights the differences in the particle sizes that are ingested by both mussels and false crabs. While all 3 study species consumed large numbers of smaller particles (between $2-14 \mu \mathrm{m}$ spherical diameter), the false crabs were able to ingest a higher number of larger particles $(15-59 \mu \mathrm{m}$ spherical diameter). Other studies have found that $P$. elongatus consume small amounts of macroalgae in addition to the brown and green 
phytoplankton that made up most of their diet (Johnston and Freeman 2005). Other false crab species, such as Petrolisthes eriomerus, have been observed using their chelipeds to chop pieces of macroalgae for consumption (Kropp 1981). Although the volume of food particles ingested by P. elongatus may be lower than that of A. maoriana and M. galloprovincialis, their diet may be more variable and it is possible for them to supplement a low quality or quantity diet with larger macroalgal particles. This may help to explain how P. elongatus can survive on the CS shores and mussels are mostly absent from WH.

\subsubsection{Seasonality of low food quantity}

Food limitation has been suggested as the main reason for the near absence of mussels in the CS, with WH having large inputs of high nutrient freshwater from the Hutt River (Gardner and Thompson 2001b, Gardner 2002, Helson et al. 2007). It is thought that waters in WH are much more productive than the CS. Studies from North America and Europe have suggested the congener Mytilus edulis can survive over many months $(4-6)$ under negative NEB conditions on stored energy reserves (Bayne and Widdows 1978, Aunaas 1982, Scrosati and Eckersley 2007), and it is likely that this is due to lower metabolic demands at colder temperatures. In the southern North Island of New Zealand, ambient air temperatures rarely go below freezing and M. galloprovincialis is distributed along warmer coastlines (Hoffman and Somero 1996, Feder and Hofmann 1999). The higher metabolic demands associated with milder winters in places such as the North Island of New Zealand compared with some other temperate regions that go below freezing suggests that adult mussels could starve in winter months along the CS when food availability is low.

In this study (and the other chapters in this thesis), it is apparent that POM in the winter months in the CS is much lower than any other time of the year. Water column data from 2009-2011 also indicate that during the winter months water in the CS has very low 
concentrations of chlorophyll $a$ (see Chapter 3). This and other studies (Helson and Gardner 2004, 2007, Helson et al. 2007) have indicated that the near absence of mussels from the CS shores may be the result of long periods of starvation. While it has yet to be determined if this is a press (oscillating periods of starvation) or a pulse (one long period of starvation) disturbance, the absence of multispecies populations of post-recruitment sized mussels on CS shores indicates that the particular species of mussel that live in $\mathrm{WH}$ cannot recover from several winters deficient in POM.

\subsubsection{Limitation at early life stages}

It has been suggested that the low number of mussels from the CS could also be the result of a) larvae that are choosing not to settle at these sites and b) post-settlement mortality due to top-down regulation of community structure (i.e. predation) (Helson and Gardner 2007). It is unlikely that mussels are actively choosing to not settle on the shore as there is ample sheltered space that supports other temperate filter-feeding invertebrates, such as larger barnacles (Calantica spinosa and Epopella plicata), smaller barnacles (Chamaesipho columna and C. brunnea) and tube worms (Families Serpulidae and Spirorbidae) that can settle and survive on the CS shore. Unlike other studies on intertidal shores with low abundances of mussels, the CS shoreline does not appear to be top-down regulated (Menge et al. 1994, 1999, Hunt and Scheibling 2001b, Bertness et al. 2004). There is a low abundance of key mussel predators such as whelks, carnivorous crabs and echinoderms at CS sites, which suggests that predation rates in the intertidal region are low compared with $\mathrm{WH}$ and consequently, mussels do not seem to be restricted in their distribution by predation (Helson and Gardner 2004).

It is possible that mussels at either the larval or juvenile stages are being limited by food availability. There are fewer mussel larvae and juveniles in the CS throughout the year 
compared with WH (Helson and Gardner 2004, Demello and Phillips 2011). However, recruitment limitation is unlikely to entirely explain the low numbers of mussels at CS sites because there are mussel larvae present in the water column. Previous studies on food limitation in mussels at early life stages indicate that both low food quality and quantity negatively affect larval growth and juvenile survival (Phillips 2002, 2004). When food concentrations were low during the early larval stages in mussels, they had a lower survival and slower growth than mussels who switched from high food concentrations to low food concentrations (Phillips 2004). In the false crab, Petrolisthes laevigatus, exposure to lower food quantity throughout its early development stages did not affect its survival (Gebauer et al. 2010). Thus, false crab larvae may not be as susceptible to starvation as mussels in the CS waters.

\subsection{Conclusions}

This study indicates that the false crab (P. elongatus) can survive on CS shores due to the smaller body size and its ability to consume larger particle sizes and incorporate macroalgae into its diet. Although both mussel and false crab species did have a lower AE and NEB in the CS winter, it is likely that crabs are either able to withstand longer periods of low food quantity or supplement their diets with larger food particles. Further research is necessary to identify why exactly they are able to successfully survive in the CS.

Comparisons of larval survivorship between filter feeder species that live in the CS and that are limited to WH would be useful in understanding the role of food limitation on CS community composition. It is uncommon for depauperate shorelines to be bottom-up driven, but it is likely that food limitation is controlling the low abundances of mussels on the CS at early life stages. This work emphasises that bottom-up driven coastlines can be very different in community composition and that there are tight links between nearshore 
oceanography and the feeding ecology of intertidal filter feeders at small spatial scales $(<10$ $\mathrm{km})$. 


\section{Chapter 6. Intertidal community structure between the Cook Strait and Wellington Harbour}

Typical temperate rocky shores are often composed of similar groups of species that occur in vertical bands across the intertidal (Stephenson and Stephenson 1949). Wellington Harbour fits this 'universal' pattern of intertidal zonation (Figure 6.1) with the upper zone dominated by littorinid snails (Austrolittorina antipodum and A. cincta) followed by the acorn barnacle (Chamaesipho columna) and a dense multispecies mussel bed (Aulacomya maoriana, Mytilus galloprovincialis and Perna canaliculus) in the mid zone and finally macroalgae in the low zone.

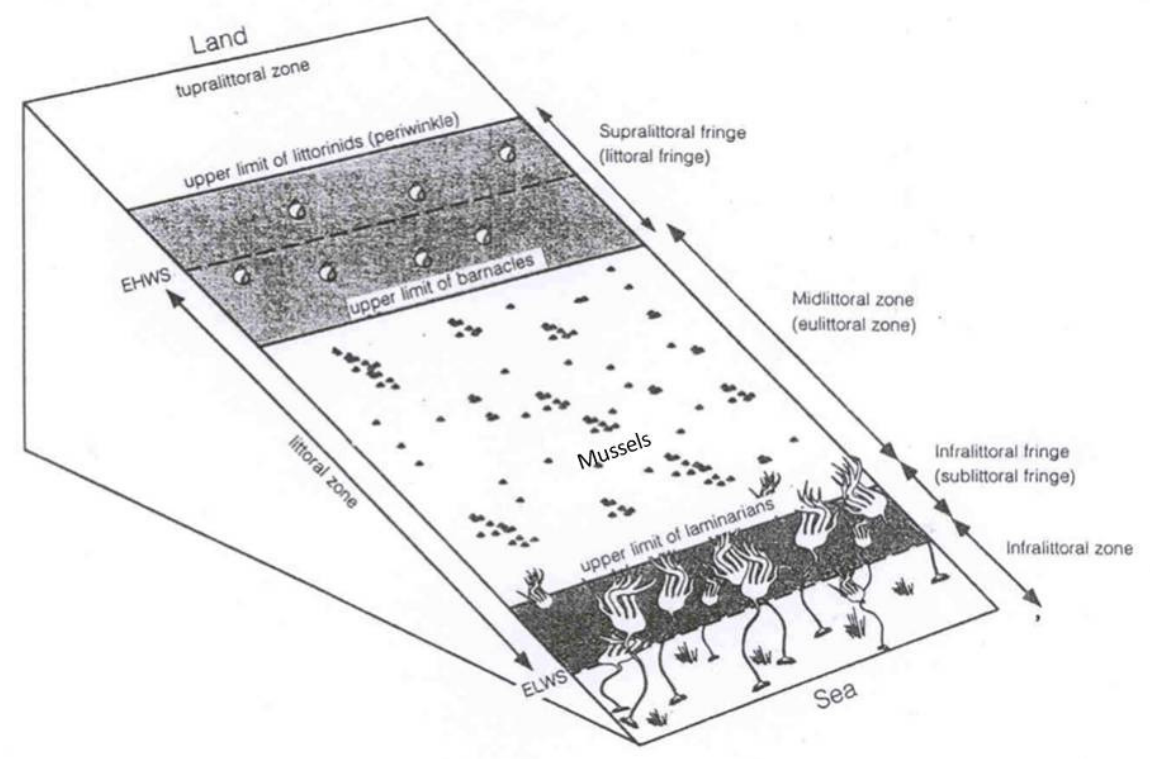

Figure 6.1. Generalised pattern of zonation on a rocky temperate shore. EHWS - extreme high water springs (highest level of high tide); ELWS - extreme low water springs (lowest level of low tide). Modified from Stephenson and Stephenson (1949). 
Cook Strait (CS) which separates the North and South Islands of New Zealand has a coastline that does not fit this pattern as it has low abundances of filter feeders and only the presence of a few individual mussels ( 1 per km, pers obs.) from the mid intertidal zone. It is unclear as to why these two shores are so different. Factors causing such a difference in community composition, such as wave exposure and nutrients have previously not been examined. Prior studies have determined that it is likely that changes in food availability are causing the differences in community composition (Gardner 2000, 2002, Gardner and Thompson 2001b, Helson and Gardner 2007, Helson et al. 2007).

This thesis aimed to determine how the two shores are different in community composition and to determine what environmental factors are causing these differences. Wave-exposure was excluded as a factor limiting mussels from the CS shore through a manipulative field experiment, and the diet composition of filter feeders from the WH and CS shores was determined through stable isotope analysis. Finally, a feeding experiment examined the size preference of food particles for mussels and a filter feeding crab. Seasonality was also examined in all chapters of this thesis.

\subsection{Chapter synopsis}

Chapter 2: This study quantified, to species level, the community composition of the midintertidal zone where mussels are known to be mostly absent from the CS and present in WH. Species percent cover, diversity, richness and evenness were sampled on a seasonal basis from 12 sites ( 8 sites in the CS and 4 sites in WH) over 2 years. Environmental variables (nitrite, nitrate, ammonia, phosphate, silicate, seston quality, chl a, turbidity, particle counts, temperature, salinity and dissolved oxygen) were also analysed on a seasonal basis at 8 sites (4 in the CS and 4 in $\mathrm{WH}$ ) to determine if there is a link between environmental variables and the observed patterns in community composition. Sea surface temperature, chl a, $\mathrm{NO}_{3}$, percent organic matter (PCOM) and particulate organic matter (POM) explained $41 \%$ of the 
differences in the multivariate community dataset. This study found that variation in POM and chl $a$ explain variation in the community composition at either shore.

Chapter 3: A transplant experiment was performed to examine the role of wave exposure explaining the low numbers of adult mussels from the Cook Strait shores. Both species of mussels were transplanted to sheltered and wave-exposed habitats at each coast (Cook Strait and Wellington Harbour). Survival, growth and condition index differed more between coasts than between wave exposure levels, with mussels transplanted to Wellington Harbour having greater growth and condition index values than those on the Cook Strait. Both species of mussel transplanted to the Cook Strait were alive at the end of the 14 month experiment, showing that mussels were able to survive for over a year at this site. This indicates that adult mussels can survive for over a year, but may not be able to survive multiple years of winter starvation in the Cook Strait or that seasonal food limitation may negatively impact mussels at a different life stage (larval, juvenile or young recruits).

Chapter 4: This study used stable carbon and nitrogen isotopes to determine if there is a difference in the diet of filter feeders that exist on both coasts as well as any seasonal differences in diet between summer and winter. Filter feeder isotopic signatures were more variable in the summer months indicating a wider range of food source availability. Low POM concentrations indicated that there is a lower food concentration in the water column along the CS coast in the winter months. IsoSource models showed that filter-feeder species in the CS may be heavily reliant on micoralgal food sources, and may go through periods of starvation during the winter season. This study reveals that the seasonal shifts in food availability may be what are causing the difference in community composition along the $\mathrm{WH}$ and CS shores. 
Chapter 5: This study aimed to examine the feeding habits of two species of mussel (Aulacomya maoriana and M. galloprovincialis) present in WH and a species of filter feeding crab (Petrolisthes elongatus) that lives on both the CS and WH shores year round. Through feeding experiments conducted in both the CS and WH as well as seasonally it was found that mussels and crabs had lower size standardised clearance rates $\left(\mathrm{CR}_{\mathrm{s}}\right)$ in the $\mathrm{CS}$ in both summer and winter. Absorption efficiencies (AE) and net energy budget (NEB) estimates were lowest during the winter months in the CS for all three species. M. galloprovincialis had lower $\mathrm{CR}_{\mathrm{s}}$ than $A$. maoriana and $P$. elongatus indicating that it likely has more efficient digestive mechanisms. A. maoriana had higher AE and NEB than both M. galloprovincialis and $P$. elongatus indicating higher absorption and energy storage, which is consistent with the length of time that it is able to survive in CS waters. $P$. elongatus consumed significantly fewer small particles $(2-14 \mu \mathrm{m})$ from the water column compared with the mussel species, but did consume significantly more large particles $(15-59 \mu \mathrm{m})$ showing a larger variation in size of the food particles that it is able to consume. This may be an indication of why $P$. elongatus is able to survive on the CS shores as it is able to supplement its diet with larger macroalgal particles during times of low phytoplankton availability.

\subsection{Changes in the intertidal zone of the Taputeranga Marine Reserve}

As three of the 12 sites examined in this study (see Chapter 2) were found within the newly formed (August 2008) Taputeranga Marine Reserve (TMR), this study was an opportunity to monitor any yearly changes in the intertidal zone during the first two years of the marine reserve. The information from this study would also be useful as a baseline for any intertidal monitoring implemented in the future. Other marine reserves in New Zealand and in the USA, have had negative effects on intertidal species. Often the attraction from tourism to marine reserves results in significant trampling of intertidal species. In California, Smith et al. (2008) found that no-take marine reserves did not protect mussel beds and associated species. 
They found that within marine reserves in areas of high use (high levels of human visitation) mussel populations were significantly smaller than those in low use. In the northeast of the North Island of New Zealand and on the eastern coast of the South Island of New Zealand, trampling during peak tourist months negatively affected algal beds and the invertebrate community within them (Brown and Taylor 1999, Schiel and Taylor 1999). In the TMR, however, no changes were observed in the intertidal zone compared to any sites outside the TMR along the CS. This contrasting result is likely due to the lack of visitors walking in the intertidal zone. The jagged shores along the CS are difficult to maneuver on or are slippery, making it unsuitable for the average visitor to trample. There are also fewer species on shore that are desirable for recreational fishermen to collect. While mussels (particularly Perna canaliculus) are regularly collected from the WH coast (MPI 2011), there are very few of these mussels on the CS coast. The lack of desirable species for personal consumption in the intertidal zone on the CS means that fewer people will detrimentally disturb the coastline along the CS. Thus the effects of human impacts on intertidal species are considered to be lower in the TMR than other marine reserves.

Other human impacts on the TMR may be the result of increased nutrient input into the CS. Currently, the nutrient concentration in both the CS and WH are relatively low compared to other temperate shores. Menge et al. (1997) found that nitrate and phosphate levels along the Oregon coast (USA) were 20 and 5 times greater, respectively, than the same nutrients found in this study along the CS coast. An increase in these nutrients into the water in the CS would likely have a substantial impact on community composition. In 2003, a small patch of multispecies mussels was found surrounding a storm drain in Lyall Bay along the CS coast. This was likely due to increased nutrient input and a localised increase in the amount of organic matter available to the mussels within the storm drain (Wightman 2003). Rogers (2003) found mussels (M. galloprovincialis) in a sewage outfall in Moa Point along the CS. 
Since the closure of the outfall in 1999, the population of mussels sampled at Moa Point is no longer there. Thus, there is some indication that a large input of nutrients and organic matter may result in large changes, not only in the intertidal zone of the TMR, but along the entire CS coastline. As a result, intertidal monitoring of invertebrate species (particularly if mussels are present) may be a good indicator of increased nutrient or particulate organic matter concentrations in the water column.

\subsection{Evidence of bottom-up limitation}

In typical temperate regions, bottom-up control of benthic intertidal communities is common in upwelling regions where nutrients are brought up to the surface waters from the bottom layers of the water column and, in turn, allow for an increase in plant biomass (micro and macroalgae). The term "bottom-up" can also include sessile filter-feeder species because, like phytoplankton and macrophytes, they receive their raw materials for growth and reproduction from the water column (Menge et al. 1999, Blanchette et al. 2009). Sessile filter feeders are also an important link between food in the water column and higher trophic levels on shore. Temperate intertidal systems that are top-down regulated comprise of communities with higher grazing and predation pressure. Often on rocky shores with low sessile filter feeder abundances, predation is the controlling factor. In the case of mussels, whelks and seastars are often the main predators in reducing their abundances (Menge et al. 1994, 1999, Hunt and Scheibling 1998, Bertness et al. 2004). On the South Island of New Zealand, Menge et al. (1999) found that the West Coast was an area of high upwelling, characterised by lower abundances of mussels, higher rates of mussel growth on shore and higher numbers of seastars . On the other hand, the East Coast had greater abundances of mussels, but lower growth rates and fewer seastars. They concluded that the intertidal zone on the west coast was top-down controlled (through predation), while the east coast shore that was dominated by mussels was bottom-up limited (regulated by nutrients in the water column). Similar results 
have been published in other studies (Menge et al. 1994, 1997, Dahlhoff and Menge 1996).

Contrastingly, this thesis shows that a near absence of mussels in the intertidal zone can be the result of bottom-up limitation.

In Chapter 2 of this thesis, low levels of particulate organic matter and chlorophyll $a$ were found during the winter season along the CS compared to WH. Similar results were found in Chapters 3, 4 and 5. The lower levels of particulate food in the water column during the winter months in the CS indicate that mussels likely starve before they are able to settle on shore. The absence of smaller blue mussels (even on a seasonal basis) in the mid-intertidal zone indicates that they do not reach the CS shore at the settlement stage. Low numbers of mussel recruits observed by Demello and Phillips (2011) also confirm that mussels do not settle in any significant numbers on shore even though mussel larvae are found in the water column (Helson and Gardner 2004). Low numbers of predatory species in the CS along with cause of mortality evidence from a field transplant in the CS (Chapter 3 ) indicate that there is a low level of predation, making top-down regulation of mussels on the CS shore unlikely. Thus, this thesis indicates that bottom-up regulation on rocky intertidal shores can manifest itself as more than one type of community composition (McQuaid and Lindsay 2007, Menge et al. 2009). The absence of multi-species mussel populations on shore is not always topdown driven, but in fact, can be regulated by low levels of food in the water column.

\subsection{Seasonal food limitation}

Seasonal food production in the water column is known to impact many marine species. Spring algal blooms coincide with spawning in fish and invertebrate species to support larval growth (Coma and Ribes 2003, Platt et al. 2003). Studies on invertebrate species indicate that early life stage starvation significantly reduces survival rates to adulthood (Gosselin and Qian 1997, Phillips 2004, Moran and Manahan 2004, Gebauer et al. 2010). Other studies have indicated that prolonged starvation of mussels over several months can lead to mortality in 
adult mussels (Gardner 2000, 2002, Gardner and Thompson 2001b, Helson and Gardner 2007, Helson et al. 2007). Decreases in the amount of food in the water column during the winter months are likely the cause of the lack of filter feeders (particularly bivalves) in the CS.

In this thesis, there were several indications that the lack of food during the winter months had a negative impact on mussel species when held in CS waters. In Chapter 3, mussels (A. maoriana and M. galloprovincialis) that were held in CS water experienced a decrease in condition index during the winter months. Diet composition constructed using the IsoSource model (in Chapter 4) indicated that mussels may not be able to cope with the dietary shift necessary to survive through CS winters. Through feeding experiments (Chapter 5), mussels were found to require more small (phytoplankton sized) particles than were filter feeding crabs. This, combined with the observed low quantities of food available in the form of particulate organic matter and chlorophyll $a$ in the winter along the CS, indicates that midintertidal mussels are unable to withstand prolonged starvation.

\subsection{How do other filter feeders survive on the CS coast?}

While this thesis highlights the low numbers of mussel species along the CS, there are many filter feeders that do exist on this shore throughout the year. The surf barnacle (Chamaesipho brunnea) and the little black mussel (Limnoperna pulex) are present in the high intertidal zone, while the false crab (Petrolisthes elongatus) occupies space under rocks and large cobbles along the intertidal in the CS. There are several mechanisms that these species can use to survive periods of low food availability. Smaller body size in mussels has been suggested as a possible reason why L. pulex are successful in the CS. Helson et al. (2007) held three species of mussel (A. maoriana, M. galloprovincialis and Perna canaliculus) in unfiltered CS water and found that the species with the smallest body size survived ( $A$. maoriana) for the longest period of time. Thus, larger body weight and increased energy 
storage does not necessarily allow mussels to survive for longer along the CS compared to smaller individuals and lower metabolic requirements may allow for some species to survive in the CS throughout the year. In Chapter 5, P. elongatus was found to eat less than mussels throughout the year, but was also able to consume a wider variety of particle sizes. The false crabs ate more large particles than either A. maoriana or M. galloprovincialis, indicating that eating a wider variety of food sources may be an effective means to survival for filter feeders in the CS.

\subsection{Future research}

While this study concluded that community composition along the intertidal CS is bottom-up regulated by a seasonal decrease in phytoplankton availability during the winter months, there are still several questions that need to be addressed to fully understand what is controlling the difference in community composition between the CS and WH. It is still unclear at which life stage mortality in mussels occurs in the CS (larval, juvenile, postsettlement or adult). Helson and Gardner (2004) and Demello and Phillips (2011) found that mussel larvae were present in the water column in the CS. Helson and Gardner (2007) also suggested that mussels were likely impacted at the pre-settlement stage as scope for growth (net energy budget) modeling did not demonstrate that adult mussels were consistently negatively impacted by feeding in CS water. Chapter 3 also concluded that adult mussels were able to survive for over 14 months in CS waters. Thus, studies of survival in early life stage mussels in CS waters compared with WH mussels would be useful in understanding their low numbers from the CS shore.

Understanding seasonal changes in the phytoplankton community composition in the

CS would also be useful. There is little information available on the species of phytoplankton that exist in both the CS and WH and how the phytoplankton community composition may change from season to season. It is evident from this thesis that there is a marked decrease in 
the particulate organic matter and chlorophyll $a$ concentration in the CS during the winter months, but there might be a seasonal shift in phytoplankton species composition that is negatively affecting both pre-settlement and adult mussels. Nasrolahi et al. (2007) found that the type of food as well as the quantity of food eaten at early life stages in barnacles (Amphibalanus sp.) affected the size of nauplius larvae. Thus, it may be that mussels may be affected by not only the quantity of food available to them throughout the year, but also the types of food that are available to them.

\subsection{Conclusions}

Understanding the dynamics between offshore and onshore ecosystems as a whole is becoming increasingly important due to the high commercial value of coastal environments in both industry (fisheries) and conservation (marine reserves and marine parks). This work concludes that rocky intertidal biota can be tightly linked to seasonal oceanographic processes that occur nearshore at small special scales $(<10 \mathrm{~km})$. Food limitation in benthic systems is proving to play an important role in the community composition in intertidal zones and for filter feeder abundances in particular (Menge et al. 1997, 1999, Gardner 2000, 2002, McQuaid and Lindsay 2000, 2007, Blanchette et al. 2007, 2009, Helson et al. 2007, Guerry et al. 2009). What is still unclear is how specific phytoplankton species and blooms change in both the CS and WH compared with other regions in relation to bottom-up driven systems. Further research in this area would help to understand the nature and importance of coupling in these two adjacent shorelines and hard-bottom coastlines worldwide. 


\section{Literature Cited}

Achituv, Y., and M. L. Pedrotti. 1999. Costs and gains of porcelain crab suspension feeding in different flow conditions. Marine Ecology Progress Series 184:161-169.

Adin, R., and P. Riera. 2003. Preferential food source utilization among stranded macroalgae by Talitrus saltator (Amphipod, Talitridae): a stable isotopes study in the northern coast of Brittany (France). Estuarine, Coastal and Shelf Science 56:91-98.

Anderson, M. J., R. N. Gorley, and K. R. Clarke. 2008. PERMANOVA+ for PRIMER: guide kto software and statistical methods. Pages 1-195, 1st edition. PRIMER-E Ltd, Plymouth, UK.

Ansart, A., and P. Vernon. 2003. Cold hardiness in molluscs. Acta Oecologica 24:95-102.

Archambault, P., and E. Bourget. 1996. Scales of coastal heterogeneity and benthic intertidal species richness, diversity and abundance. Marine Ecology Progress Series 136:111121.

Aunaas, T. 1982. Nucleating agents in haemolymph of an intertidal mollusc tolerant of freezing. Experimentia 38:1456-1457.

Barille, L., J. Prou, M. Heral, and D. Razet. 1997. Effects of high natural seston concentrations on the feeding, selection, and absorption of the oyster Crassostrea gigas (Thunberg). Journal of Experimental Marine Biology and Ecology 212:149-172.

Bayne, B. L., A. J. S. Hawkins, and E. Navarro. 1987. Feeding and digestion by the common mussel Mytilus edulis L. (Bivalvia: Mollusca) in mixtures of silt and algal cells at low concentrations. Journal of Experimental Marine Biology and Ecology 111:1-22.

Bayne, B. L., J. Iglesias, A. J. S. Hawkins, E. Navarro, M. Heral, and J.-M. Deslous-Paoli. 1993. Feeding behaviour of the mussel, Mytilus edulis: responses to variations in quantity and organic content of the seston. Journal of Marine Biological Association of the United Kingdom 73:813-829.

Bayne, B. L., and J. Widdows. 1978. The physiological ecology of two populations of Mytilus edulis L. Oecologia 37:137-162.

Bergeron, P., and E. Bourget. 1986. Shore topography and spatial partitioning of crevice refuges by sessile epibenthos in an ice disturbed environment. Marine Ecology Progress Series 28:129-145.

Bertness, M. D. 2007. Atlantic shorelines - natural history and ecology, 1st edition. Princeton University Press, Princeton, N.J.

Bertness, M. D., C. M. Crain, B. R. Silliman, M. C. Bazterrica, M. V. Reyna, F. Hildago, and J. K. Farina. 2006. The community structure of western Atlantic Patagonian rocky shores. Ecological Monographs 76:439-460. 
Bertness, M. D., and G. H. Leonard. 1997. The role of positive interactions in communities: lessons from intertidal habitats. Ecology 78:1976-1989.

Bertness, M. D., G. H. Leonard, J. M. Levine, and P. R. Schmidt. 1999. Testing the relative contribution of positive and negative interactions in rocky intertidal communities. Ecology 80:2711-2726.

Bertness, M. D., G. C. Trussell, P. J. Ewanchuk, and B. R. Silliman. 2002. Do alternate stable community states exist in the Gulf of Maine rocky intertidal zone? Ecology 83:34343448 .

Bertness, M. D., G. C. Trussell, P. J. Ewanchuk, B. R. Silliman, and C. M. Crain. 2004. Consumer-controlled community states on Gulf of Maine rocky shores. Ecology 85:1321-1331.

Blanchette, C. A., B. R. Broitment, and S. D. Gaines. 2006a. Intertidal community structure and oceanographic patterns around Santa Cruz Island, CA, USA. Marine Biology 149:689-701.

Blanchette, C. A., B. Helmuth, and S. D. Gaines. 2006b. Spatial patterns of growth in the mussel, Mytilus californianus, across a major oceanographic and biogeographic boundary at Point Conception, California, USA. Journal of Experimental Marine Biology and Ecology 340:126-148. doi: 10.1016/j.jembe.2006.09.022.

Blanchette, C. A., B. Helmuth, and S. D. Gaines. 2007. Spatial patterns of growth in the mussel, Mytilus californianus, across a major oceanographic and biogeographic boundary at Point Conception, California, USA. Journal of Experimental Marine Biology and Ecology 340:126-148.

Blanchette, C. A., C. M. Miner, P. T. Raimondi, D. Lohse, K. E. K. Heady, and B. R. Broitman. 2008. Biogeographical patterns of rocky intertidal communities along the Pacific coast of North America. Journal of Biogeography 35:1593-1607.

Blanchette, C. A., E. A. Wieters, B. R. Broitman, B. P. Kinlan, and D. R. Schiel. 2009. Progress in oceanography trophic structure and diversity in rocky intertidal upwelling ecosystem: a comparison of community patterns across California, Chile, South Africa and New Zealand. Progress in Oceanography 83:107-116. Elsevier Ltd.

Bode, A., M. T. Alvarez-Ossorio, J. M. Cabanas, A. Miranda, and M. Varela. 2009. Recent trends in plankton and upwelling intensity off Galicia (NW Spain). Progress In Oceanography 83:342-350. Elsevier Ltd.

Bougrier, S., and A. J. S. Hawkins. 1997. Preingestive selection of different microalgal mixtures in Crassostrea gigas and Myilus edulis, analysed by flow cytometry. Aquaculture 150:123-134.

Bradford, J. M., P. P. Lapennas, R. A. Murtagh, F. H. Chang, and V. Wilkinson. 1986. Factors controlling summer phytoplankton production in greater Cook Strait, New Zealand. New Zealand Journal of Marine and Freshwater Research 20:253-279. 
Bradford, J. M., and P. E. Roberts. 1978. Distribution of reactive phosphorus and plankton in relation to upwelling and surface circulation around New Zealand. New Zealand Journal of Marine and Freshwater Research 12:1-15.

Broitman, B. R., and B. P. Kinlan. 2006. Spatial scales of benthic and pelagic producer biomass in a coastal upwelling ecosystem. Marine Ecology Progress Series 327:15-25.

Brown, P. J., and R. B. Taylor. 1999. Effects of trampling by humans on animals inhabiting coralline algal turf in the rocky intertidal. Journal of Experimental Marine Biology and Ecology 235:45-53.

Bruno, J. F., J. J. Stachowicz, and M. D. Bertness. 2003. Inclusion of facilitation into ecological theory. Trends in Ecology and Evolution 18:119-125.

Bustamante, R. H., and G. M. Branch. 1996a. Large scale patterns and trophic structure of southern African rocky shores: the roles of geographic variation and wave exposure. Journal of Biogeography 23:339-351.

Bustamante, R. H., and G. M. Branch. 1996b. The dependence of intertidal consumers on kelp-derived organic matter on the west coast of South Africa. Journal of Experimental Marine Biology and Ecology 196:1-28.

Cabana, G., and J. B. Rasmussen. 1994. Modelling food chain structure and contaminant bioaccumulation using stable nitrogen isotopes. Nature 372:255-257.

Cabana, G., and J. B. Rasmussen. 1996. Comparison of aquatic food chains using nitrogen isotopes. Proceedings of National Academy of Sciences (USA) 93:10844-10847.

Carabel, S., E. Godinezdominguez, P. Verisimo, L. Fernandez, and J. Freire. 2006. An assessment of sample processing methods for stable isotope analyses of marine food webs. Journal of Experimental Marine Biology and Ecology 336:254-261.

Carpenter, E. J., and R. R. L. Guillard. 1971. Intraspecific differences in half-saturation constants for three species of marine phytoplankton. Ecology 52:183-185.

Carrington, E. 2002. Seasonal variation in the attachment strength of blue mussels: causes and consequences. Limnology and Oceanography 47:1723-1733.

Chapman, A. R. O., and J. S. Craigie. 1977. Seasonal growth in Laminaria iongicruris: relations with dissolved inorganic nutrients and internal reserves of nitrogen. Marine Biology 40:197-205.

Clarke, K. R., and R. N. Gorley. 2006. PRIMER v6. user manual/ tutorial. Pages 1-190. PRIMER-E Ltd, Plymouth, UK.

Coma, R., and M. Ribes. 2003. Seasonal energetic constraints in Mediterranean benthic suspension feeders: effects at different levels of ecological organization. Oikos 101:205215. 
Connell, J. H. 1972. Community interactions on marine rocky intertidal shores. Annual Review of ecological systematics 3:169-192.

Crain, C. M., and M. D. Bertness. 2006. Ecosystem engineering across environmental gradients: implications for conservation and management. BioScience 56:211-218.

Dahlhoff, E. P., and B. A. Menge. 1996. Influence of phytoplankton concentration and wave exposure on the ecophysiology of Mytilus californianus. Marine Ecology Progress Series 144:97-107.

Demello, R., and N. E. Phillips. 2011. Variation in mussel and barnacle recruitment parallels a shift in intertidal community structure in the Cook Strait region of New Zealand. Marine and Freshwater Research 62:1211-1229.

Denny, M. W., and R. T. Paine. 1998. Celestial mechanics, sea-level changes, and intertidal ecology. Biological Bulletin 194:108-115.

Doi, H., M. Matsumassa, T. Toya, N. Satoh, C. Mizota, Y. Maki, and E. Kikuchi. 2005. Spatial shifts in food sources for macrozoobenthos in an estuarine ecosystem: carbon and nitrogen stable isotope analysis. Estuarine, Coastal and Shelf Science 64:316-322.

Dubois, S., F. Orvain, J. C. Marín Leal, M. Ropert, and S. Lefebvre. 2007. Small-scale spatial variability of food partitioning between cultivated oysters and associated suspensionfeeding species, as revealed by stable isotopes. Marine Ecology Progress Series 336:151-160.

Dugdale, R. C., and F. P. Wilkerson. 1998. Silicate regulation of new production in the equatorial Pacific upwelling. Nature 391:270-273.

Eddy, T. D., A. MacDairmid, T. T. Byfield, J. C. Tam, T. T. Jones, J. J. Bell, and J. P. A. Gardner. 2012. The ecosystem effects of fishing: past present and future at the Taputeranga Marine Reserve, New Zealand. PLoS ONE In submiss.

Eldridge, M., C. Trick, M. Alm, G. DiTullio, E. Rue, K. Bruland, D. Hutchins, and S. Wilhelm. 2004. Phytoplankton community response to a manipulation of bioavailable iron in HNLC waters of the subtropical Pacific Ocean. Aquatic Microbial Ecology 35:79-91.

Enderlein, P., and M. Wahl. 2004. Dominance of blue mussels versus consumer-mediated enhancement of benthic diversity. Journal of Sea Research 51:145-155.

Eppley, R. W., J. N. Rogers, and J. J. Mccarthy. 1969. Half-saturation constants for uptake of nitrate and ammonium by marine phytoplankton. Limnology and Oceanography 14:912920.

Erwin, D. H. 2008. Macroevolution of ecosystem engineering, niche construction and diversity. Trends 23:304-310. 
Feder, M. E., and G. E. Hofmann. 1999. Heat-shock proteins, molecular chaperones, and the stress response: evolutionary and ecological physiology. Annual review of physiology $61: 243-82$.

Finke, G. R., S. A. Navarrete, and F. Bozinovic. 2007. Tidal regimes of temperate coasts and their influences on aerial exposure for intertidal organisms. Marine Ecology Progress Series 343:57-62.

Frechette, M., and E. Bourget. 1985. Energy flow between the pelagic and benthic zones: factors controlling particulate organic matter available to an intertidal mussel bed. Canadian Journal of Fisheries and Aquatic Sciences 42:1158-1165.

Fredriksen, S. 2003. Food web studies in a Norwegian kelp forest based on stable isotope $(\delta 13 \mathrm{C}$ and $\delta 15 \mathrm{~N})$ analysis. Marine Ecology Progress Series 260:71-81.

Froneman, P. W., C. D. McQuaid, and R. Perissinotto. 1995. Biogeographic structure of the microphytoplankton assemblages of the south Atlantic and Southern Ocean during austral summer. Journal of Plankton Research 17:1791-1802.

Fukumoiri, K., M. Oi, H. Doi, D. Takahashi, N. Okuda, T. W. Miller, M. Kuwae, H. Miyaskaka, M. Genkai-Kato, Y. Kiozumi, K. Omori, and H. Takeoka. 2008. Bivalve tissue as a carbon and nitrogen isotope baseline indicator in coastal ecosystems. Estuarine, Coastal and Shelf Science 79:45-50.

Furnas, M. J., and A. W. Mitchell. 1986. Phytoplankton dynamics in the central Great Barrier Reef-I. Seasonal changes in biomass and community structure and their relation to intrusive activity. Continental Shelf Research 6:363-384.

Gardner, J. P. A. 2000. Where are the mussels on Cook Strait (New Zealand) shores? Low seston quality as a possible factor limiting multi-species distributions. Marine Ecology Progress Series 194:123-132.

Gardner, J. P. A. 2002. Effects of seston variability on the clearance rate and absorption efficiency of the mussels Aulacomya maoriana, Mytilus galloprovincialis and Perna canaliculus from New Zealand. Journal of Experimental Marine Biology and Ecology 268:83-101.

Gardner, J. P. A. 2008. Where are the mussels on Wellington's South Coast? Pages 288-304 in J. P. A. Gardner and J. J. Bell, editors. THe Taputeranga Marine Reserve. Jonathan Gardner, Wellington, NZ.

Gardner, J. P. A., and J. Bell. 2008. The Taputeranga Marine Reserve. Gardner, Wellington, NZ.

Gardner, J. P. A., and D. O. F. Skibinski. 1991. Biological and physical factors influencing genotype dependent mortality in hybrid mussel populations. Marine Ecology Progress Series 71:235-243. 
Gardner, J. P. A., and R. J. Thompson. 2001a. The effects of coastal and estuarine conditions on the physiology and survivorship of the mussels Mytilus edulis, M. trossulus and their hybrids. Journal of Experimental Marine Biology and Ecology 265:119-140.

Gardner, J. P. A., and R. J. Thompson. 2001b. Naturally low seston concentration and the net energy balance of the greenshell mussel, (Perna canaliculus) at Island Bay, Cook Strait, New Zealand. New Zealand Journal of Marine and Freshwater Research 35:457-468.

Gebauer, P., K. Paschke, and K. Anger. 2010. Seasonal variation in the nutritional vulnerability of first-stage larval porcelain crab, Petrolisthes laevigatus (Anomura: Porcellanidae) in southern Chile. Journal of Experimental Marine Biology and Ecology 386:103-112. Elsevier B.V.

Geider, R. J., and J. La Roche. 1994. The role of iron in phytoplankton photosynthesis, and the potential for iron-limitation of primary productivity in the sea. Photosynthesis Research 39:275-301.

Gilman, S. E., D. S. Wethey, and B. Helmuth. 2006. Variation in the sensitivity of organismal body temperature to climate change over local and geographic scales. Proceedings of the National Academy of Science (USA) 103:9560-9565.

Gosling, E. 1992. Systematics and geographic distribution of Mytilus. Developmental Aquaculture and Fisheries Sciences 25:1-20.

Gosselin, L. A., and P. Qian. 1996. Early post-settlement mortality of an intertidal barnacle: a critical period for survival. Marine Ecology Progress Series 135:69-75.

Gosselin, L. A., and P. Qian. 1997. Can bacterivory alone sustain larval development in the polychaete Hydroides elegans and the barnacle Balanus amphitrite? Marine Ecology Progress Series 161:93-101.

Gouhier, T. C., and F. Guichard. 2007. Local disturbance cycles and the maintenance of heterogeneity across scales in marine metapopulations. Ecology 88:647-657.

Griffen, B. D., and D. G. Delaney. 2007. Species invasion shifts the importance of predator dependence. Ecology 88:3012-3021.

Griffen, B. D., T. Guy, and J. C. Buck. 2008. Inhibition between invasives: a newly introduced predator moderates the impacts of a previously established invasive predator. Journal of Animal Ecology 77:32-40.

Guerry, A. D., B. A. Menge, and R. A. Dunmore. 2009. Effects of consumers and enrichment on abundance and diversity of benthic algae in a rocky intertidal community. Journal of Experimental Marine Biology and Ecology 369:155-164. Elsevier B.V.

Guichard, F., E. Bourget, and J. Robert. 2001. Scaling the influence of topographic heterogeneity on intertidal benthic communities: alternate trajectories mediated by hydrodynamics and shading. Marine Ecology Progress Series 217:27-41. 
Gutierez, J. L., C. G. Jones, D. L. Strayer, and O. O. Iribarne. 2003. Mollusks as ecosystem engineers: the role of shell production in aquatic habitats. Oikos 101:79-90.

Habib, O. A., R. Tippett, and K. J. Murphy. 1997. Seasonal changes in phytoplankton community structure in relation to physico-chemical factors in Loch Lomond, Scotland. Hydrobiologia 350:63-79.

Harley, C. D. G., and B. S. T. Helmuth. 2003. Local- and regional-scale effects of wave exposure, thermal stress and absolute versus effective shore level on patterns of intertidal zonation. Limnology and Oceanography 48:1498-1508.

Harley, C. D. G., A. R. Hughes, K. Hultgren, B. G. Miner, C. J. B. Sorte, C. S. Thornber, L. F. Rodriguez, L. Tomanek, and S. L. Williams. 2006. The impacts of climate change in coastal marine systems. Ecology Letters 9:228-241.

Hawkins, A. J. S., R. F. M. Smith, S. H. Tan, and Z. B. Yasin. 1998. Suspension-feeding behaviour in tropical bivalve molluscs: Perna virdis, Crassostrea belcheri, Crassostrea iradelei, Saccostrea cucculata and Pinctada margarifera. Marine Ecology Progress Series 166:173-185.

Heaven, C., and R. A. Scrosati. 2008. Benthic community composition across gradients of intertidal elevation, wave exposure, and ice scour in Atlantic Canada. Marine Ecology Progress Series 369:13-23.

Helmuth, B., B. R. Broitman, C. A. Blanchette, S. Gilman, P. Halpin, C. D. G. Harley, M. J. O'Donnell, G. E. Hoffman, and B. A. Menge. 2006a. Mosaic patterns of thermal stress in the rocky intertidal zone implications for climate change. Ecological Monographs 76:461-479.

Helmuth, B., and M. W. Denny. 2003. Predicting wave exposure in the rocky intertidal zone: do bigger waves always lead to larger forces? Limnology and Oceanography 48:13381345 .

Helmuth, B., C. D. G. Harley, P. M. Halpin, M. O. Donnell, G. E. Hofmann, and C. A. Blanchette. 2007. Climate change and latitudinal patterns of intertidal thermal stress. Science 289:1015-1017.

Helmuth, B., N. Mieszkowska, P. Moore, and S. J. Hawkins. 2006b. Living on the edge of two changing worlds: forecasting the responses of rocky intertidal ecosystems to climate change. Annual Review of ecological systematics 37:373-404.

Helmuth, B. S. T., and G. E. Hofmann. 2001. Microhabitats, thermal heterogeneity, and patterns of physiological stress in the rocky intertidal zone. Biology Bulletin 201:374384.

Helson, J., and J. P. A. Gardner. 2004. Contrasting patterns of mussel abundance at neighbouring sites: does recruitment limitation explain the absence of mussels on Cook Strait (New Zealand) shores? Journal of Experimental Marine Biology and Ecology 312:285-298. 
Helson, J., and J. P. A. Gardner. 2007. Variation in scope for growth: a test of food limitation among intertidal mussels. Hydrobiologia 586:373-392.

Helson, J., S. Pledger, and J. P. A. Gardner. 2007. Does differential particulate food supply explain the presence of mussels in Wellington Harbour (New Zealand) and their absence on neighbouring Cook Strait shores? Estuarine, Coastal and Shelf Science 72:223-234.

Hickman, R. w., and J. Illingworth. 1980. Condition cycle of the green-lipped mussel Perna canaliculus in New Zealand. Marine Biology 27:27-38.

Hill, J. M., C. D. Mcquaid, and S. Kaehler. 2006. Biogeographic and nearshore - offshore trends in isotope ratios of intertidal mussels and their food sources around the coast of southern Africa. Marine Ecology Progress Series 318:63-73.

Hill, J., and C. D. McQuaid. 2008. $\delta 13 \mathrm{C}$ and $\delta 15 \mathrm{~N}$ biogeographic trends in rocky intertidal communities along the coast of South Africa: Evidence of strong environmental signatures. Estuarine, Coastal and Shelf Science 80:261-268. Elsevier Ltd.

Hoffman, G. E., and G. N. Somero. 1996. Interspecific variation in thermal denaturation of proteins in the congeneric mussels Mytilus trossulus and M . galloprovincialis: evidence from the heat-shock response and protein ubiquitination. Marine Biology 126:65-75.

Howarth, R. W. 1988. Nutrient limitation of net primary production in marine ecosystems. Annual Review of Ecology 19:89-110.

Hunt, H. L., and R. E. Scheibling. 1996. Physical and biological factors influencing mussel (Mytilus trossulus, M. edulis) settlement on a wave-exposed rocky shore. Marine Ecology Progress Series 142:135-145.

Hunt, H. L., and R. E. Scheibling. 1998. Effects of whelk (Nucella lapillus (L.)) predation on mussel (Mytilus trossulus (Gould), M . edulis (L.)) assemblages in tidepools and on emergent rock on a wave-exposed rocky shore in Nova Scotia, Canada. Journal of Experimental Marine Biology and Ecology 226:87-113.

Hunt, H. L., and R. E. Scheibling. 2001a. Predicting wave dislodgment of mussels: variation in attachment strength with body size, habitat, and season. Marine Ecology Progress Series 213:157-164.

Hunt, H., and R. E. Scheibling. 2001b. Patch dynamics of mussels on rocky shores: integrating process to understand pattern. Ecology 82:3213-3231.

Hutchins, L. W. 1947. The basis for temperature zonation in geographical distributions. Ecological Monographs 17:325-355.

Hutchinson, G. E. 1953. The concept of pattern in ecology. Proceedings of National Academy of Sciences (USA) 105:1 - 12 .

Jacob, U., K. Mintenbeck, T. Brey, R. Knust, and K. Beyer. 2005. Stable isotope food web studies: a case for standardized sample treatment. Marine Ecology Progress Series 287:251-253. 
James, M. R., M. A. Weatherhead, and A. H. Ross. 2001. Size specific clearance, excretion, and respiration rates, and phytoplankton selectivity for the mussel Perna canaliculus at low levels of natural food. New Zealand Journal of Marine and Freshwater Research 35:37-41.

Jansen, J. M., A. E. Pronker, S. Kube, A. Sokolowski, J. C. Sola, M. A. Marquiegui, D. Schiedek, and S. Wendelaar. 2007. Geographic and seasonal patterns and limits on the adaptive response to temperature of European Mytilus spp . and Macoma balthica populations. Oecologia 154:23-34.

Jensen, G. C., and D. A. Armstrong. 1991. Intertidal zonation among congeners: factors regulating distribution of porcelain crabs Petrolisthes spp. (Anomura: Porcellanidae) 73:47-60.

Jernakoff, P. 1985. An experimental evaluation of the influence of barnacles, crevices and seasonal patterns of grazing on algal diversity and cover in intertidal barnacle zone. Journal of Experimental Marine Biology and Ecology 88:287-302.

Johnston, D., and J. Freeman. 2005. Dietary preference and digestive enzyme activities as indicators of trophic resource utilization by six species of crab. The Biological bulletin 208:36-46.

Kang, C. K., P. Sauriau, P. Richard, and G. F. Blanchard. 1999. Food sources of the infaunal suspension-feeding bivalve Cerastoderma edule in a muddy sandflat of MarennesOlQon Bay, as determined by analyses of carbon and nitrogen stable isotopes. Marine Ecology Progress Series 187:147-158.

Kautsky, N. 1982. Growth and size structure in a Baltic Mytilus edulis population. Marine Biology 68:117-133.

Kennedy, P., H. Kennedy, and S. Papadimitriou. 2005. The effect of acidification on the determination of organic carbon, total nitrogen and their stable isotopic composition in algae and marine sediment. Rapid communications in a mass spectrometry 19:10631068.

King, P. A., D. McGarth, and W. Britton. 1990. The use of artificial substrates in monitoring mussel (Mytilus edulis L.) settlement on an exposed rocky shore in the west of Ireland. Journal of the Marine Biological Association of the United Kingdom 70:371-380.

Kling, G. W., and B. Fry. 1992. Stable isotopes and planktonic trophic structure in arctic lakes. Ecology 73:561-566.

Kolasinski, J., K. Rogers, and P. Frouin. 2008. Effects of acidification on carbon and nitrogen stable isotopes of benthic macrofauna from a tropical coral reef. Rapid communications in a mass spectrometry 22:2955-2960.

Kropp, R. K. 1981. Additional Porcelain Crab feeding methods (Decapoda, Porcellanidae). Crustaceana 40:307-310. 
Lachowicz, L. S. 2005. Population biology of mussels (Aulacomya maoriana, Mytilus galloprovincialis and Perna canaliculus) from rocky intertidal shores in Wellington Harbour, New Zealand. Victoria University of Wellington.

Langdon, C., and R. E. I. Newell. 1990. Utilization of detritus and bacteria as food sources by two bivalve suspension-feeders, the oyster Crossostrea virginica and the mussel Gukensia demissa. Marine Ecology Progress Series 58:299-310.

Laurand, S., and P. Riera. 2006. Trophic ecology of the supralittoral rocky shore (Roscoff, France): a dual stable isotope and experimental approach. Journal of Sea Research 56:27-36.

Lefebvre, S., C. Harma, and J. 1. Blin. 2009a. Trophic typology of coastal ecosystems based on $\delta 13 \mathrm{C}$ and $\delta 15 \mathrm{~N}$ ratios in an opportunistic suspension feeder. Marine Ecology Progress Series 390:27-37.

Lefebvre, S., J. C. Marín Leal, S. Dubois, F. Orvain, J.-L. Blin, M.-P. Bataillé, A. Ourry, and R. Galois. 2009b. Seasonal dynamics of trophic relationships among co-occurring suspension-feeders in two shellfish culture dominated ecosystems. Estuarine, Coastal and Shelf Science 82:415-425.

Leppard, G. G. 1995. The characterization of algal mucilages and their aggregates in aquatic ecosystems. Science of the total environment 165:103-131.

Lewandowska, J., and A. Kosakowska. 2004. Effect of iron limitation on cells of the diatom Cyclotella meneghiniana Kutzing. Oceanologia 46:269-287.

Lopez Grappa, J. J., A. Tablado, and N. H. Magaldi. 1990. Influence of sewage pollution on a rocky intertidal community dominated by the mytilid Brachidontes rodriguezi. Marine Ecology Progress Series 63:163-175.

Lubchenco, J. 1980. Algal zonation in the New England rocky intertidal community: an experimental analysis. Ecology 61:333-344.

Lubchenco, J. 1983. Plant species diversity in a marine intertidal community: importance of herbivore food preference and algal competitive abilities. American Naturalist 112:2329.

Lubchenco, J., S. R. Palumbi, S. D. Gaines, and S. Andelman. 2003. Plugging a hole in the ocean: the emerging science of Marine Reserves. Ecological Applications 13:3-7.

Marín Leal, J. C., S. Dubois, F. Orvain, R. Galois, J.-L. Blin, M. Ropert, M.-P. Bataillé, A. Ourry, and S. Lefebvre. 2008. Stable isotopes $(\delta 13 \mathrm{C}, \delta 15 \mathrm{~N})$ and modelling as tools to estimate the trophic ecology of cultivated oysters in two contrasting environments. Marine Biology 153:673-688.

McCook, L. J., and A. R. O. Chapman. 1993. Community succession following massive icescour on a rocky intertidal shore: recruitment, competition and predation during early, primary succession. Marine Biology 115:565-575. 
McCook, L. J., and A. R. O. Chapman. 1997. Patterns and variations in natural succession following massive ice-scour of a rocky intertidal seashore. Journal of Experimental Marine Biology and Ecology 214:121-147.

Mckindsey, C. W., and E. Bourget. 2000. Explaining mesoscale variation in intertidal mussel community structure. Marine Ecology Progress Series 205:155-170.

Mckinney, R. A., W. G. Nelson, M. A. Charpentier, and C. Wigand. 2001. Ribbed mussel nitrogen isotope signatures reflect nitrogen sources in coastal salt marshes. Ecological Applications 11:203-214.

McQuaid, C. D., and S. M. Lawrie. 2005. Supply-side ecology of the brown mussel, Perna perna: an investigation of spatial and temporal variation in, and coupling between, gamete release and larval supply. Marine Biology 147:955-963.

McQuaid, C. D., J. R. Lindsay, and T. L. Lindsay. 2000. Interactive effects of wave exposure and tidal height on population structure of the mussel Perna perna. Marine Biology 137:925-932.

McQuaid, C. D., and T. L. Lindsay. 2000. Effect of wave exposure on growth and mortality rates of the mussel Perna perna: bottom-up regulation of intertidal populations. Marine Ecology Progress Series 206:147-154.

McQuaid, C. D., and T. L. Lindsay. 2007. Wave exposure effects on population structure and recruitment in the mussel Perna perna suggest regulation primarily through availability of recruits and food, not space. Marine Biology 151:2123-2131.

McQuaid, C. D., and T. E. Phillips. 2006. Mesoscale variation in reproduction, recruitment and population structure of intertidal mussels with low larval input: a bay/open coast comparison. Marine Ecology Progress Series 327:193-206.

Menge, B. A. 1976. Organization of the New England Rocky intertidal community: role of predation, competition and environmental heterogeneity. Ecological Monographs 46:355-393.

Menge, B. A., E. L. Berlow, C. A. Blanchette, S. A. Navarrete, and S. B. Yamada. 1994. The keystone species concept: variation in interaction strength in a rocky intertidal habitat. Ecological Monographs 64:249-286.

Menge, B. A., F. Chan, K. J. Nielsen, E. Di Lorenzo, and J. Lubchenco. 2009. Climatic variation alters supply-side ecology : impact of climate patterns on phytoplankton and mussel recruitment. Ecological Monographs 79:379-395.

Menge, B. A., B. A. Daley, J. Lubchenco, E. Sanford, E. P. Dahlhoff, P. M. Halpin, G. Hudson, and J. L. Burnaford. 1999. Top-down and bottom-up regulation of New Zealand rocky intertidal communities. Ecological Monographs 69:297-330.

Menge, B. A., B. A. Daley, P. A. Wheeler, and T. Strub. 1997. Rocky intertidal oceanography: an association between community structure and nearshore phytoplankton concentration. Limnology and Oceanography 42:57-66. 
Menge, B. A., J. Lubchenco, M. E. S. Bracken, F. Chan, M. M. Foley, T. L. Freidenburg, S. D. Gaines, G. Hudson, C. Krenz, H. Leslie, D. N. L. Menges, R. Russell, and M. S. Webster. 2003. Coastal oceanography sets the pace of rocky intertidal community dynamics. Proceedings of National Academy of Sciences (USA) 21:12229-12234.

Menge, B. A., and J. P. Sutherland. 1976. Species diversity gradients: synthesis of the roles of predation, competition, and temporal heterogeneity. The American naturalist 110:351-369.

Minchinton, T. E., and R. E. Scheibling. 1997. Recovery of an intertidal assemblage following a rare occurence of scouring by sea ice in Nova Scotia, Canada. Botanica Marina 40:139-148.

Moran, A. L., and D. T. Manahan. 2004. Physiological recovery from prolonged "starvation" in larvae of the Pacific oyster Crassostrea gigas. Journal of Experimental Marine Biology and Ecology 306:17-36.

Morelissen, B., and C. D. G. Harley. 2006. The effects of temperature on producers, consumers, and plant - herbivore interactions in an intertidal community. Journal of Experimental Marine Biology and Ecology 348:162-173.

Morton, J. 2004. Seashore Ecology of New Zealand and the Pacific. David Bateman Ltd., Auckland, NZ.

Morton, J., and M. Miller. 1968. New Zealand Seashore. Collins, Auckland, NZ.

Moyse, J. 1963. A comparison of the value of various flagellates and diatoms as a food for barnacle larvae. ICES Journal of Marine Science 28:175-187.

MPI. 2011. Ministry of Primary Industries: Shellfish. Retrieved July 7, 2012, from http://www.fish.govt.nz/ennz/Recreational/Fishery+Management+Areas/Central/Shellfish.htm.

Nasrolahi, A., A. Sari, S. Saifabadi, and M. Malek. 2007. Effects of algal diet on larval survival and growth of the barnacle Amphibalanus (Balanus) improvisus. Journal of the Marine Biological Association of the United Kingdom 87:1227-1233.

Navarrete, S. A., E. A. Wieters, B. R. Broitman, and J. C. Castilla. 2006. Scales of benthic pelagic coupling and the intensity of species interactions: from recruitment limitation to top-down control. Proceedings of the National Academy of Science (USA) 102:1804618051.

Navarrete, S., B. R. Broitment, and B. A. Menge. 2008. Interhemispheric comparison of recruitment to intertidal communities: pattern persistence and scale of variation. Ecology 89:1308-1322.

Neira, S., C. L. Moloney, P. Cury, C. Mullon, and V. Christensen. 2009. Mechanisms affecting recovery in an upwelling food web: The case of the southern Humboldt. Progress In Oceanography 83:404-416. Elsevier Ltd. 
Nelson, W. 2008. Macroalgae of the Wellington South Coast. Pages 196-214 in J. P. A. Gardner and J. J. Bell, editors. The Taputeranga Marine Reserve. Jonathan Gardner, Wellington, NZ.

Nielsen, K. J., and S. A. Navarrete. 2003. Mesoscale regulation comes from the bottom-up: intertidal interactions between consumers and upwelling. Ecology Letters 7:31-41.

Paine, R. T. 1969. The Pisaster-Tegula interaction: prey patches, predator food preference and intertidal community structure. Ecology 50:950-961.

Pande, A., and J. P. A. Gardner. 2009. A baseline biological survey of the proposed Taputeranga Marine Reserve (Wellington, New Zealand): spatial and temporal variability along a natural environmental gradient. Aquatic Conservation: Marine and Freshwater Ecosystems 19:237-248.

Peterson, B. J., and B. Fry. 1987. Stable isotopes in ecosystem studies. Ecology 18:293-320.

Petraitis, P. S., and S. R. Dudgeon. 2004. Do alternate stable community states exist in the Gulf of Maine rocky intertidal zone? Ecology 85:1160-1165.

Phillips, D. L. 2008. IsoSource: stable isotope mixing model for partitioning an excess number of sources.

Phillips, D. L., and J. W. Gregg. 2003. Source partitioning using stable isotopes: coping with too many sources. Oecologia 136:261-9.

Phillips, D. L., S. D. Newsome, and J. W. Gregg. 2005. Combining sources in stable isotope mixing models: alternative methods. Oecologia 144:520-7.

Phillips, N. E. 2002. Effects of nutrition-mediated larval condition on juvenile performance in a marine mussel. Ecology 83:2562-2574.

Phillips, N. E. 2004. Variable timing of larval food has consequences for early juvenile performance in a marine mussel. Ecology 85:2341-2346.

Pincebourde, S., E. Sanford, B. Helmuth, D. Worth, J. Blum, and S. Porter. 2008. Body temperature during low tide alters the feeding performance of a top intertidal predator. Limnology and Oceanography 53:1562-1573.

Pitchford, J. W., and J. Brindley. 1999. Iron limitation, grazing pressure and oceanic high nutrient - low chlorophyll (HNLC) regions. Journal of Plankton Research 21:525-547.

Platt, T., C. Fuentes-Yaco, and K. T. Frank. 2003. Marine ecology: spring algal bloom and larval fish survival. Nature 423:398-399.

Porri, F., C. D. McQuaid, and S. Radloff. 2006a. Spatio-temporal variability of larval abundance and settlement of Perna perna: differential delivery of mussels. Marine Ecology Progress Series 315:141-150. 
Porri, F., C. D. McQuaid, and S. Radloff. 2006b. Temporal scales of variation in settlement and recruitment of the mussel Perna perna (Linnaeus , 1758). Journal of Experimental Marine Biology and Ecology 332:178-187.

Qiu, J., R. Tremblay, and E. Bourget. 2002. Ontogenetic changes in hyposaline tolerance in the mussels Mytilus edulis and M. trossulus: implications for distribution. Marine Ecology Progress Series 228:143-152.

Quinn, G., and M. Keogh. 2002. Experimental design and data analysis for biologists. Cambridge University Press.

Reed, D. C., and M. S. Foster. 1984. The effects of canopy shading on algal recruitment and growth in a giant kelp (Macrocystis pyrifera) forest. Ecology 65:937-948.

Riera, P. 2007. Trophic subsidies of Crassostrea gigas, Mitilus edulis and Crepidula fornicata, in the Bay of Mont Saint Michel (France): a $\delta 13 \mathrm{C}$ and $\delta 15 \mathrm{~N}$ investigation. Estuarine, Coastal and Shelf Science 72:1-15.

Rilov, G., and D. R. Schiel. 2006a. Trophic linkages across seascapes : subtidal predators limit effective mussel recruitment in rocky intertidal communities. Marine Ecology Progress Series 327:83-93.

Rilov, G., and D. R. Schiel. 2006b. Seascape-dependent subtidal-intertidal trophic linkages. Ecology 87:731-44. Retrieved from http://www.ncbi.nlm.nih.gov/pubmed/16602302.

Rodgers, K., and S. Wing. 2008. Spatial structure and movement of blue cod Parapercis colias in Doubtful Sound, New Zealand, inferred from $\delta 13 \mathrm{C}$ and $\delta 15 \mathrm{~N}$. Marine Ecology Progress Series 359:239-248.

Rogers, K. M. 1999. Effects of sewage contamination of macroalgae and shellfish at Moa Point, New Zealand using stable carbon and nitrogen isotopes. New Zealand Journal of Marine and Freshwater Research 33:181-188.

Rogers, K. M. 2003. Stable carbon and nitrogen isotope signatures indicate recovery of marine biota from sewage pollution at Moa Point, New Zealand. Marine pollution bulletin 46:821-827.

Rouillon, G., and E. Navarro. 2003. Differential utilization of species of phytoplankton by the mussel Mytilus edulis. Acta Oecologica 24.

Runge, J. A. 1985. Relationship of egg production of Calanus pacificus to in phytoplankton seasonal changes availability in Puget Sound, Washington. Limnology and Oceanography 30:382-396.

Sasai, Y., K. J. Richards, A. Ishida, and H. Sasaki. 2012. Spatial and temporal variabilities of the chlorophyll distribution in the northeastern tropical Pacific: The impact of physical processes on seasonal and interannual time scales. Journal of Marine Systems 96-97:2431. Elsevier B.V. 
Savoye, N., A. Aminot, P. Tréguer, M. Fontugne, N. Naulet, and R. Kérouel. 2003. Dynamics of particulate organic matter $\delta 15 \mathrm{~N}$ and $\delta 13 \mathrm{C}$ during spring phytoplankton blooms in a macrotidal ecosystem Bay of Seine, France). Marine Ecology Progress Series 255:2741.

Schiel, D. R., and D. I. Taylor. 1999. Effects of trampling on a rocky intertidal algal assemblage in southern New Zealand. Journal of Experimental Marine Biology and Ecology 235:213-235.

Scrosati, R. A., and L. K. Eckersley. 2007. Thermal insulation of the intertidal zone by the ice foot. Journal of Sea Research 58:331-334.

Scrosati, R. A., and C. Heaven. 2006. Field technique to quantify intensity of scouring by sea ice in rocky intertidal habitats. Marine Ecology Progress Series 320:293-295.

Seed, R. 1969a. The Ecology of Mytilus edulis L . (Lamellibranchiata) on exposed rocky shores II. Growth and mortality. Oecologia 350:317-350.

Seed, R. 1969b. The Ecology of Mytilus edulis L. (Lamellibranchiata) on exposed rocky shores I. Breeding and settlement. Oecologia 3:277-316.

Seitz, R. D., and R. N. Lipcius. 2001. Variation in top-down and bottom-up control of marine bivalves at differing spatial scales. ICES Journal of Marine Science 58:689-699.

Shumway, S., T. Cucci, R. Newell, and Y. C. 1985. Particle selection, ingestion and absorption in filter feeding bivalves. Journal of Experimental Marine Biology and Ecology 91:77-92.

Smaal, A. C. 1991. The ecology and cultivation of mussels: new advances. Aquaculture 94:245-261.

Smith, J. R., P. Fong, and R. F. Ambrose. 2008. The impacts of human visitation on mussel bed communities along the California coast: are regulatory marine reserves effective in protecting these communities? Environmental management 41:599-612.

Smith, J. R., P. Fong, and R. F. Ambrose. 2009. Spatial patterns in recruitment and growth of the mussel Mytilus californianus (Conrad) in southern and northern California, USA, two regions with differing oceanographic conditions. Journal of Sea Research 61:165173. Elsevier B.V.

Sousa, W. P. 1984. Intertidal mosaics: patch size, propagule availability and spatially variable patterns of succession. Ecology 65:1918-1935.

Stapp, P., G. A. Polis, and F. S. Pinero. 1999. Stable isotopes reveal strong marine and El Niño effects on island food webs. Nature 401:467-469.

Steffani, C. N., and G. M. Branch. 2003. Growth rate, condition, and shell shape of Mytilus galloprovincialis: responses to wave exposure. Marine Ecology Progress Series 246:197-209. 
Steger, K., and J. P. A. Gardner. 2007. Laboratory experiments on the effects of variable suspended sediment concentrations on the ecophysiology of the porcelain crab Petrolisthes elongatus (Milne Edwards, 1837). Journal of Experimental Marine Biology and Ecology 344:181-192.

Stephens, S., and D. Ramsay. 2006. Predicting storm events at the coast. Water and Atmosphere 14:14-15.

Stephenson, T. A., and A. Stephenson. 1949. The universal features of zonation between tide marks on rocky coasts. Ecology 37:289-305.

Stillman, J. H. 2002. Causes and consequences of thermal tolerance limits in rocky intertidal porcelain crabs, Genus Petrolisthes. Integrative and comparative biology 42:790-796.

Stillman, J. H. 2003. Acclimation capacity underlies susceptibility to climate change. Science 301:65.

Suchanek, T. H. 1981. The role of disturbance in the evolution of life history strategies in the intertidal mussels Mytilus edulis and Mytilus californianus. Oecologia 50:143-152.

Tam, J. C., and R. A. Scrosati. 2011. Mussel and dogwhelk distribution along the north-west Atlantic coast: testing predictions derived from the abundant-centre model. Journal of Biogeography 38:1536-1545.

Tam, J. C., and R. A. Scrosati. 2013. Distribution of cryptic mussel species (Mytilus edulis and $M$. trossulus) along wave exposure gradients on northwest Atlantic rocky shores. Marine Biology Research: in press.

Trager, G. C., and A. Genin. 1993. Flow velocity induces a switch from active to passive suspension feeding in the Porcelain crab Petrolisthes leptocheles ( Heller ). Biology Bulletin 185:20-27.

Underwood, A. J. 1981. Structure of a rocky intertidal community in New South Wales: patterns of vertical distribution and seasonal changes. Journal of Experimental Marine Biology and Ecology 51:57-85.

Vizzini, S., and A. Mazzola. 2003. Seasonal variations in the stable carbon and nitrogen isotope ratios $(13 \mathrm{C} / 12 \mathrm{C}$ and $15 \mathrm{~N} / 14 \mathrm{~N})$ of primary producers and consumers in a western Mediterranean coastal lagoon. Marine Biology 142:1009-1018.

Vizzini, S., and A. Mazzola. 2006. Sources and transfer of organic matter in food webs of a Mediterranean coastal environment: evidence for spatial variability. Estuarine, Coastal and Shelf Science 66:459-467.

Wells, M. L. 2003. The level of iron enrichment required to initiate diatom blooms in HNLC waters. Marine Chemistry 82:101-114.

Westerbom, M., M. Kilpi, and O. Mustonen. 2002. Blue mussels, Mytilus edulis, at the edge of the range: population structure, growth and biomass along a salinity gradient in the north-eastern Baltic Sea. Marine Biology 140:991-999. 
Widdows, J. 1985. Physiological procedures. Pages 161-178 in B. L. Bayne, editor. The Effects of Stress and Pollution on Marine Animals. Praegar Scientific, New York, USA.

Widdows, J., and D. Johnson. 1988. Physiological energetics of Mytilus edulis: scope for growth. Marine Ecology Progress Series 46:113-121.

Wiedemeyer, W. L., and R. Schwamborn. 1996. Detritus derived from eelgrass and macroalgae as potential carbon source for Mytilus edulis in Kiel Fjord, Germany: a preliminary carbon isotopic study. Helgoland Marine Research 5:409-413.

Wightman, C. 2003. An investigation into the presence and abscence of mussels from the Wellington region, New Zealand. Victoria University of Wellington, Wellington, NZ.

Yaikin, J., R. A. Quifones, and R. R. Gonzdlez. 2002. Aerobic respiration rate and anaerobic enzymatic activity of Petrolisthes laevigatus (Anomura, Porcellanidaee) under laboratory conditions. Journal of Crustacean Biology 22:345-352.

Yokoyama, H., A. Tamaki, K. Koyama, Y. Ishihi, K. Shimoda, and K. Harada. 2005. Isotopic evidence for phytoplankton as a major food source for macrobenthos on an intertidal sandflat in Ariake Sound, Japan. Marine Ecology Progress Series 304:101-116.

Zardi, G. I., C. D. McQuaid, and K. R. Nicastro. 2007. Balancing survival and reproduction: seasonality of wave action, attachment strength and reproductive output in indegenous Perna perna and invasive Mytilus galloprovincialis mussels. Marine Ecology Progress Series 334:155-163.

Zardi, G. I., K. R. Nicastro, C. D. McQuaid, M. Ruis, and F. Porri. 2006. Hydrodynamic stress and habitat partitioning between indigenous (Perna perna) and invasive (Mytilus galloprovincialis) mussels: constraints of an evolutionary strategy. Marine Biology 150:79-88. 